\title{
Recent Studies Related to Head-End Fuel Processing at the Hanford PUREX Plant
}

\author{
J. L. Swanson
}

August 1988

Prepared for the U.S. Department of Energy under Contract DE-AC06-76RLO 1830

Pacific Northwest Laboratory

Operated for the U.S. Department of Energy by Battelle Memorial Institute 


\section{DISCLAIMER}

This report was prepared as an account of work sponsored by an agency of the United States Government. Neither the United States Government nor any agency thereof, nor Battelle Memorial Institute, nor any or their employees, makes any warranty, expressed or implied, or assumes any legal liability or responsibility for the accuracy, completeness, or usefulness of any information, apparatus, product, or process disclosed, or represents that its use would not infringe privately owned rights. Reference herein to any specific commercial product, process, or service by trade name, trademark, manufacturer, or otherwise does not necessarily constitute or imply its endorsement, recommendation, or favoring by the United States Government or any agency thereof, or Battelle Memorial Institute. The views and opinions of authors expressed her ein do not necessarily state or reflect those of the United States Government or any agency thereof, or Battelle Memorial Institute.

\section{PACIFIC NORTHWEST LABORATORY operated by \\ BATTELLE MEMORIAL INSTITUTE for the \\ UNITED STATES DEPARTMENT OF ENERGY under Contract DE-ACO6-76RLO 1830}

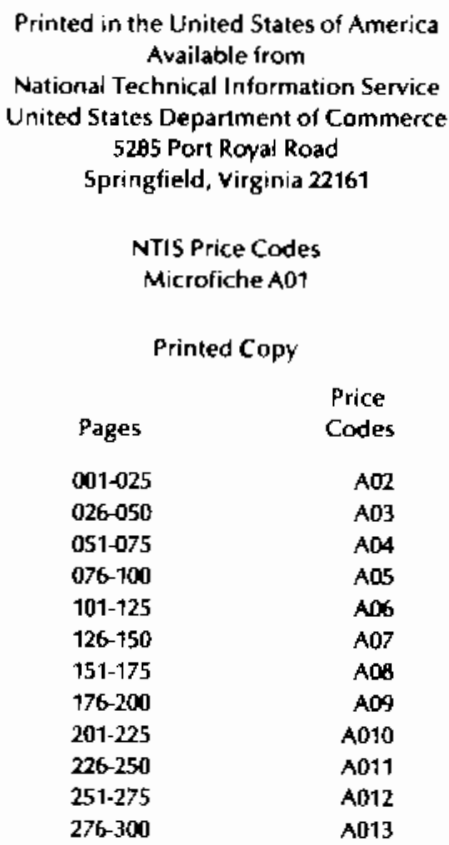




\section{Recent Studies Related to Head-End Fuel Processing at the Hanford PUREX Plant}

J. L. Swanson

August 1988

Prepared for the U.S. Department of Energy under Contract DE-AC06-76RLO 1830

Pacific Northwest Laboratory

Operated for the U.S. Department of Energy by Battelle Memorial Institute 


\title{
DISCLAIMER
}

This report was prepared as an account of work sponsored by an agency of the United States Government. Neither the United States Government nor any agency thereof, nor Battelle Memorial Institute, nor any or their employees, makes any warranty, expressed or implied, or assumes any legal liability or responsibility for the accuracy, completeness, or usefuiness of any information, apparatus, product, or process disclosed, or represents that its use would not infringe privately owned rights. Reference herein to any specific commercial product, process, or service by trade name, trademark, manufacturer, or otherwise does not necessarily constitute or imply its endorsement, recommendation, or favoring by the United States Government or any agency thereof, or Battelle Memorial Institute. The views and opinions of authors expressed herein do not necessarily state or reflect those of the United States Government or any agency thereof, or Battelle Memorial Institute.

\author{
PACIFIC NORTHWEST LABORATORY \\ operated by \\ BATTELLE MEMORIAL INSTITUTE \\ for the \\ UNITED STATES DEPARTMENT OF ENERGY \\ under Contract DE-ACO6-76RLO 1830
}

\begin{tabular}{|c|c|}
\hline \multicolumn{2}{|c|}{$\begin{array}{l}\text { Printed in the United States of America } \\
\text { Available from } \\
\text { National Technical Intormation Service } \\
\text { United States Department of Commerce } \\
5285 \text { Pon Royal Road } \\
\text { Sprıngífield. Virginia } 22161\end{array}$} \\
\hline \multicolumn{2}{|c|}{$\begin{array}{l}\text { NTIS Price Codes } \\
\text { Microfiche A0t }\end{array}$} \\
\hline \multicolumn{2}{|c|}{ Printed Copy } \\
\hline Pages & $\begin{array}{l}\text { Price } \\
\text { Codes }\end{array}$ \\
\hline$\infty 01-025$ & $\mathrm{AO2}$ \\
\hline $026-050$ & $\mathrm{~A} 03$ \\
\hline $051-075$ & $A 04$ \\
\hline $076-100$ & A05 \\
\hline $101-325$ & $A 06$ \\
\hline $126-150$ & $A 07$ \\
\hline 157.175 & AMB \\
\hline $176-200$ & $\mathrm{~A} 09$ \\
\hline $201-225$ & $A 010$ \\
\hline $226-250$ & A011 \\
\hline 251.275 & $A 012$ \\
\hline $276-300$ & A013 \\
\hline
\end{tabular}


RECENT STUDIES RELATED TO HEAD-END FUEL

PROCESSING AT THE HANFORD PUREX PLANT

J. L. Swanson

August 1988

Prepared for

the U.S. Department of Energy

under Contract DE-AC06-76RLO 1830

Pacific Northwest Laboratory

Richland, Washington 99352 


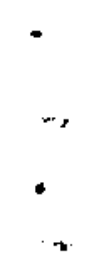

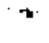

-

. 
SUMMARY

This report presents the results of studies addressing several problems in the head-end processing (decladding, metathesis, and core dissolution) of $\mathrm{N}$ Reactor fuel elements in the Hanford PUREX plant. These studies were conducted over 2 years: FY 1986 and FY 1987. The studies were divided into three major areas: 1) differences in head-end behavior of fuels having different histories, 2) suppression of ${ }^{106}$ Ru volatilization when the ammonia scrubber solution resulting from decladding is decontaminated by distillation prior to being discharged, and 3) suitability of flocculating agents for lowering the amount of transuranic (TRU) element-containing solids that accompany the decladding solution to waste.

The major study area addressed the reasons why operating problems in the plant were more severe during processing of aged fuels grade (FG) fuel than when shorter-cooled weapons grade (WG) fuel was processed. This was investigated primarily in a series of flowsheet simulation runs with sections of $\mathrm{N}$ Reactor fuels of different histories. These studies showed that the plant problems with $F G$ fuel likely resulted from the presence of waterreacted fuel in the dissolver charges. Such fuel gives more extensive reaction of the uranium core during decladding; this results in a greater quantity of insoluble uranium fluoride salts, which leads to a higher likelihood of jet pluggages as well as to an increased likelihood of a "runaway chemical reaction" at the start of the acid cut because of the increased quantity of highly reactive (to nitric acid) hydrous uranium dioxide present after metathesis.

Based on the results of this work, several flowsheet changes were made that led to largely trouble-free operation during the next $F G$ fuel campaign.

The flowsheet simulation runs also provided valuable information in a number of other areas such as 1) uranium reaction during decladding by a previously unrecognized reaction, 2) fission product behavior during decladding, 3) ammonium hydroxide behavior during decladding, 4) precipitation of an unknown zirconium compound from declad solutions, 5) transfer of actinide-containing solids along with the declad and metathesis solutions, 
6) effectiveness of different metathesis conditions, 7) foaming and reaction rates during the acid cut, and 8 ) presence of excessive zirconium in the acid cut solutions.

The second major area of study in this project was the suppression of ${ }^{106} \mathrm{Ru}$ volatilization when the ammonia scrubber solution resulting from the decladding process was decontaminated by distillation prior to being discharged. It was found that the ${ }^{106} \mathrm{Ru}$ content of the ammonia scrubber distillate (ASD) could be significantly reduced by the addition of either permanganate or peroxide to the evaporator.

The third major area of the study was related to the solid/liquid separations problems that led to the neutralized cladding removal waste (NCRW) containing too much plutonium and americium to allow the resultant sludge to be disposed of (after grouting) as low-level waste. Data were obtained on particle sizes and densities, and the effectiveness of flocculating agents was tested under several conditions (including work with an irradiated element). The flocculating agents appeared to give little, if any, improvement in the settling of plutonium and americium-containing solids. 


\section{ACKNOWLEDGMENTS}

Funding for this work was provided through the PUREX Systems Engineering Group managed by K. E. Plummer. The cognizant engineers were $L$. L. Jacobs for the work addressing the differences between weapons grade (WG) and fuels grade $(F G)$ fuel, J. D. Moore for the work on ruthenium volatilization suppression, and C. J. Yeager for the work on enhancement of solid/liquid separations. D. C. Hedengren of this group also provided the results of ORIGEN calculations of radionuclide contents. The assistance and cooperation of these people is especially appreciated.

Special thanks are also due to N. N. Takata and G. A. Wolf for their assistance with the mechanics of selecting and shipping the irradiated fuel elements and to D. J. Deschane for directing the irradiated fuel sectioning activities. J. W. Sharp did the unirradiated fuel sectioning and A. E. De Mers provided the storage basin sludge to be tested.

Photographic support was expertly provided by R. B. Sinclair.

The laboratory and hot cell experiments were performed by A. D. Peoples and G. M. Richardson, respectively. Many people contributed significant analytical support, including C. L. Matsuzaki, D. L. Widrig, F. T. Hara, D. E. Rinehart, C. W. Thomas, and A. C. Leaf. J. E. Coleman performed the SEM examinations.

The report was typed by J. M. Zama and edited by T. L. Gilbride. 


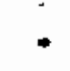




\section{CONTENTS}

SUMHARY .......................................

ACKNOWLEDGMENTS ........................ . . . v

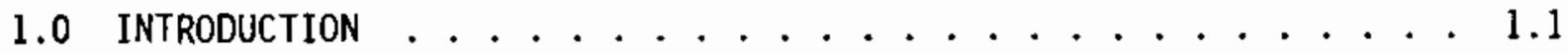

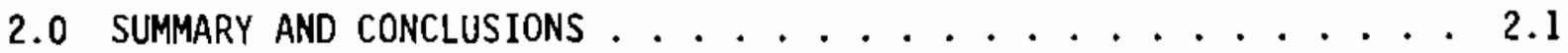

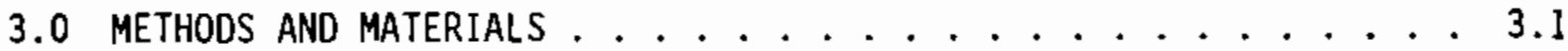

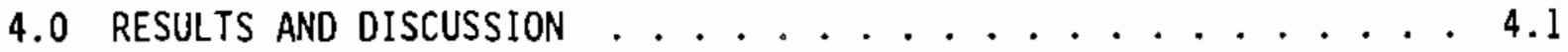

4.1 DECLADOING . . . . . . . . . . . . . . . 4.2

4.1.1 Cladding Removal .............. 4.2

4.1.2 Reaction of Uranium Fuel Core with Ammonium
Fluoride-Ammonium Nitrate Solutions . . . . . . 4.13

4.1.3 Foaming During Decladding . . . . . . . . . . 4.31

4.1.4 Transfer of Uranium Soljds with Declad 4.32

4.1.5 Plutonium-to-Uranium Ratio in Declad Solution/

Solids Suspensions ............. . . 4.34

4.1.6 Fission Product Behavior During Decladding . . . . 4.38

4.1.7 Ammonium Hydroxide Behavior During Decladding . . . . 4.39

4.1.8 Precipitation of Unknown Zirconium Compound from Declad Solution . . . . . . . . . . . . 4.41

4.2 REACTION DURING LONG STORAGE OF EXPOSED FUEL IN DECLAD RINSE SOLUTION . . . . . . . . . . . . . . 4.43

4.3 METATHESIS OF SOLID FLUORIDES FORMED DURING

DECLADDING . . . . . . . . . . . . . . . . . 4.46

4.3.1 Foaming During Metathesis . . . . . . . . . . 4.46

4.3.2 Transfer of Actinide Solids with Metathesis

Solutions ............... . . 4.47

4.3.3 Check for Soluble Plutonium and Americium in

Metathesis Solution............ 4. . 48 
4.3.4 Check for Reaction of Uranium Metal During

Metathesis ............. 4.49

4.3.5 Conditions Necessary for Complete Metathesis . . . 4.49

4.4 ACID CUT REACTIONS . . . . . . . . . . 4.51

4.4.1 Rates of Dissolution of Uranium Metal in

Nitric Acid . . . . . . . . . . . . . 4.51

4.4.2 "Runaway Chemical Reactions" During Acid Cut . . . 4.60

4.4.3 Foaming During Acid Cut ........... 4.66

4.4.4 Zirconium in Acid Cut Solutions ......... 4.71

4.4.5 Potassium in Acid Cut Solutions . . . . . . . . 4.72

4.4.6 Tin in Acid Cut Solutions ........... 4.73

4.5 OTHER STUDIES RELATED TO HEAD-END PROCESSING . . . . . 4.74

4.5.1 Suppression of Ruthenium Volatilization when

Ammonia Scrubber Solution is Distilled ..... 4.74

4.5.2 Characterization of Declad and Metathesis

Solids ............... 4.95

4.5.3 Flocculating Agents to Improve Settling of Solids . . . . . . . . . . . . 4.107

5.0 FUTURE WORK . . . . . . . . . . . . 5.1

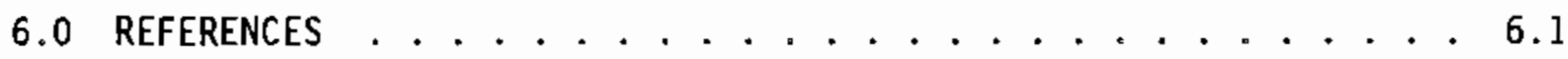




\section{FIGURES}

1.1 N Reactor Fuel Element Schenatic .............. I.1

3.1 Effect of Ammonium Hydroxide Concentration on $\mathrm{pH}$ of Diluted Declad Solution ............. 3.4

3.2 Photographs of WG Inner Element Used in Run $6 \ldots 3.5$

3.3 Photographs of WG Outer Element Used in Run $7 \ldots 3.6$

3.4 Photographs of $F G$ Inner Element Used in Run $3 \ldots \ldots .7$

3.5 Photographs of FG Outer Element Used in Run $4 \ldots \ldots .8$

3.6 Photographs of Water-Reacted FG Inner Element

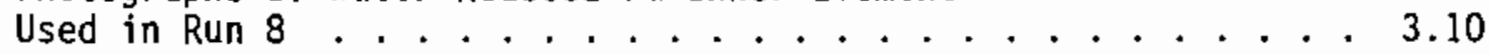

3.7 Side-Views of Water-Reacted FG Outer Element

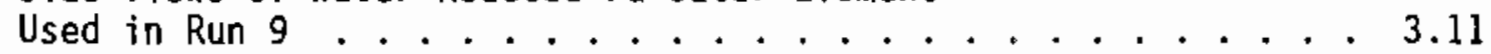

3.8 End Views of Water-Reacted FG Element Used in Run 9 . . . . 3.12

4.1 Rates of Zircaloy Dissolution in Flowsheet

Simulation Runs .............. . 4.4

4.2 Photographs of Partially Declad Outer Element . . . . . . . 4.5

4.3 Photographs of Partially Declad Inner Element . . . . . . 4.6

4.4 Photographs of Water-Reacted Inner Element After

Flowsheet Simulation Run 8............ . 4.9

4.5 Appearance of Water-Reacted Outer Element on

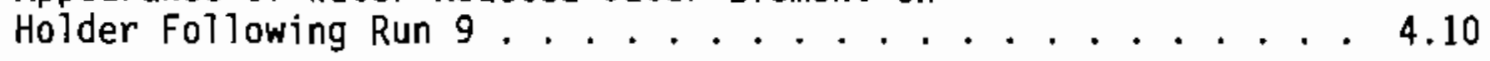

4.6 Individual Pieces of Water-Reacted Outer Element

on Holder Following Run $9 . . . . . . . . . . . .4411$

4.7 Pieces of Water-Reacted Outer Element That Had

Fallen to Bottom of Dissolver in Run 9.......... 4.12

4.8 Uranium Reaction During Decladding . . . . . . . . . . 4.17

4.9 Uranium Reaction in First and Second Decladding Cuts . . . . 4.18

4.10 Comparison of Uranium Content of Dip Samples with That

Expected Based on Uranium (IV) Solubility . . . . . . 4.19

4.11 Uranium Content of Dip Samples During Declad Runs . . . . . . 4.20 
4.12 Comparison of Quantities Reacted During Decladding of

Intact and Water-Reacted FG Elements ............ 4.22

4.13 Quantities Reacted in Other Decladding Steps with Uranium Initially Exposed ................ 4.23

4.14 Reaction Rates of Uranium with Water and with Dilute

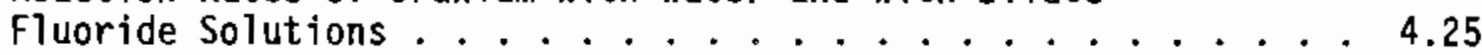

4.15 Uranium Reaction Rates in AFAN Solution Before and After

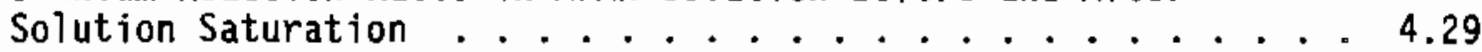

4.16 Foam Volumes and Dissolution Rates During Initial Portions of Decladding in Flowsheet Simulation Runs .......... 4.33

4.17 Ammonium Hydroxide Distribution During Decladding . . . . . . 4.40

4.18 Photographs of Fuel Following Long Storage in Declad Rinse

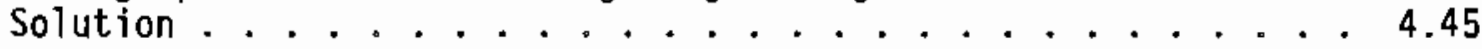

4.19 Uranium Contents of Acid Cut SoTutions Over Time . . . . . . 4.53

4.20 Photograph of Foaming During Acid Cut . . . . . . . 4.67

4.21 Foaming During Heat-Up of Acid Cuts . . . . . . . . . . 4.68

4.22 Effect of ANN Concentration on Foaming . . . . . . . . 4.70

4.23 Radionuclide Concentrations in ASD from Distillation Without Additives ................ 4.80

4.24 Radionuclide Concentrations in ASD with Alkaline Permanganate Added to Evaporator Bottoms . . . . . . . . 4.84

4.25 Radionuclides in ASD with Neutral Permanganate Added to Evaporator Bottoms . . . . . . . . . . . 4.86

4.26 Radionuclides in ASD Made with PUREX Raw Water, with Neutral Permanganate Added to Evaporator 8ottoms . . . . . . 4.88

4.27 Radionuclides in ASD Distilled with Peroxide Present . . . . 4.90

4.28 Second Run on Use of Peroxide to Suppress Ruthenium

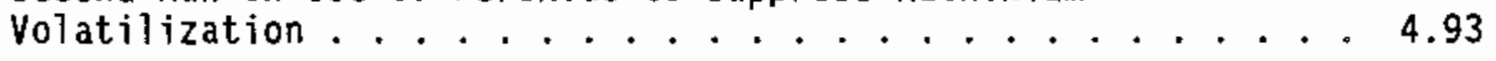

4.29 SEM of Solids Present After Decladding and After Metathesizing ................. 4.99

4.30 Declad Solids Particle Sizing by Sedimentation Rate . . . . 4.102

4.31 Declad Solids Particle Sizing by Particle Counting . . . . . 4 4.104 
4.32 Rare Earth-Treated Declad Solids Particle Sizing . . . . . . 4 4.105

4.33 Metathesis Solids Particle Sizing . . . . . . . . . . . 4.106

4.34 Solids Flocculation by Adding ANN to Metathesis

Rinse Solution.................. . . . 4.112 


\section{$\underline{\text { TABLES }}$}

3.1 ICP Analysis of KE Reactor Basin Segregation Pit Sludge . . . 3.13

4.1 Summary of Flowsheet Simulation Runs . . . . . . . . . . . 4.1

4.2 Comparison of Effectiveness of Cladding Removal from

Outer and Inner Element Surfaces ............ . . 4.7

4.3 Comparison of ${ }^{137} \mathrm{Cs}-\mathrm{to}$-Uranium Determinations and of Uranium Reaction During Decladding in Flowsheet

Simulation Runs. . . . . . . . . . . . . . . 4.15

4.4 Reaction of Uranium with AFAN Solutions: Rates with

Different Unirradiated Sections . . . . . . . . . . 4.30

4.5 Transfer of Uranium Solids with Declad Solutions . . . . . . 4.34

4.6 Plutonium-to-Uranium Ratio in Declad and Acid Cut

Solutions . . . . . . . . . . . . . . . . 4.35

4.7 Plutonium-to-Uranium Ratio in Declad Solution Suspension . . . 4.37

4.8 Fission Product Behavior Data . . . . . . . . . . . 4.38

4.9 Estimated Anmonium Hydroxide in Solution During
Decladding . . . . . . . . . . . . . . . . . 4.42

4.10 Transfer of Actinide Solids with Metathesis Solutions . . . . 4.48

4.11 Results of Metathesis Efficiency Tests............ . 4.50

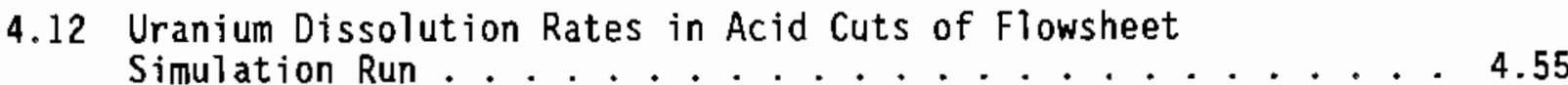

4.13 Rates of Uranium Dissolution at Terminal Acid
Cut Conditions. . . . . . . . . . . . . . 4.57

4.14 Effects of Specimen Irradiation and of Direction of
Attack on Rates of Uranium Dissolution in 5 M HNO $\mathrm{HN}_{3} \ldots \ldots . . .4 .59$

4.15 Analysis of Declad Condensate Samples . . . . . . . . . . 4.76

4.16 Fission Product Ratios in Declad Condensate, in
Declad Solution, and in Irradiated Fuel ........ 4.77

4.17 Declad and Metathesis Solids Densities . . . . . . . . . . 4 4.97

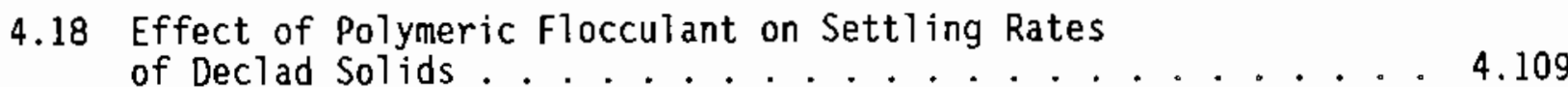




\subsection{INTRODUCTION}

The processes currently used in the Hanford Plutonium-Uranium Recovery by Extraction (PUREX) Plant to dissolve irradiated fuel for solvent extraction processing are unique. This uniqueness arises because of the nature of the fuel elements to be processed, which are metallic uranium clad in a zirconium alloy (Zircaloy) and because the plant was built before processing of such fuel elements was considered. Process options are thus constrained by the size and number of available tanks and other equipment, and by the materials of construction.

A schematic drawing of a typical fuel element for Hanford's $N$ Reactor is shown in Figure 1.1; this is the only type of fuel currently being processed at the Hanford PUREX plant. It is a tube-in-tube type of fuel, with the inner tube having an ID of $\sim 0.5 \mathrm{in}$. and an 00 of $-1.3 \mathrm{in}$. and the outer tube having diameters of -1.7 and -2.4 in. A typical element is 26 in. long.

The first step in processing such fuel is the Zirflex decladding process (Swanson 1958, 1961). This process involves dissolution of the Zircaloy cladding in a solution containing a mixture of ammonium fluoride and ammonium

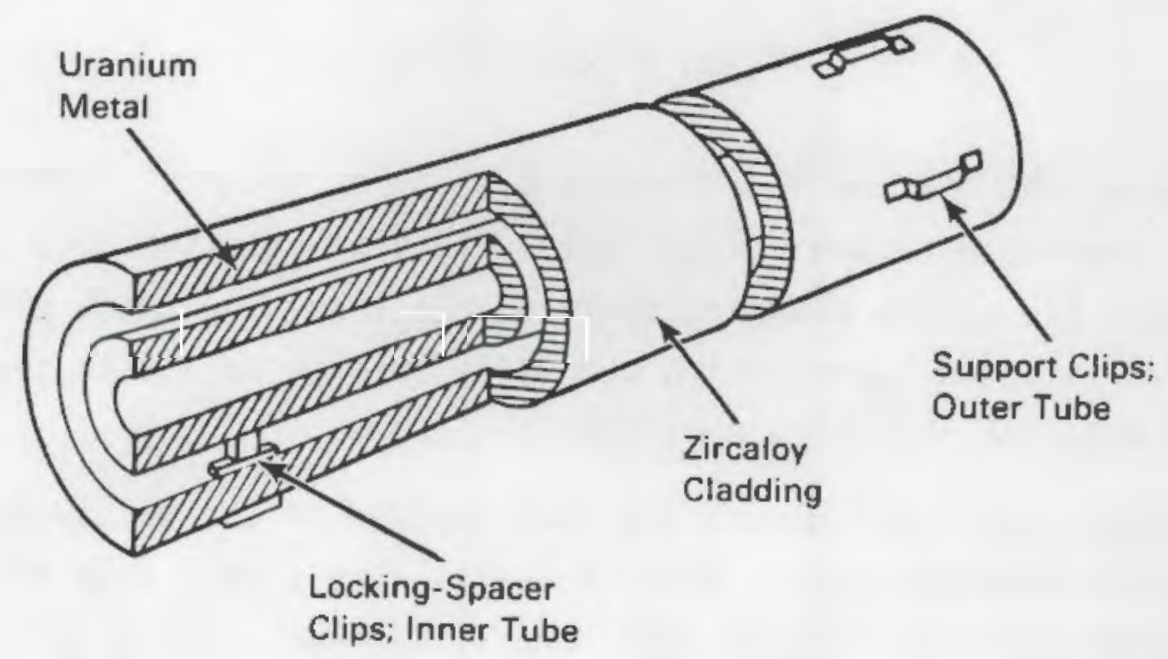

FIGURE 1.1. N Reactor Fuel Element Schematic 
nitrate (AFAN). The dissolution of zirconium in boiling ammonium fluoride solution (alone) proceeds according to

$$
\mathrm{Zr}+6 \mathrm{NH}_{4} \mathrm{~F} \rightarrow\left(\mathrm{NH}_{4}\right)_{2} \mathrm{ZrF}_{6}+4 \mathrm{NH}_{3}(\mathrm{~g})+2 \mathrm{H}_{2}(\mathrm{~g})
$$

The ammonium nitrate present in the Zirflex solution minimizes the evolution of hydrogen and gives an overall reaction approaching

$$
\mathrm{Zr}+6 \mathrm{NH}_{4} \mathrm{~F}+0.5 \mathrm{NH}_{4} \mathrm{NO}_{3} \rightarrow\left(\mathrm{NH}_{4}\right)_{2} \mathrm{ZrF}_{6}+5 \mathrm{NH}_{3}(\mathrm{~g})+1.5 \mathrm{H}_{2} \mathrm{O}
$$

Ammonium nitrate also causes dissolution of a portion of the tin present in the Zircaloy, thus decreasing the quantity of this element that is carried forward to subsequent process steps. These zirconium dissolution reactions proceed at $\mathrm{pH}$ values that are high enough (near 7) that fluoride corrosion of the stainless steel dissolvers is not excessive. The ammonia produced during these reactions must be continuously removed or the $\mathrm{pH}$ will rise to a high value and the dissolution reaction will become too slow. This removal is accomplished by sparging with steam. The volatilized ammonia is then removed from the off-gas stream by scrubbing with water:

$$
\mathrm{NH}_{3}(\mathrm{~g})+\mathrm{H}_{2} \mathrm{O}=\mathrm{NH}_{4} \mathrm{OH}
$$

Because of the coating of zirconium dioxide on the fuel elements (from exposure to high-temperature water), the decladding reaction does not proceed uniformly over the entire cladding surface. Instead, the oxide coating is penetrated in selected spots, which gradually enlarge as attack proceeds on the exposed edges of the Zircaloy around the spots.

Portions of the uranium core are thus exposed to the decladding solution early in the decladding cycle. Uranium reacts more slowly than zirconium, but appreciable uranium reaction does occur. Exposed uranium left behind in the dissolver from the previous cycle also contributes to this reaction. 
The uranium reacted during decladding is not lost, however. The uranium (IV) resulting from this reaction has a limited solubility in the terminal declad solution so that only a small fraction is soluble:

$$
U^{4+}+(4+x) F^{-}+x N H_{4}^{+}=U F_{4} \cdot x H_{4} F(s)
$$

Nearly all of the $\mathrm{UF}_{4} \cdot \mathrm{NNH}_{4} \mathrm{~F}$ remains behind in the dissolver but a portion of it accompanies the solution when it is transferred to centrifuge feed tanks. Another portion of the $\mathrm{NH}_{4} \mathrm{~F} \cdot \mathrm{xNH}_{4} \mathrm{~F}$ solids is recovered by centrifugation, but a small fraction passes through the centrifuge and is discarded with the soluble materials that are present in the solution.

If the $\mathrm{UF}_{4} \cdot \mathrm{XNH}_{4} \mathrm{~F}$ solids were dissolved in nitric acid along with the uranium metal core, the contained fluoride would lead to excessive corrosion or to the need to add large amounts of a fluoride-complexing metal ion such as aluminum to minimize corrosion. Such an addition has an adverse effect on waste treatment costs, and it is necessary to minimize it. Accordingly, the next process step is to metathesize the $\mathrm{UF}_{4} \cdot \mathrm{NNH}_{4} \mathrm{~F}$ to hydrous uranium (IV) oxide $\left(\mathrm{UO}_{2} \cdot \mathrm{yH}_{2} \mathrm{O}\right)$. This is accomplished by boiling with a basic solution:

$$
\mathrm{UF}_{4} \cdot \mathrm{XNH}_{4} \mathrm{~F}(\mathrm{~s})+4 \mathrm{KOH}=\mathrm{UO}_{2} \cdot \mathrm{yH}_{2} \mathrm{O}(\mathrm{s})+4 \mathrm{KF}+\mathrm{xNH}_{4} \mathrm{~F}
$$

Potassium hydroxide is preferred for this application because the solubility of potassium fluoride is much higher than the solubility of sodium fluoride. Most of the fluoride that precipitated as $\mathrm{UF}_{4} \cdot \mathrm{XNH}_{4} \mathrm{~F}$ is thus discarded to waste in the spent metathesis sotution.

The $\mathrm{UO}_{2} \cdot \mathrm{yH}_{2} \mathrm{O}$ metathesis product and the uranium core are then dissolved in nitric acid containing aluminum nitrate nonahydrate (ANN), which is added to minimize corrosion caused by the portion of the fluoride that still remains. Because of volume constraints, it is necessary to use multiple acid cuts to dissolve the uranium core to (hopefully) completion before the next batch of fuel elements is charged to the dissolver. The resulting solutions are then ready for the mainline PUREX solvent extraction steps in which the uranium and plutonium are recovered and purified. 
This head-end procedure had worked adequately well in the pre-1972 time frame before the PUREX plant was placed on standby and the fuel discharged from $N$ Reactor was allowed to accumulate in water-filled storage basins. Much of the fue 7 discharged during this period was irradiated to burnups that resulted in $>7 \%$ of the plutonium being present as $240 \mathrm{Pu}$; such material is referred to as fuels grade $(F G)$ fuel. More recently, fuel has again been irradiated to burnups that resulted in $5 \%$ to $6 \%$ of the plutonium being present as $240 \mathrm{Pu}$; this material is referred to as weapons grade (WG) fuel.

When the PUREX plant was restarted in 1983, WG fuel was processed first. Both long-cooled and short-cooled fuels were processed, with little apparent difference. However, when a batch of long-cooled FG material was processed, severe processing problems were encountered. These problems included 1) frequent pluggage of transfer jets when the spent declad and metathesis solutions were being removed from the dissolver, 2) excessive entrainment of plutonium-bearing solids from the dissolver into the centrifuge feed tanks, 3) excessively rapid reaction rates at the start of the first acid cuts, and 4) excessive foam formation in the dissolvers.

From initial considerations, it was concluded that the most probable cause of most of the problems was excessive reaction of uranium during deciadding. This would result in the formation of higher concentrations of solids, which would increase the probabilities of jet pluggages and excessive entrainment of solids from the dissolver, as well as result in more hydrous oxide, which can react very vigorously when nitric acid is added to initiate the first acid cut. An experimental program was initiated to obtain comparative data under controlled conditions to test this hypothesis and to evaluate possible methods of alleviating the observed problems.

The main thrust of this experimental program was to perform head-end simulation experiments with three different categories of irradiated fuel: 1) short-cooled, intact WG fuel elements; 2) long-cooled, intact FG elements; and 3) long-cooled $F G$ elements that had their cladding breached sufficiently to allow appreciable reaction of uranium with water during storage. Other categories of fuel were not available for study. Related studies were carried out concurrently in other experiments. 
Additional studies were Jater done in two problem areas that are not a function of differences between $F G$ fuel and $W G$ fuel (although the severity of these problems can vary with the fuel age and its behavior during decladding). The first of these areas involved study of the volatilization (and ways to suppress it) of ${ }^{106_{\mathrm{Ru}}}$ when the ammonium hydroxide solution, which results when the declad off-gas stream is scrubbed with water (Equation 1.3), was distilled before it was released to the environment. The other area involved testing the use of flocculating agents to reduce the amount of plutonium-containing solids that are transferred from the dissolver along with the spent declad and metathesis solutions. 
.

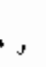

-

. 


\subsection{SUMMARY AND CONCLUSIONS}

This report presents the results of studies addressing several problems in the head-end processing (decladding, metathesis, and core dissolution) of $N$ Reactor fuel elements in the Hanford PUREX plant. These studies were divided into three major areas: 1) differences in head-end behavior of fuels having different histories, 2) suppression of ${ }^{106}$ Ru volatilization when the ammonia scrubber solution resulting from declad is decontaminated by distillation prior to being discharged, and 3) suitability of flocculating agents to lower the amount of transuranic (TRU) eTement-containing solids that accompany the decladding solution to waste.

The major problem area was to determine the reason for the severe operating problems that had been encountered in the plant during processing of aged $F G$ fuel instead of shorter-cooled WG fuel. This problem area was addressed primarily in a series of flowsheet simulation runs with sections of N Reactor fuel of different histories, as follows: 1) unirradiated fuel, 2) -1-yr-cooled WG fuel, 3) -12-yr-cooled $F G$ fuel that had remained intact during storage, and 4) -12-yr-cooled $F G$ fuel that had (partialty) reacted with water during the storage period. The flowsheet simulation runs involved partial decladding with AFAN solution, metathesis with $\mathrm{KOH}$ solution, and dissolution of a small portion of the uranium metal core in nitric acid $\left(\mathrm{HNO}_{3}\right)$.

The results of this comparison showed that the plant problems with FG fuel likely resulted primarily from the presence of water-reacted fuel in the dissolver charges. Such fuel gives more extensive reaction of the uranium core during decladding; this results in a greater quantity of insoluble uranium fluoride salts, which leads to a higher likelihood of jet pluggages as well as to an increased Tikelihood of a "runaway reaction" at the start of the acid cut because of the increased quantity of highly reactive (to $\mathrm{HNO}_{3}$ ) hydrous uranium oxide present after metathesis. 
Based on the results of this work, several flowsheet changes were made before the next FG fuel reprocessing campaign was run:

1. The dissolver charge size was reduced (from 10.2 MTU to 7.3 MTU) with proportional reduction in solution volumes. This decreased the reactive surface area, which gave lower quantities reacting per unit time, and increased the vapor volume, which allowed more foam to be accommodated without incident.

2. The declad reaction time was reduced from $8 \mathrm{~h}$ to $6 \mathrm{~h}$, in an effort to decrease the extent of uranium reaction during decladding.

3. The second acid cut end-point criterion was changed in an effort to reduce the area of exposed uranium remaining at the end of the acid cut, so that less uranium reaction would occur in the next cycle in that dissolver.

The results of this work also verified and provided a sound bas is for another flowsheet change that had been successfully implemented by plant personnel during the problem-plagued campaign with $F G$ fuel; this change was to use a low concentration of nitric acid at the start of the first acid cut so that slower reaction rates occurred.

The FG campaign that was run under these conditions was largely troublefree, indicating that the changes were indeed effective in avoiding the problems encountered earlier. The overall processing rate of the latest $F G$ campaign was comparable to that of the earlier campaign, indicating that the time saved by avoiding the problems offset the time lost by reducing the charge size.

The flowsheet simulation runs also provided valuable information in a number of areas that appeared to be independent of the type of fuel being processed. One of these areas was foaming during acid cuts where, in addition to the foaming that results from the runaway reactions that occur when a large amount of hydrous uranium oxide reacts with nitric acid, another type of foaming was observed. This foaming occurred during dissolution of the uranium metal core in nitric acid; it was found to increase in severity as the concentration of ANN, which is added to complex residual fluoride, 
increased and was also found to be increased by the presence of 0 il from an air compressor. The severity of this type of foaming increases dramatically as the temperature nears boiling; thus, slight cooling of the solution (e.g., by sparging, using a cooling coil, or adding water) gives a dramatic decrease in the volume of this type of foam.

Another important result of these flowsheet simulation runs was the discovery that extensive reaction of the uranium core during decladding can continue to occur after the free fluoride concentration has become so low that dissolution of Zircaloy has essentially stopped. This not only can lead to excessive attack of the core, but can also lead to continued reaction after all the nitrate present in the currently used AFAN blend has been consumed; this would result in an increased hydrogen evolution. Such occurrences are more likely with water-reacted fuel than with intact fue] because of the higher area of uranium that can be exposed in the waterreacted case.

In a related area, it was also found that extensive reaction of uranium will occur during storage in dilute fluoride solutions at room temperature; thus, long exposure of declad fuel to declad or declad rinse solutions should be avoided.

Data were also obtained regarding the rate of dissolution of uranium metal in nitric acid. No dramatic effect of irradiation exposure on dissolution rate (per unit area) was observed. However, a markedly higher total dissolution rate was observed with an element that had reacted extensively with water during storage; this came about because this element "fell apart" during decladding, thereby giving a markedly higher exposed uranium area.

The flowsheet simulation runs also provided some data in other headend areas. Among these are 1) transfer of actinide-containing solids along with the declad and metathesis solutions, 2) fission product behavior during decladding, 3) ammonium hydroxide behavior during decladding, 4) precipitation of an unknown zirconjum compound from declad solutions, 5) effectiveness of different metathesis conditions, and 6) presence of excessive zirconium in 
the acid cut solutions. This last area is another case that appears to be worse during processing of extensively water-reacted fuel.

The second major area of study in this project was the suppression of ${ }_{106}$ Ru volatilization when the ammonia scrubber solution resulting from the decladding process is decontaminated by distillation prior to being discharged. It was found that the ${ }^{106} \mathrm{Ru}$ content of the ammonia scrubber distillate (ASD) could be significantly reduced by the addition of either permanganate or peroxide to the evaporator. The work reported here was done before the determination was made that the anmonium hydroxide contained in this strean could not be discharged to the environment, and thus is not directly relevant to currently considered processes designed to destroy ammonia as well as to provide decontamination from fission products.

The third major area of the study was related to the solid/liquid separations problems that led to the neutralized cladding removal waste (NCRW) containing too much plutonium and americium to allow the resultant sludge to be disposed of (after grouting) as low-level waste. Data were obtained on particle sizes and densities, and the effectiveness of flocculating agents was tested under several conditions (including work with an irradiated element). The flocculating agents appeared to give little, if any, improvement in the settling of plutonium- and americium-containing solids. 


\subsection{METHODS AND MATERIALS}

The dissolver pot used in the flowsheet simulation runs was a glass cylindrical vesse $1 \sim 33 \mathrm{~cm}$ tall and $\sim 13 \mathrm{~cm}$ in diameter having a nominal capacity of $4 \mathrm{~L}$. It was fitted with a removable top containing four openings; one opening was fitted (through a ground glass joint) with a steam condenser of the Eastman type and the other three were filled with silicone rubber stoppers through which passed a cooling coil, a water-add line connected to a graduated reservoir, an air sparge line, or a thermometer. This dissolver pot was heated by a heating mantle, which extended nearly half-way up the walls of the pot.

Most of the flowsheet simulation runs used 6 -in. lengths cut from the end of fuel elements. A 6-in. inner element end section is estimated to contain a total of $150 \mathrm{~g}$ zirconium, of which $96 \mathrm{~g}$ is in the cladding and the remainder is in the end cap. A 6-in. outer element end section is estimated to contain $292 \mathrm{~g}$ zirconium, of which $193 \mathrm{~g}$ is in the cladding. All flowsheet simulation runs started with $1.7 \mathrm{~L}$ of $5.0 \mathrm{M} \mathrm{NH} 4$ F thus the molar charge ratios in typical experiments were 8.1 fluoride/clad zirconium in an inner element run and 4.0 fluoride/clad zirconium in an outer element run. Complete decladding was therefore not expected in an outer element run; the comparative behavior of sections having different reactor exposures was still valid, however.

At the completion of the time allowed for decladding, the solution was diluted to $2.6 \mathrm{~L}$ and cooled to $-60^{\circ} \mathrm{C}$ while being air-sparged. The sparge was then stopped and, after a -20 -min settling time, the declad solution was slurped from the dissolver pot through a slurp line inserted in the pot untiT it almost touched the bottom and held in place as suction was applied and the solution was removed. The slurp line had feet attached to its sides so that its end could not get closer than $1 / 8$ in. to the bottom of the dissolver; however, transfer of some settled solids along with the solution and suspended solids was observed in all cases.

After the declad solution had been removed, the dissolver contents were rinsed with $2.0 \mathrm{~L}$ water, which was sparged to mix the loose solids. After a 
20-min settling time, this solution (and some solids) was slurped from the dissolver and combined with the declad solution for dissolution (in nitric acid/ANN) and analysis.

The remaining solids were then treated with hot potassium hydroxide solution to metathesize the fluoride salts to hydrous oxides (hydroxides). This step usually employed $3.0 \mathrm{~L}$ of $3.3 \mathrm{M} \mathrm{KOH}$, which was heated to boiling and held there (with sparging) for $1 \mathrm{~h}$. The solution was then cooled, allowed to settle, and slurped out as before. The metathesis rinse procedure was the same as the declad rinse procedure except that this rinse solution was combined with the metathesis solution for analysis.

A solution containing $6.6 \mathrm{MNO}_{3}+0.6 \underline{\mathrm{M}}$ ANN was then added to dissolve the hydrous oxides and, when hot enough, a portion of the uranium metal. The volume of this solution was generally $1.9 \mathrm{~L}$. This solution was sparged while it was being warmed, and was sampled at temperatures of $-50,-60$, and $\sim 70^{\circ} \mathrm{C}$ to obtain a measure of the uranium that had been present as hydrous oxide. Sparging was then stopped and the solution was heated to boiling, or to a lower temperature if the severity of foaming would not allow that high of a temperature, and samples were taken over a period of $-1 \mathrm{~h}$ to determine the rate of dissolution of the uranium metal.

In general, the solutions were not sparged during the decladding and core dissolution reactions, as the boiling action and the reaction gas evolution were very adequate to provide good mixing. The action of the steam sparge used during decladding in the plant was simulated by increasing the externally supplied heat input so that more water was converted to steam in situ. Our target condensate collection rate during decladding was $400 \mathrm{~mL} / \mathrm{h}$, which is comparable (per liter of decladding solution) to the total condensate rate in the plant resulting from the steam sparge and from external heating.

A relatively constant solution volume was maintained during the decladding and core dissolution reactions by periodically adding water to replace the condensate. These additions were generally 50 or $100 \mathrm{~mL}$ in size.

The procedure used to sample the dissolver pot during the runs was primitive, but effective. It involved simply dipping a cup of known volume 
$(-1 \mathrm{~mL})$ into the solution and then emptying it into a known volume of dilution acid. This procedure was chosen because of its ease of operation in the hot cell and because it avoids potential problems of solids precipitating on cooling in the sampler. If precipitation does occur, the precipitates are dissolved by the dilution acid and are included in the analyzed material.

Fuel element sections were weighed before and after the runs. The weighings in the hot cell were made on a hanging scale that was probably accurate to only $\pm 15 \mathrm{~g}$. The weighings in the laboratory were accurate to within $\pm 0.1 \mathrm{~g}$.

The flowsheet simulation runs all used dilutions of the same plant AFAN stock, which was taken on January 22, 1986. Plant stocks also supplied the ANN solutions that were used to make up the dissolvents used in the acid cuts; some runs used material taken on January 22, 1986, while others used material taken on May 30, 1986. Rẹagent-grade nitric acid and potassium hydroxide solutions were generally used. One run included a test of potassium hydroxide solution taken from plant stock on April 9, 1986.

Most analyses were performed by standard chemical and radiochemical techniques. One exception was the estimation of the concentration of ammonium hydroxide in the declad solution; this was done by comparing the $\mathrm{pH}$ of water dilutions of this solution with ph values measured in standard solutions of similar composition having different concentrations of added ammonium hydroxide. Figure 3.1 shows the results obtained with the standard solutions.

The rate of Zircaloy dissolution was followed by measuring the zirconium concentration in the decladding solution over time. The rate of uranium reaction during decladding was followed by measuring the ${ }^{137} \mathrm{Cs}$ content of the solution over time, and the ${ }^{137} \mathrm{Cs}$-to- $U$ ratio found in the reacted portion of the fuel. This indirect approach was necessary because much of the reacted uranium was insoluble in the decladding solution, and could not be found by analysis of the solution. Uranium concentrations in acidified samples were determined in a number of ways: liquid scintillation counting was sometimes used in the experiments with unirradiated uranium; ICP analyses were frequently used in all experiments for the more concentrated samples; and 


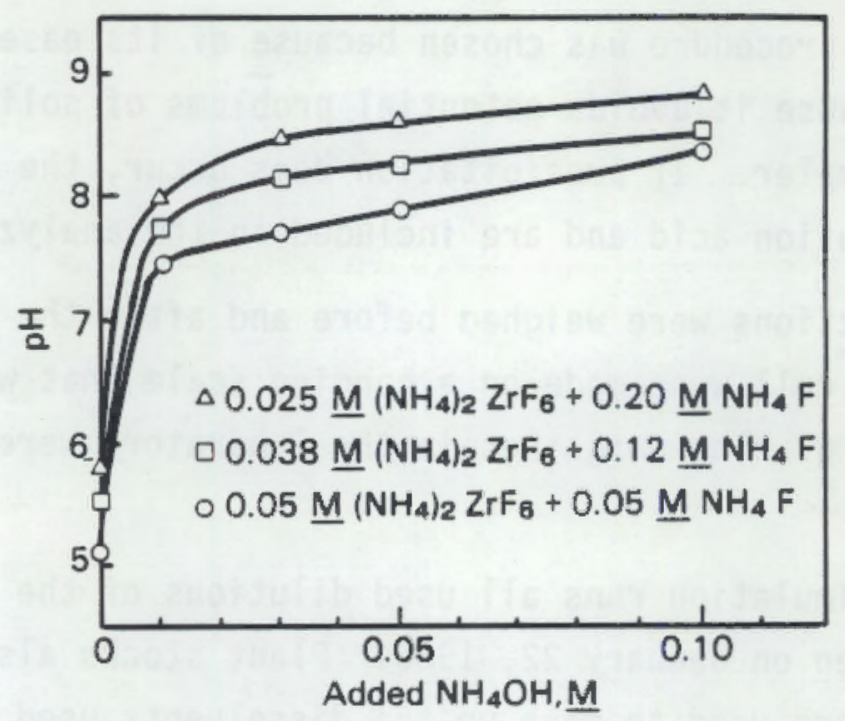

FIGURE 3.1. Effect of Ammonium Hydroxide Concentration on pH of Diluted Declad Solution

some dilutions containing low uranium concentrations were analyzed by laser fluorimetry while others were analyzed by chemical separation and alpha counting.

The fuel elements that were used in this work were obtained through the contractor responsible for $\mathrm{N}$ Reactor operation, which was UNC Nuclear Industries at the time (and is Westinghouse Hanford Company now). Three categories of irradiated fuel were used: 1) short-cooled WG fuel, 2) longcooled FG fuel that had remained intact during storage, and 3) long-cooled FG fuel with cladding that had been breached sufficiently to allow appreciable reaction of the uranium core and water during storage. Unirradiated fuel was also used; these elements were reject elements that had gone through the normal autoclaving procedure, and thus were covered with a protective oxide film similar to that on the irradiated fuel. The elements were handled carefully during sectioning operations so that additional damage to the oxide films was minimized.

Photographs taken of the intact irradiated elements before they were sectioned for use in the flowsheet simulation runs are shown in Figures 3.2 through 3.5. These pictures show the outer surfaces of these elements to be 

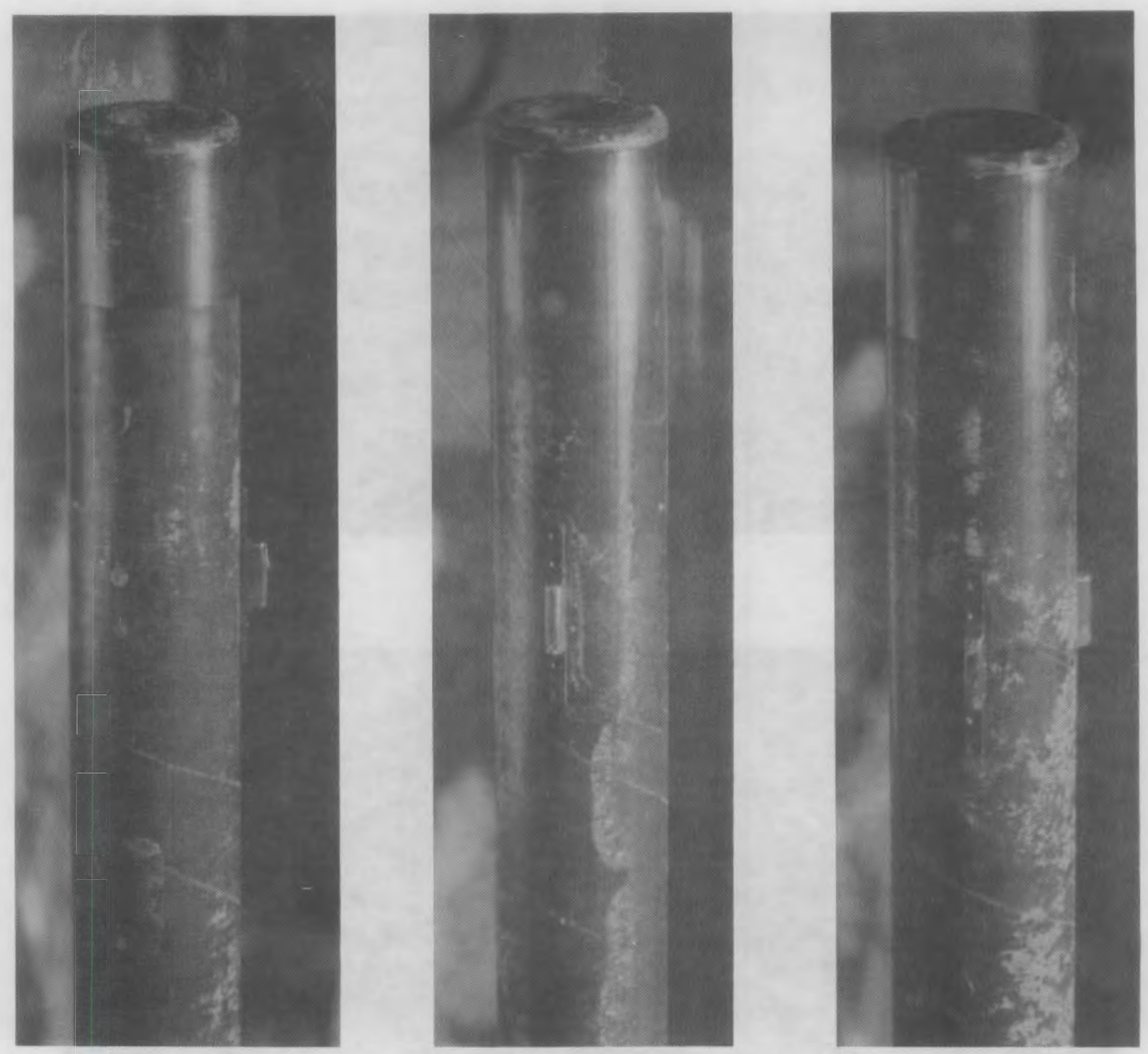

FIGURE 3.2. Photographs of WG Inner Element Used in Run 6

scratched and gouged in varying degrees; this fact affects the ease of cladding dissolution, which occurs preferentially in such places that are not protected by the zirconium oxide film. It is also interesting to note that with both WG elements (Figures 3.2 and 3.3 ), the oxide film is much shinier near the end caps; this is presumed to be related to some metallurgical effect that occurred in the heat-affected zone when the end caps were welded onto the elements. It is not known why this effect was not apparent in the $\mathrm{FG}$ elements (Figures 3.4 and 3.5 ). 

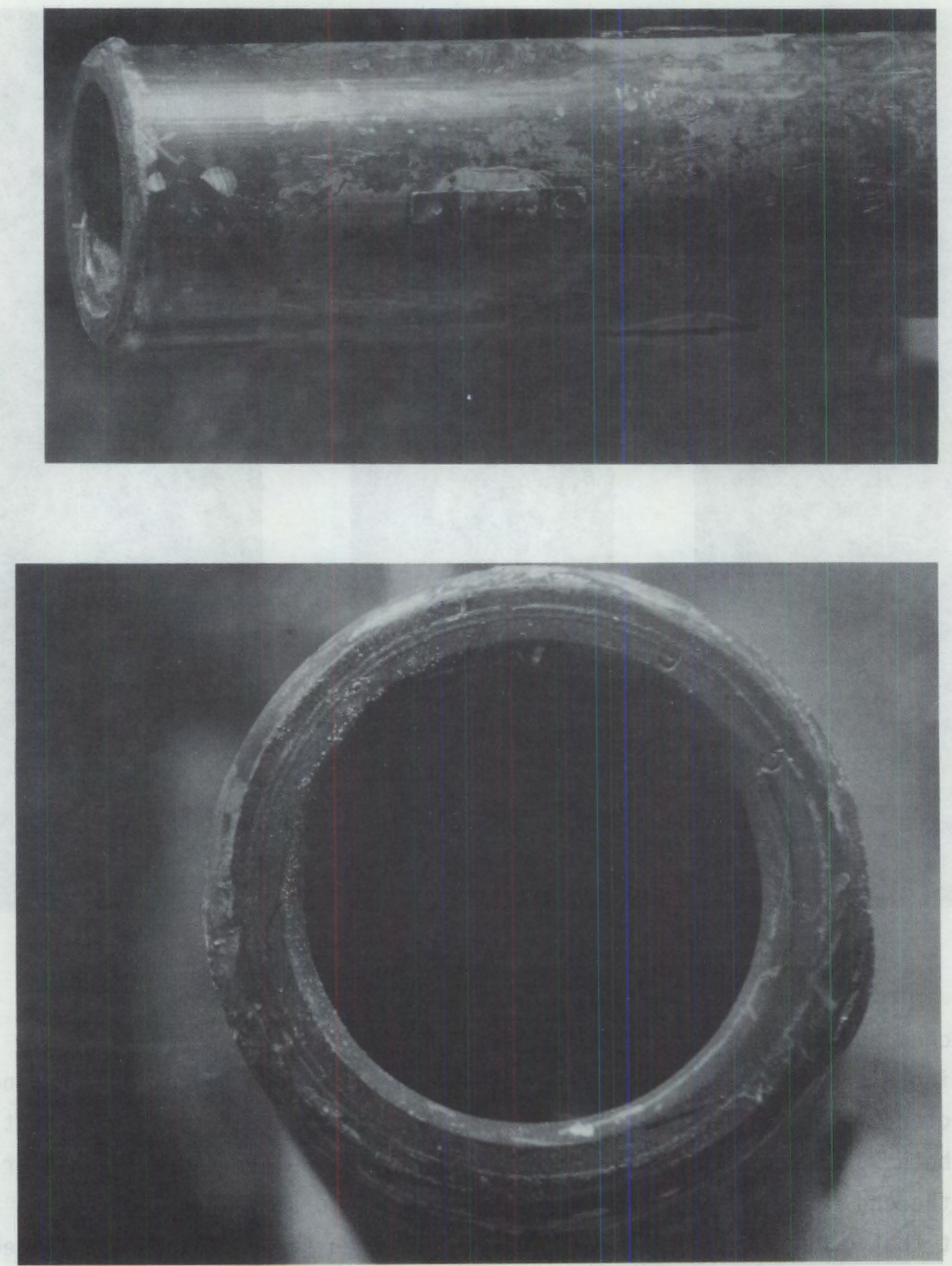

FIGURE 3.3. Photographs of WG Outer Element Used in Run 7 

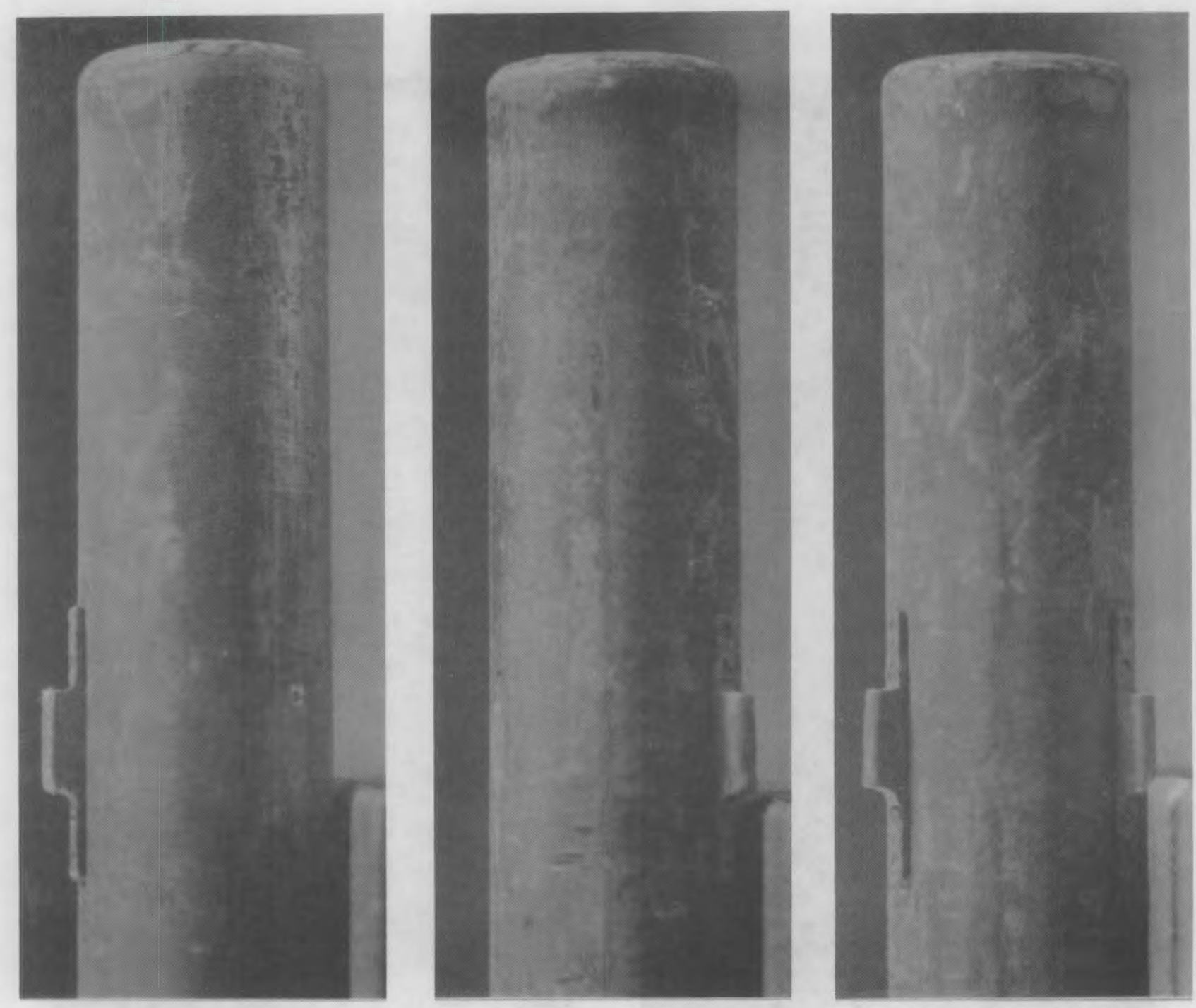

FIGURE 3.4. Photographs of FG Inner Element Used in Run 3

Areas of a deposited corrosion products are apparent around the support clips of both outer elements (Figures 3.3 and 3.5). These areas doubtless resulted from the corrosion of carbon steel "shoes" that were crimped onto the support clips to prevent the Zircaloy clips from rubbing against the walls of the fuel tubes in the reactor.

The end view of the WG outer element shown in Figure 3.3 shows an important feature; that is, the cladding is split away from the end cap in one location (the "four $0^{\prime} c$ lock" position). This was almost certainly caused 

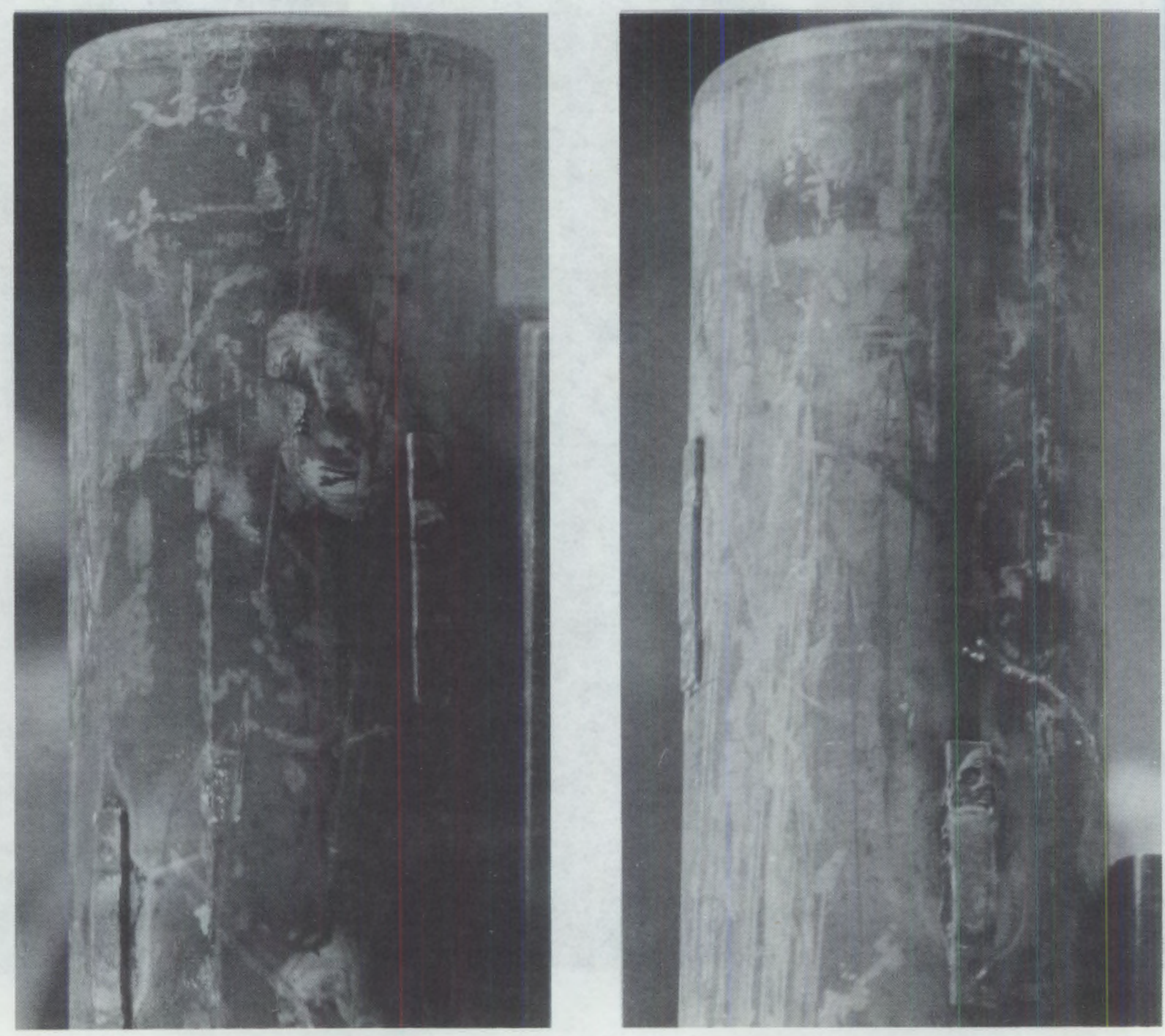

FIGURE 3.5. Photographs of FG Outer Element Used in Run 4

by the impact that occurred when the element was pushed from the reactor tube and fell into the storage pool. A small defect like this can have important effects if the fuel is stored very long, as will be shown in the following discussion of the elements that had reacted extensively with water during storage. 
Figures 3.6 through 3.8 contain photographs of fuel elements that had reacted extensively with water during long-term storage. These elements were selected for study because of the suspicion that they might behave differently than intact elements during processing. These two elements were selected from a storage basket that purportedly contained only intact elements.

The damage to the inner element resulting from reaction with water had not yet become extensive (Figure 3.6). The flattened spot on the end cap at the point where the cladding was peeling away indicates that the water reaction began in a defect that resulted from impact when the element fell into the storage poot. The uranium oxide formed in the reaction of water with uranium metal is less dense than the metal, so a swelling occurred that bulged and split the cladding.

Much greater damage was apparent to the water-reacted outer element (Figures 3.7 and 3.8). In this case, a substantial portion of the cladding had peeled away and the underlying uranium core had completely reacted from near the end cap in one quadrant of the element. The inner cladding had also been breached in two places in this region, as can be seen in the end-view photographs (Figure 3.8).

Cladding cracks had propagated for appreciable distances beyond the area of major reaction. However, the side directly opposite the site of major reaction did not appear to be cracked.

The section shown in Figure 3.7 and 3.8 was $\sim 8.5$ in. 1ong. It broke away from the remainder of the element while the element was being packaged for shipment. Photographs (Figure 3.8 ) of the broken end show that several cracks had extended that far.

Samples of sludge from the storage basin in which the FG fuel had aged were also used, primarily to see if they contributed to the severity of foaming. Portions of these samples were dissolved for inductively coupled plasma (ICP) analysis; these results are given in Table 3.1. The major components were found to be uranium, iron, and aluminum. 

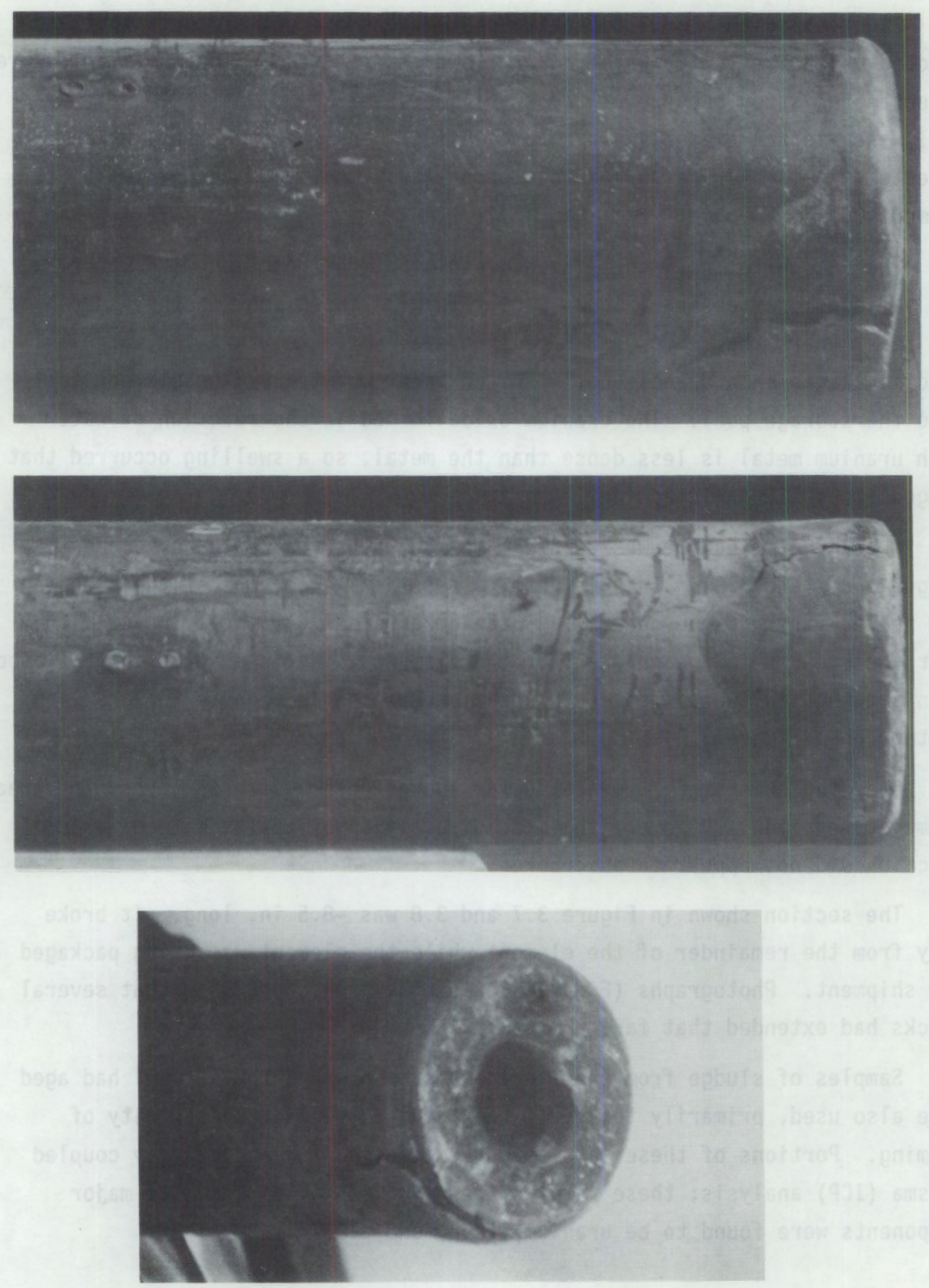

FIGURE 3.6. Photographs of Water-Reacted FG Inner Element Used in Run 8 

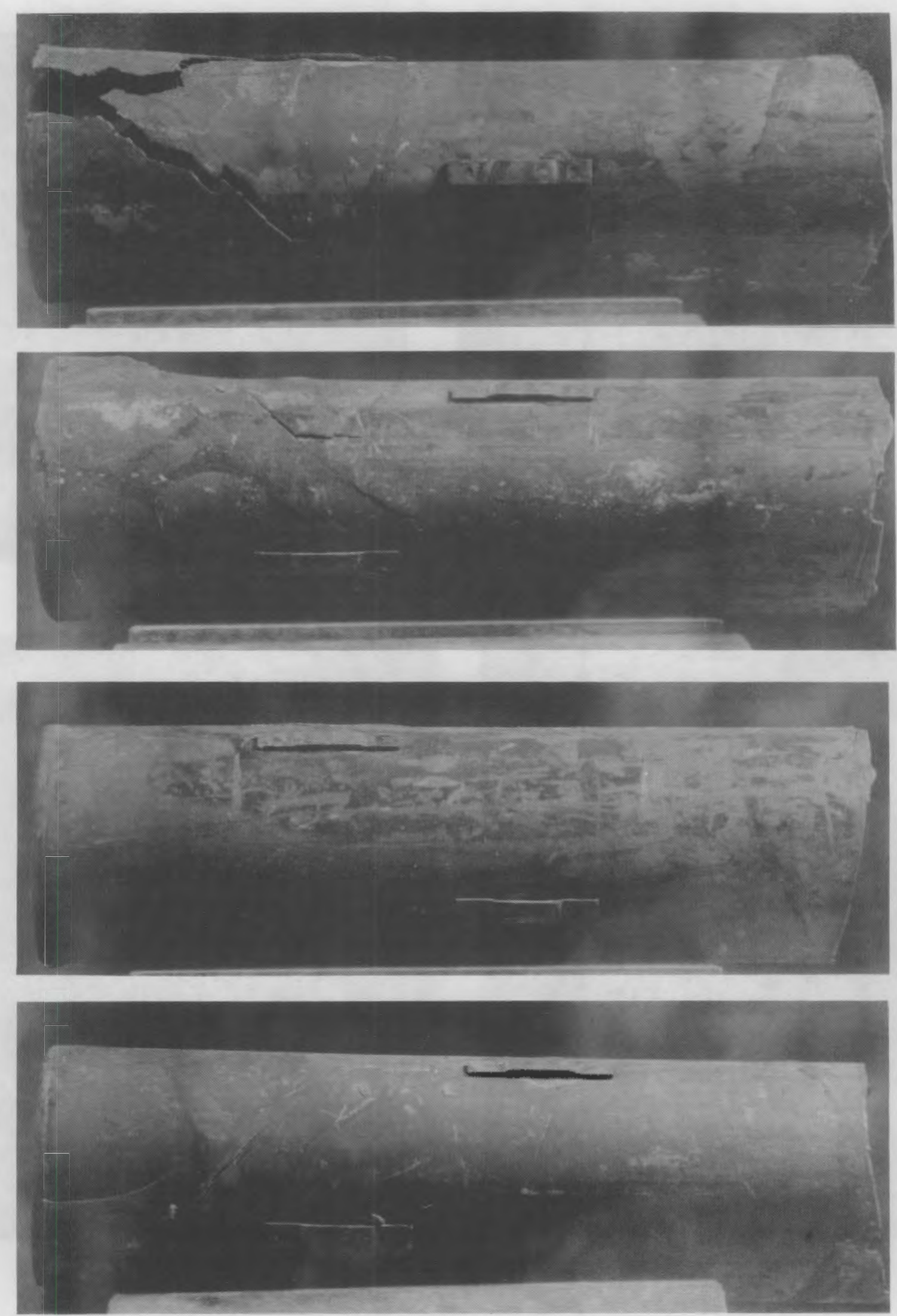

FIGURE 3.7. Side-Views of Water-Reacted FG Outer Element Used in Run 9 

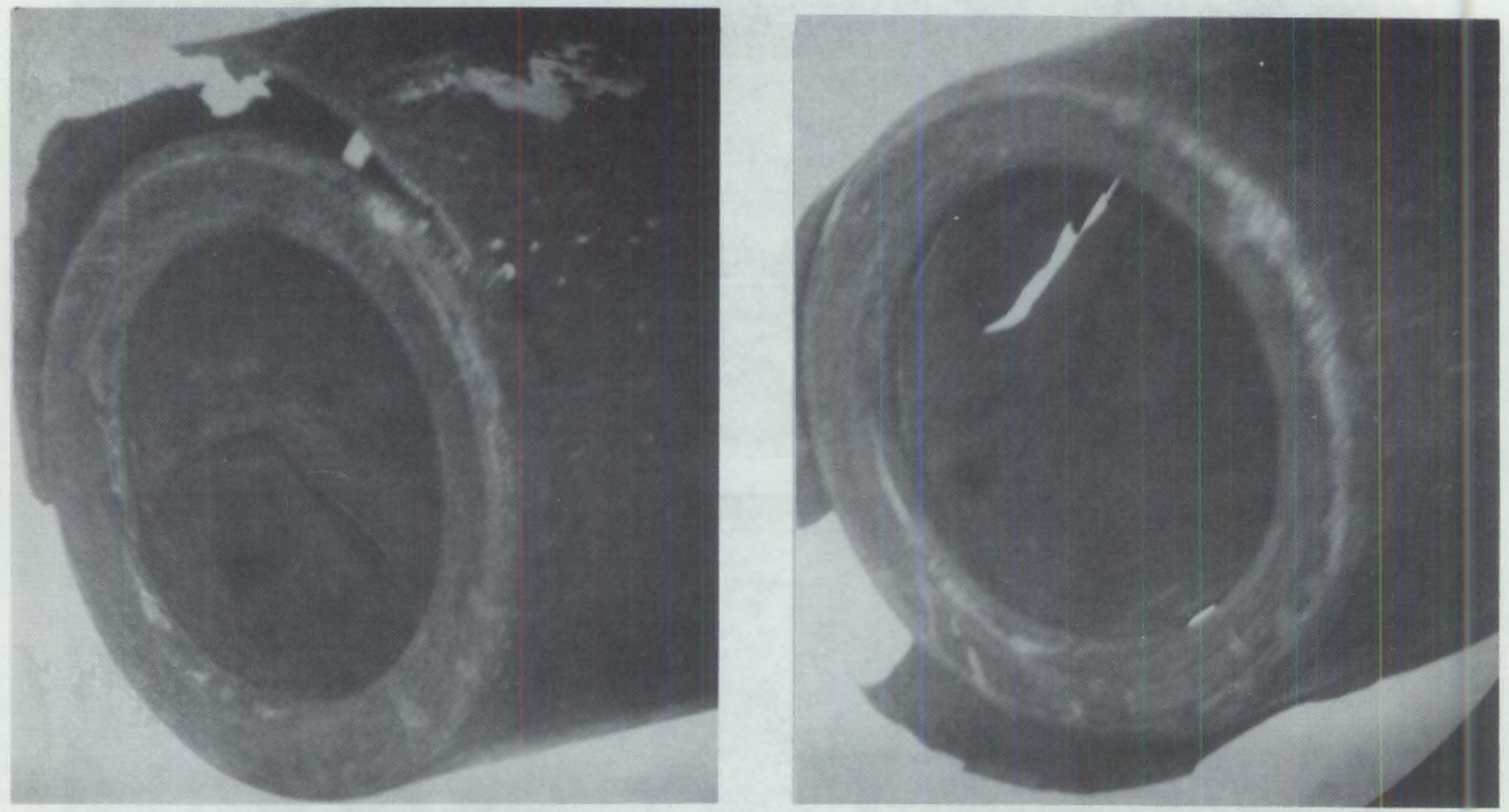

(a) Cap End
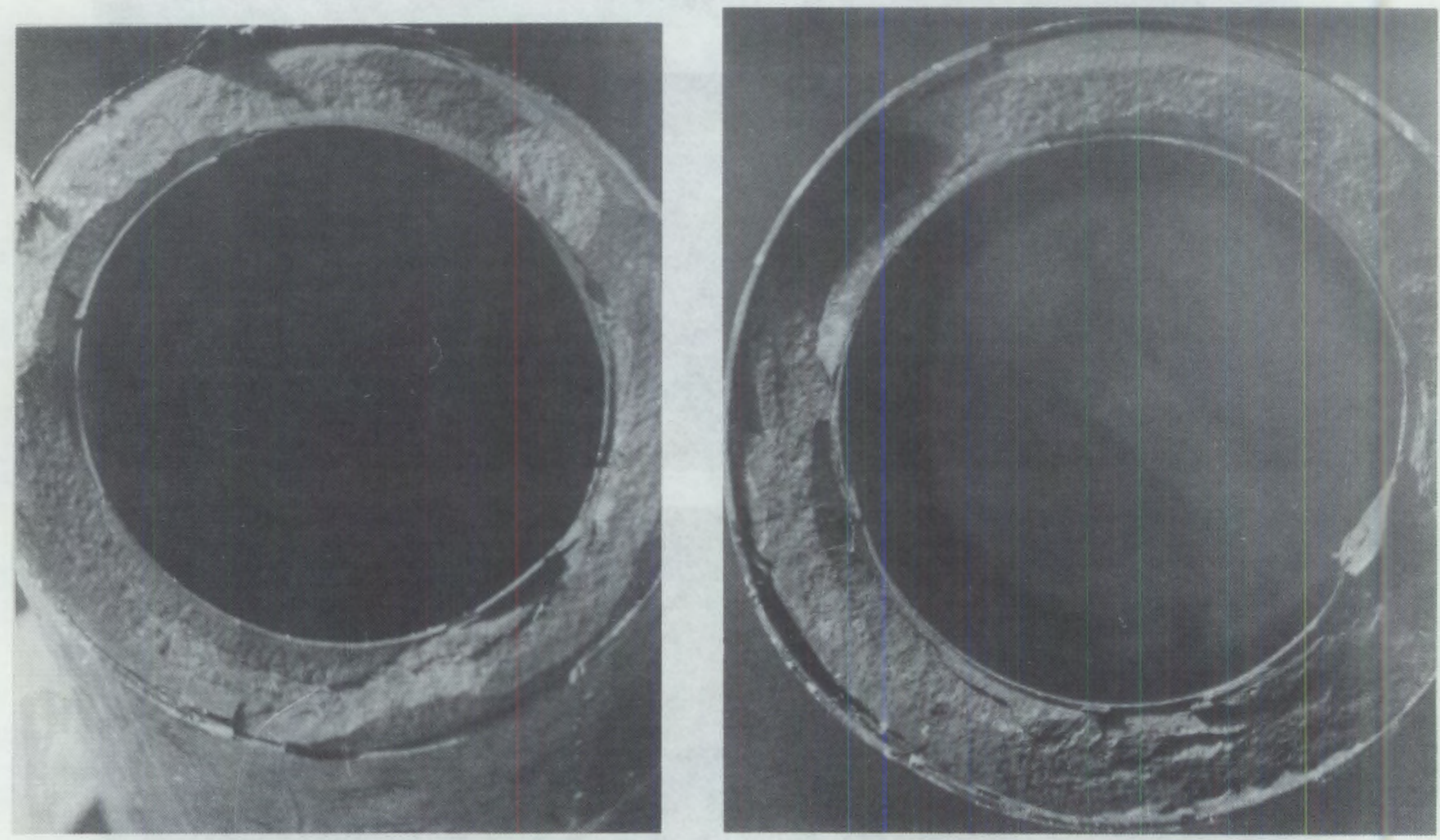

(b) Broken End

FIGURE 3.8. End Views of Wlater-Reacted FG Element Used in Run 9 
TABLE 3.1. ICP Analys is of KE Reactor Basin Segregation Pit Sludge

\begin{tabular}{|c|c|c|c|c|}
\hline \multirow{2}{*}{ Element } & \multicolumn{4}{|l|}{ Gra } \\
\hline & 1 & 2 & 3 & 4 \\
\hline Al & 0.049 & 0.108 & 0.076 & 0.104 \\
\hline $\mathrm{Ba}$ & 0.0011 & 0.0009 & 0.0038 & 0.0008 \\
\hline $\mathrm{Ca}$ & 0.0059 & 0.0070 & 0.017 & 0.0043 \\
\hline $\mathrm{Cr}$ & 0.0004 & 0.0004 & -- & 0.0006 \\
\hline $\mathrm{Fe}$ & 0.084 & 0.183 & 0.135 & 0.225 \\
\hline $\mathrm{Mg}$ & 0.0010 & 0.0014 & 0.0044 & 0.0009 \\
\hline Mn & 0.0003 & 0.0004 & -- & -- \\
\hline $\mathrm{Na}$ & 0.0098 & 0.0078 & 0.045 & 0.0096 \\
\hline $\mathrm{Ni}$ & 0.0003 & 0.0004 & 0.0013 & - \\
\hline Si & 0.0131 & 0.0097 & 0.041 & 0.011 \\
\hline $\mathrm{Sr}$ & 0.0002 & 0.0002 & -- & -- \\
\hline $\mathrm{Ti}$ & 0.0003 & 0.0002 & -- & - \\
\hline $\mathrm{Zn}$ & -- & -- & 0.0022 & -- \\
\hline $\mathrm{Zr}$ & 0.0011 & 0.0016 & 0.0014 & 0.0011 \\
\hline U & $\underline{0.359}$ & $\underline{0.245}$ & $\underline{0.033}$ & $\underline{0.024}$ \\
\hline Total Found & 0.52 & 0.57 & 0.36 & 0.38 \\
\hline
\end{tabular}

Elements that were tested for but not seen were: B, Ce, Dy, K, La, Li, Mo, Nd, Rh, Ru, and Te. 



\subsection{RESULTS AND DISCUSSION}

The major experimental effort to determine the reasons for the operating problems encountered in the plant when processing aged $F G$ fuel involved a series of flowsheet simulation runs, in which sections of elements having different histories were put through decladding, metathesis, and brief acid cut cycles to compare their behaviors. The results of these runs also provided valuable information in areas of interest other than the one that prompted this experimental effort. Table 4.1 contains a summary of the types of fuel used in these runs. In some cases, the residual fuel was used again in another run; such runs are denoted "B" runs (e.g., Run 9B) in the text.

In the second year of this effort, two studies that were related to head-end operations, but not to problems with aged $\mathrm{FG}$ fuel, were included in this project. One of these studies involved testing (especially with irradiated fuel) the use of flocculating agents to improve the removal of suspended solids from the decladding waste solutions, so that this waste

TABLE 4.1. Summary of Flowsheet Simulation Runs

\begin{tabular}{|c|c|c|c|c|c|}
\hline \multirow[b]{2}{*}{ Run } & \multirow[b]{2}{*}{$\begin{array}{c}\text { Irradiation } \\
\text { Level }\end{array}$} & \multicolumn{4}{|c|}{ Fuel Section Description } \\
\hline & & $\begin{array}{l}\text { Cooling } \\
\text { Time, yr }\end{array}$ & Type & Intact? & $\begin{array}{c}\text { Section } \\
\text { Length, in. }\end{array}$ \\
\hline 1 & None & -- & Inner & Yes & 8 \\
\hline 2 & None & -- & Outer & Yes & 6 \\
\hline 3 & FG & 12 & Inner & Yes & 6 \\
\hline 4 & FG & 12 & Outer & Yes & 6 \\
\hline 5 (a) & None & -. & Inner & Yes & 6 \\
\hline 6 & WG & 1 & Inner & Yes & 6 \\
\hline 7 & WG & 1 & Outer & Yes & 6 \\
\hline 8 & $\mathrm{FG}$ & 12 & Inner & No & 6 \\
\hline 9 & FG & 12 & Outer & No & $\sim 8.5$ \\
\hline 10 & None & -- & Inner & Yes & 6 \\
\hline 12 & None & -- & Outer & Yes & 6 \\
\hline
\end{tabular}

(a) Run to evaluate the foam-producing tendency of storage basin sludge. 
would contain a low concentration of transuranic elements and would not have to be disposed in a deep geologic repository, probably following vitrification. The other study involved means of suppressing the volatility of fission-product ruthenium when the ammonia scrubber solutions obtained during decladding were distilled to give a slightly radioactive waste stream to be discharged to the ground.

\subsection{DECLADDING}

Data were obtained bearing on many aspects of the decladding process. In addition to the speed and nature of the cladding removal process, important observations were made on the reaction of the uranium fuel core, on foaming, on the solids that form as a result of the decladding process, and on the behavior of fission products and ammonium hydroxide.

\subsubsection{Cladding Removal}

The flowsheet simulation runs all used the same volume and composition of decladding solution; $1.7 \mathrm{~L}$ of a 2.34-fold dilution of a plant AFAN mixture, which gives $5.0 \underline{\mathrm{M} \mathrm{NH}} 4 \mathrm{~F}+0.45 \mathrm{M} \mathrm{NH}_{4} \mathrm{NO}_{3}$. Ferric nitrate was also added to give $100 \mathrm{ppm} \mathrm{Fe}$; this was done to lower the quantity of hydrogen evolved, as had been demonstrated in earlier (unpublished) work. Water was added in $0.1-\mathrm{L}$ increments at the start and then throughout the run as $0.1-\mathrm{L}$ increments of condensate were collected. At the end of the time period allowed for decladding, the solution was diluted with water to a volume of $2.6 \mathrm{~L}$.

The following subsections will address the rate of Zircaloy dissolution, the nature of $\mathrm{cladding}$ removal, and the nature of attack during decladding of water-reacted fue1. Data were obtained in each of these areas that bear on the extent of reaction of the uranium core during decladding. The data indicate that it should be possible to decrease decladding time without decreasing markedly the extent of cladding removal; the decreased exposure time would lead to decreased core reaction. The removal of cladding from the inner channel of inner FG elements was found to be poor; this increases the likelihood that a heel of exposed uranium will remain after the acid cuts, which will lead to increased reaction of uranium during the next declad 
cycle. The nature of attack on extensively water-reacted fuel resulted in exposure of a large area of uranium, which led to increased reaction of uranium during decladding.

\subsubsection{Rate of Zircaloy Dissolution}

Data on the rates of dissolution of Zircaloy cladding observed in the flowsheet simulation runs are summarized in Figure 4.1, where the amounts of zirconium found in solution over time are presented for each of the runs. There is appreciable scatter to these data, probably caused by uncertainties in volume measurements, but two important conclusions appear to be quite clear. One is that there was no great difference in Zircaloy dissolution rates among unirradiated, $W G$, and $F G$ fuel. The other is that the extent of Zircaloy dissolution was nearly the same after $4 \mathrm{~h}$ as after $8 \mathrm{~h}$. The latter observation was probably due, in many cases, to a nearly complete consumption of fluoride ion (124 $\mathrm{g}$ zirconium is the maximum possible amount dissolved for the quantity of AFAN used in these experiments). However, in some cases, the reaction leveled off well before complete fluoride consumption, indicating that the surface area of reacting Zircaloy had become quite small. In such cases, there is little benefit to be obtained by a longer declad cycle, and there are drawbacks to a longer cycle, as will be discussed later (Section 4.1.2).

\subsubsection{Nature of $\mathrm{Cl}$ adding Removal}

The Zircaloy cladding on $\mathrm{N}$ Reactor fuels that have been exposed to hightemperature water, as in the reactor, is not uniformly attacked by the AFAN decladding solution. This is because the reaction with high-temperature water results in the formation on the surface of a protective oxide film that inhibits reaction not only in the reactor, but in the decladding solution as wel1. Attack of the underlying Zircaloy by the decladding solution is initiated only in spots where the oxide $f i 1 \mathrm{~m}$ is weak or has been broken during element handling. Dissolution of the cladding thus does not proceed at all uniformly; it starts in these localized spots, and the spots then enlarge as the reaction proceeds on the edges of unoxidized Zircaloy thus exposed. This type of attach is well illustrated by the pictures of a partially declad outer element section shown in Figure 4.2 , which were taken 

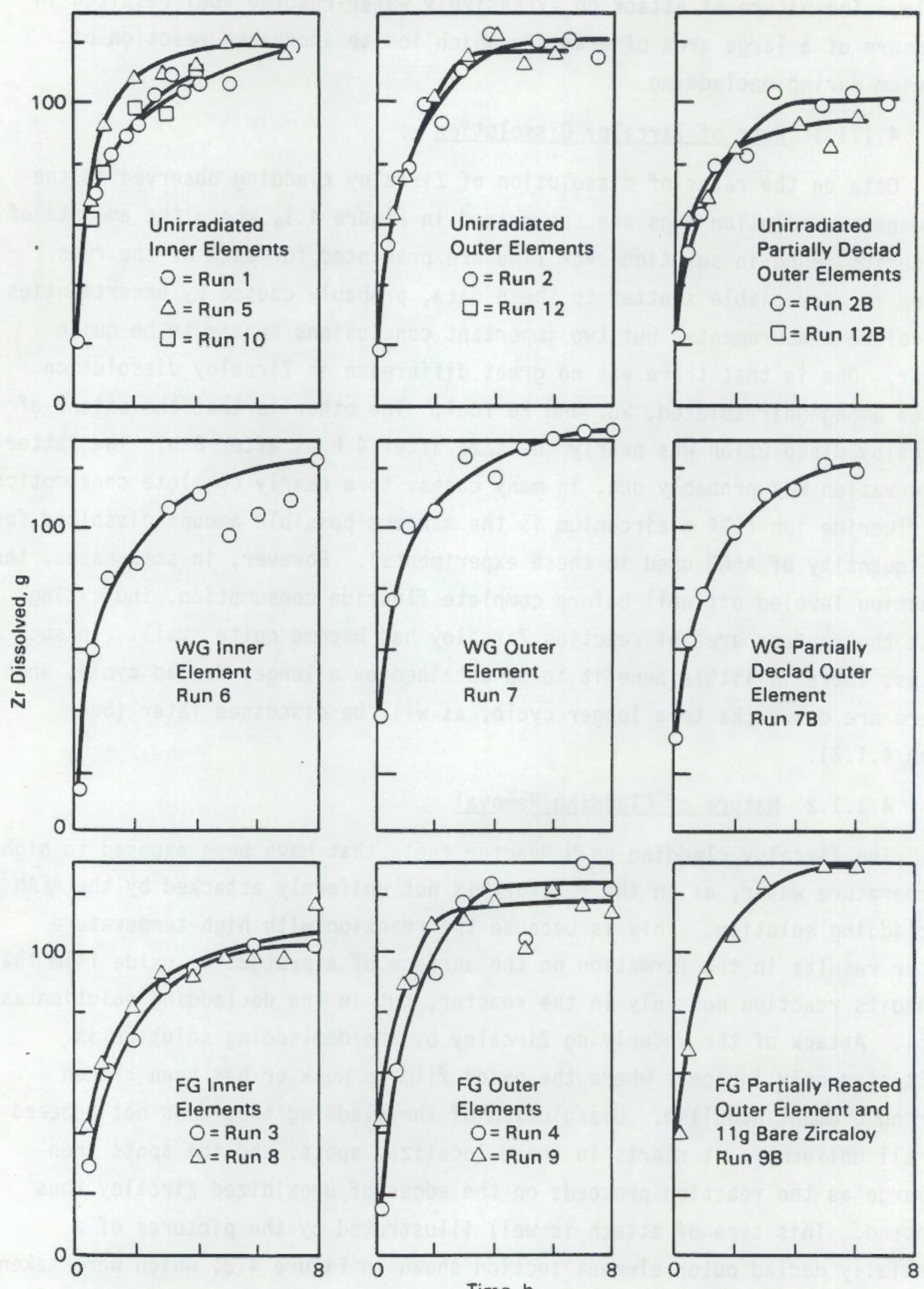

FIGURE 4.1. Rates of Zircaloy Dissolution in Flowsheet Simulation Runs 

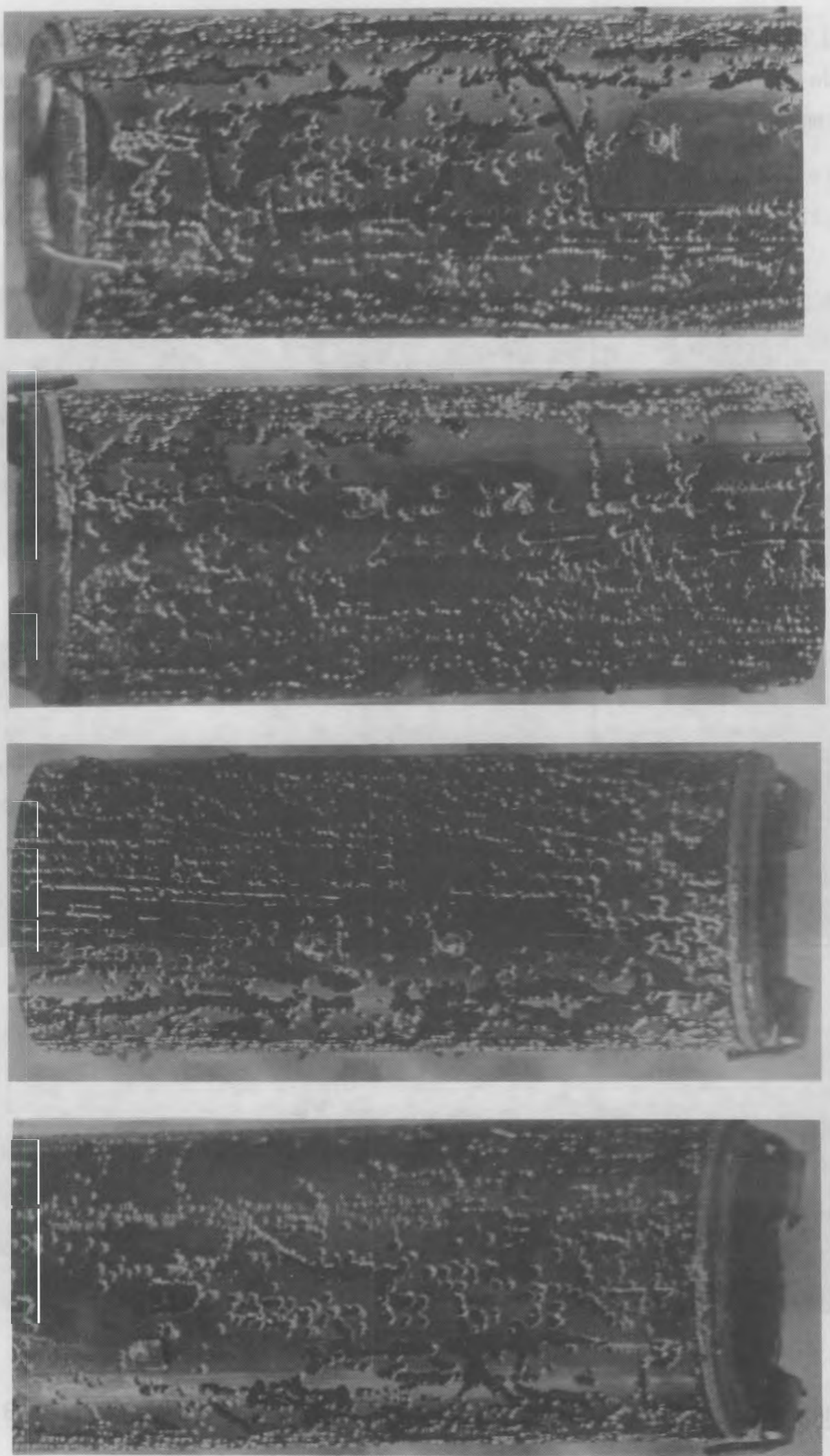

FIGURE 4.2. Photographs of Partially Declad Outer Element (Run 7) 
at the end of Run 7. It should be remembered that our outer element runs did not provide enough AFAN solution to dissolve the cladding, which is the reason so much of the cladding remains.

Figure 4.3 contains pictures of the partially declad inner element remaining in Run 3 (as in Figure 4.2 for the outer element, these pictures
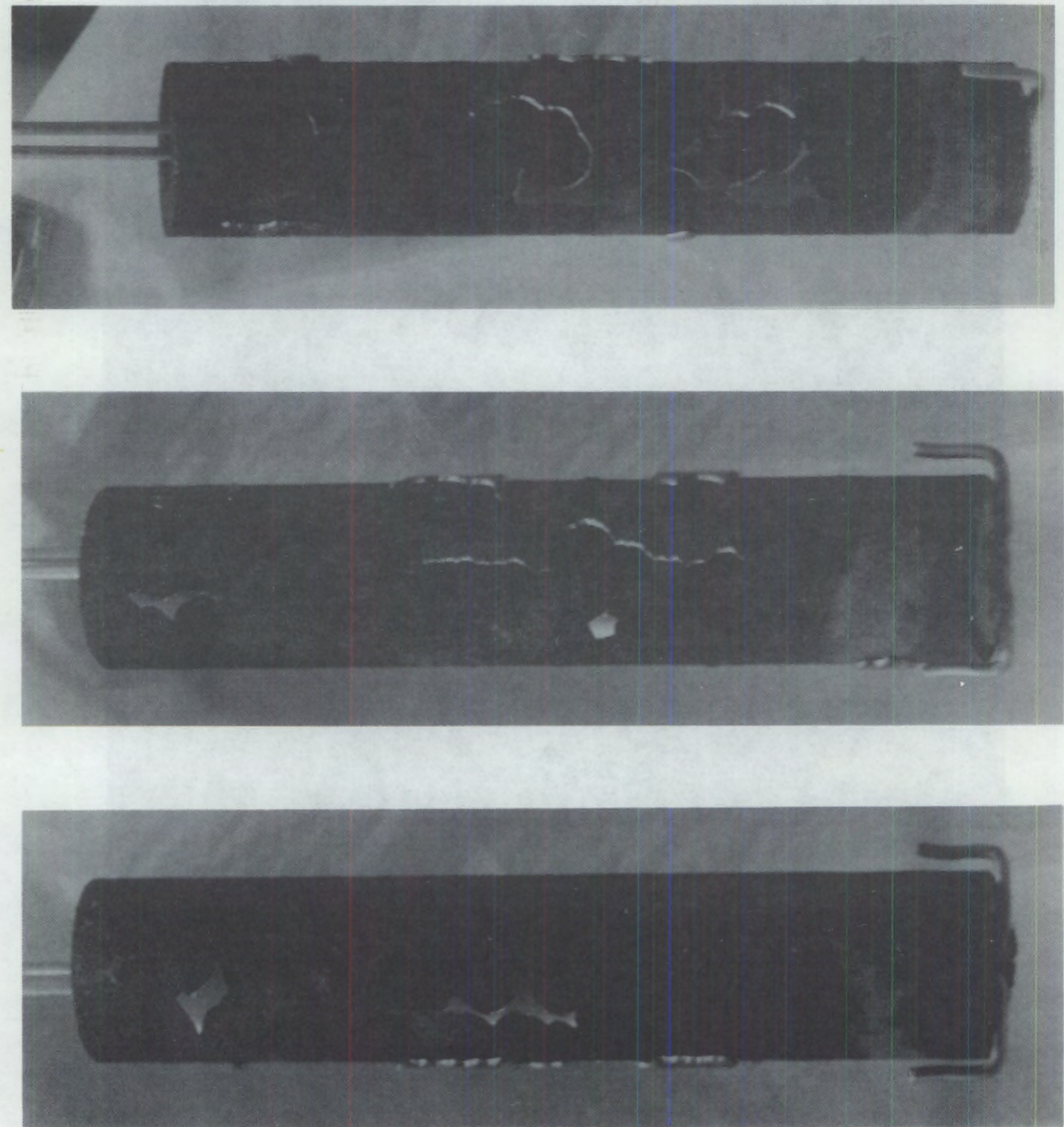

FIGURE 4.3. Photographs of Partially Declad Inner Element (Run 3) 
were taken at the end of the run, after the acid cut). Most of the cladding was removed from the outer surface of this section, but very little of the inner surface cladding was removed. This is an important observation because of the importance of the size of the acid cut heel to the extent of uranium reaction during decladding; a large heel remaining after the acid cut is much more likely with elements such as this because the acid penetration would be from only the outer side instead of from both the inner and outer sides, so that it would take much longer to complete the acid dissolution.

Table 4.2 contains data comparing the effectiveness of cladding removal from the outer and inner surfaces in the flowsheet simulation runs. In most cases, the cladding was removed more effectively from the outer surface than from the inner surface; perhaps this reflects more damage to the oxide film on the outer surfaces during handling. However, only in the two FG inner element cases (Runs 3 and 8 ) was this difference really dramatic. If this effect is indeed real, so that the inner cladding of all aged $F G$ inner

TABLE 4.2. Comparison of Effectiveness of Cladding Removal from Outer and Inner Element Surfaces

\begin{tabular}{|c|c|c|c|}
\hline \multirow[b]{2}{*}{ RuI } & & \multicolumn{2}{|c|}{ Cladding Removed, \%(a) } \\
\hline & Fuel & Outer Surface & Inner Surface \\
\hline \multicolumn{4}{|c|}{ Inner Elements } \\
\hline 1 & Unirradiated & 90 & 70 \\
\hline 5 & Unirradiated & 90 & 90 \\
\hline 6 & WG & 90 & 100 \\
\hline 3 & $\mathrm{FG}$ & 90 & 10 \\
\hline 8 & FG & 100 & 20 \\
\hline \multicolumn{4}{|c|}{ Outer Elements $(b)$} \\
\hline 2 & Unirradiated & 45 & 30 \\
\hline 7 & WG & 30 & 25 \\
\hline 4 & FG & 30 & 20 \\
\hline
\end{tabular}


elements is resistant to removal, it would be much more difficult to obtain complete acid dissolution of aged FG material than of WG material.

\subsubsection{Nature of Attack During Decladding of Water-Reacted Fuel}

Special attention is directed to the nature of the attack that occurred during the decladding portion of the flowsheet simulation run (Run 9) with the aged $F G$ element section that had reacted extensively with water during storage. Not only were the results quite interesting, but they have important process implications.

First, however, the results obtained with the water-reacted inner element (Run 8) will be discussed. Pictures taken at the end of this run are shown in Figure 4.4. These pictures show that the cladding was removed nearly completely from the outer surface (but not from the inner surface, as was shown in Table 4.2). A substantial crack is seen in this element section; it presumably originated near the end cap where the water reaction has occurred during storage. The crack extended $\sim 5$ in. up the section.

More startling results were obtained with the water-reacted outer element, which had reacted much more extensively than the inner element (Figures 3.6 and 3.7). When this fuel element section was raised from the dissolver at the completion of Run 9, the holder held a jumbled array of broken pieces instead of a solid cylinder of uranium with partially removed cladding, as was the case in all the other runs. Four views of this array are shown in Figure 4.5. The array was $-5 \mathrm{in}$. high, as opposed to the $>8$ in. length of the section initially.

Part of this missing height was accounted for by a piece that broke off the top of the section during removal from the dissolver. A picture of this piece is shown in Figure 4.6, along with the disassembled array of pieces that had remained together during removal.

In addition to the pieces that were still arrayed together on the holder, many pieces had fallen to the bottom of the dissolver. Figure 4.7 shows pictures of many of these pieces. Some were several inches in size with most of the cladding remaining while others were small pieces of uranium with no cladding attached. 

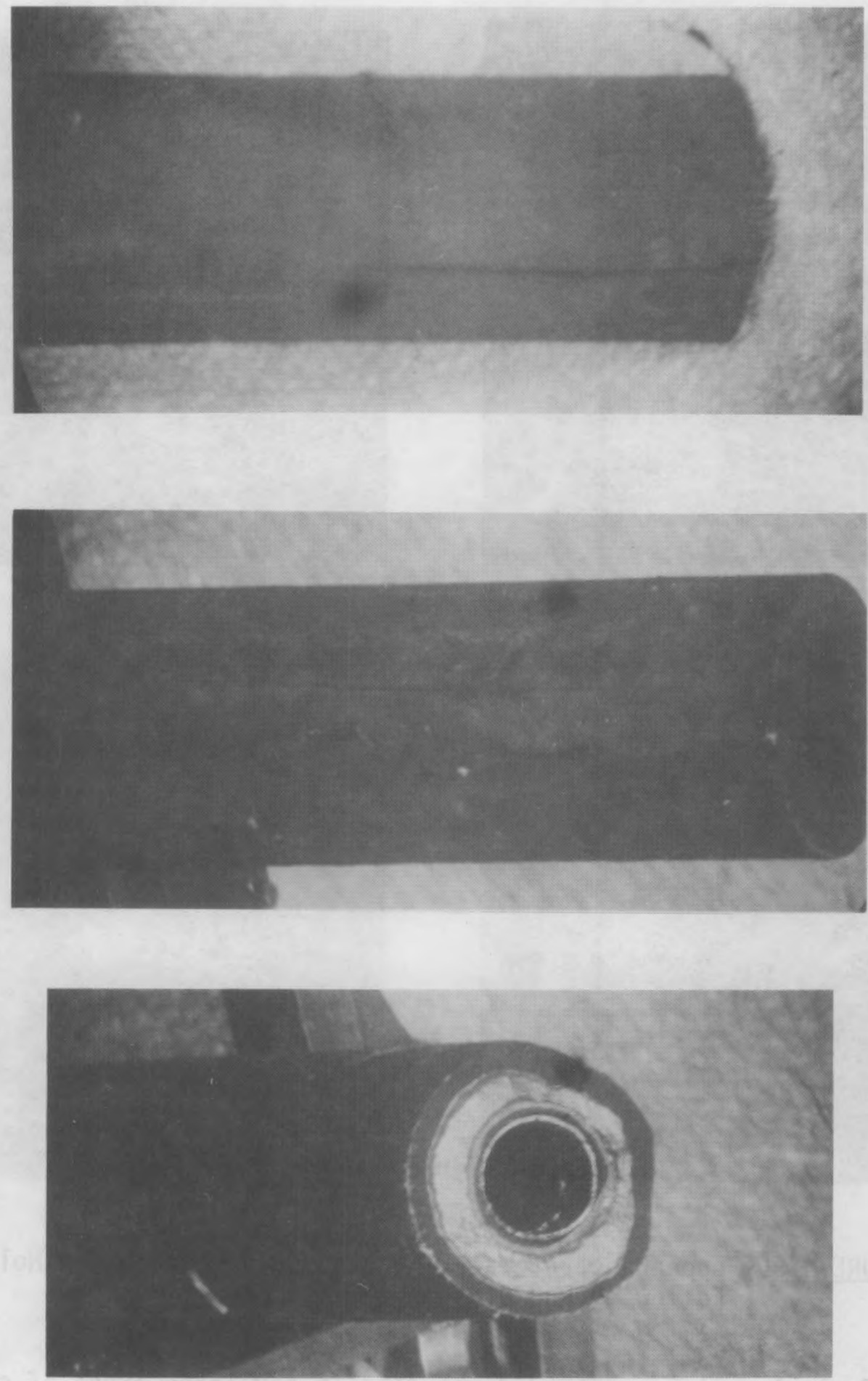

FIGURE 4.4. Photographs of Water-Reacted Inner Element After Flowsheet Simulation Run 8 

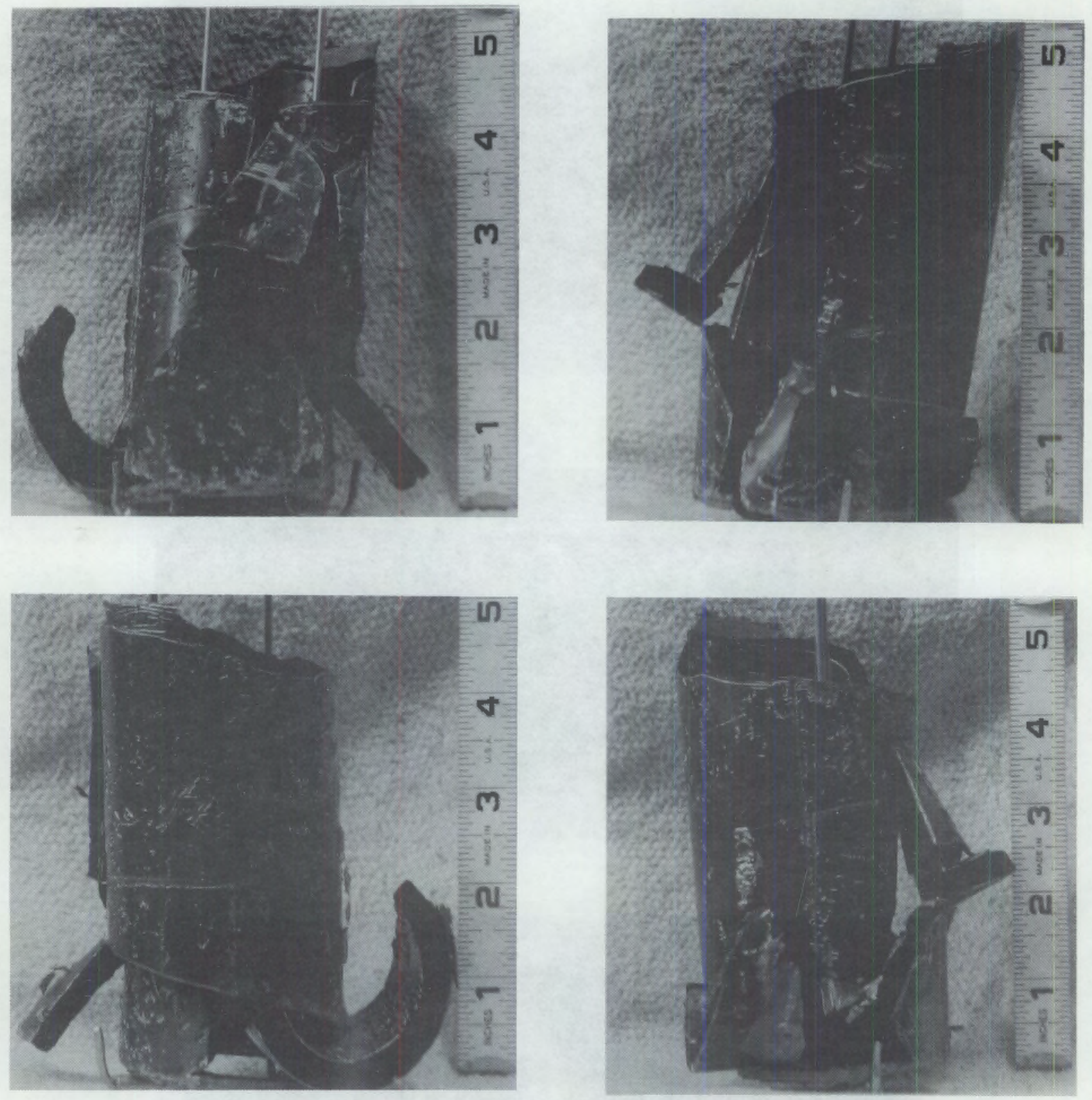

FIGURE 4.5. Appearance of Water-Reacted Outer Element on Holder Following Run 9

The fuel element remnants did not contain any large areas of cladding that were not bonded to the uranium core, indicating that the cladding surrounding the area where the uranium was missing (Figure 3.7) had dissolved completely. This is as expected because the side of the Zircaloy that had 


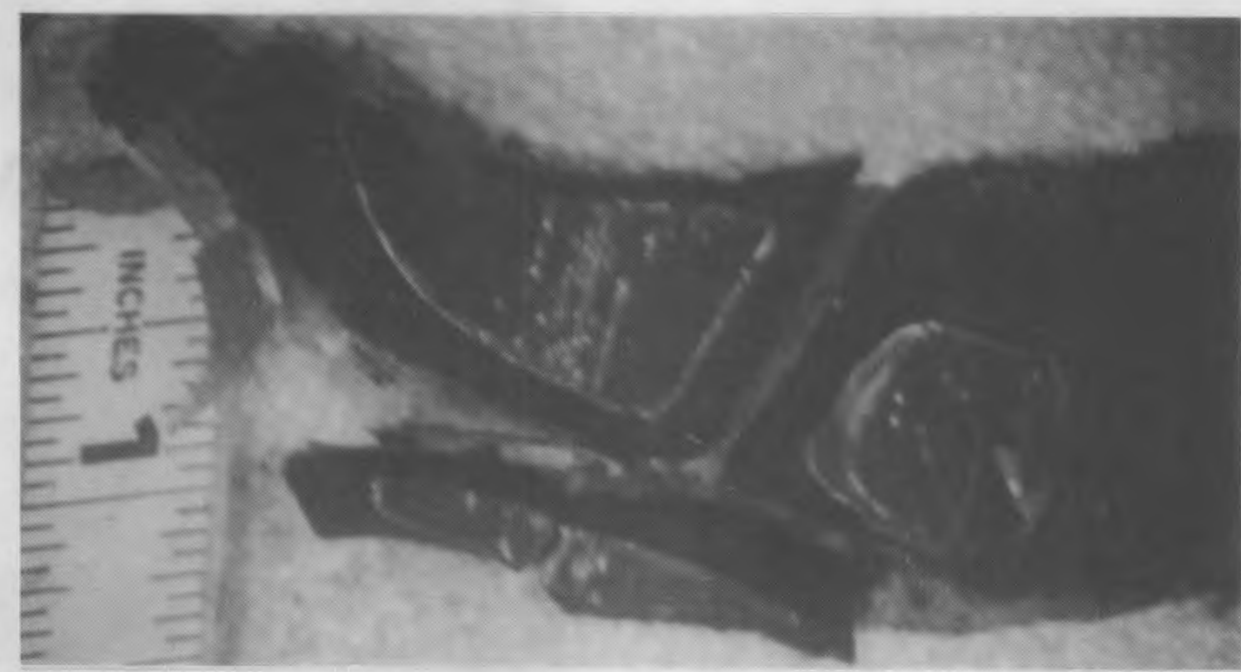

Piece that broke off the top during removal from dissolver

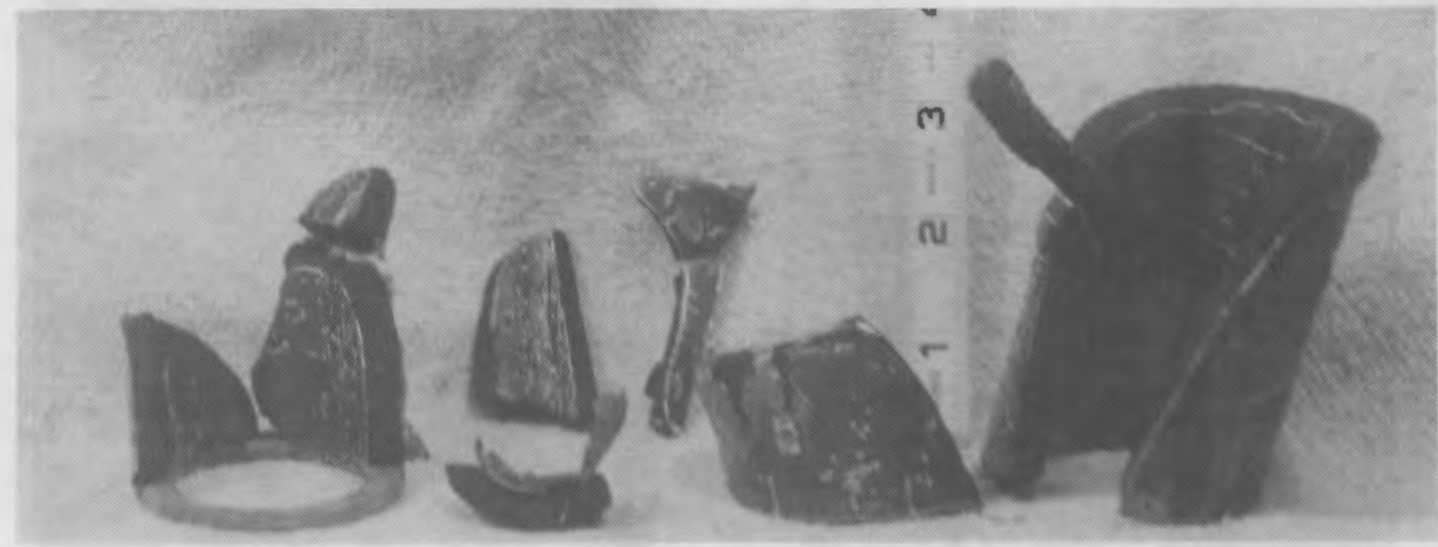

Disassembled array of pieces that remained together during removal

FIGURE 4.6. Individual Pieces of Water-Reacted Outer Element on Holder Following Run 9

faced the uranium would not have a protective zirconium oxide film on it; dissolution could thus proceed rapidly over that entire surface.

The reason that the water-reacted element section became highly segmented during Run 9, even though only a small fraction of the cladding was dissolved, is not known with certainty but a plausible explanation can be advanced. This explanation is an extension of that advanced by Swanson et a1. (1985), which was based on a mechanism involving hydriding of an impurity at grain boundaries (Mueller et al. 1968). Because storage of defected fuel 

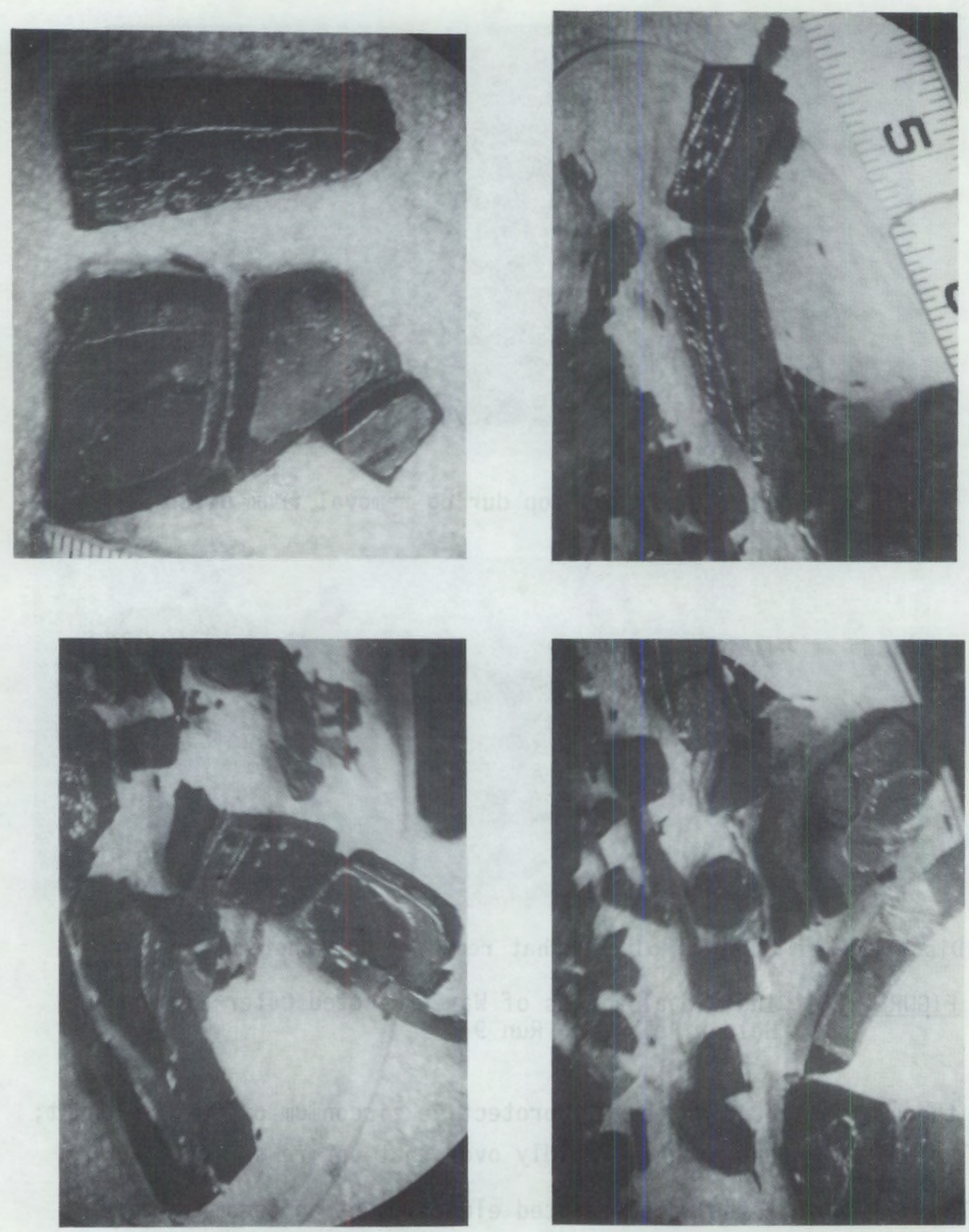

FIGURE 4.7. Pieces of Water-Reacted Outer Element That Had Fallen to Bottom of Dissolver in Run 9 
elements in water basins for long periods of time has allowed prolonged contact with the hydrogen produced by reaction of water and metal, it is conceivable that hydrogen may have diffused along microcracks formed during irradiation and attacked grain boundaries throughout an appreciable depth into the fuel elements. Swelling that accompanies such attack could lead to cracks in the cladding and/or its oxide film over the affected microcracks. As was discussed earlier, reaction of the AFAN decladding solution would occur preferentially at these cracks in the cladding and/or its oxide film, thus effectively segmenting the element along the lines where hydrogen diffused down the microcracks.

The segmentation of the water-reacted fuel during decladding has important process impacts. The resultant high uranium surface area leads to reaction of more uranium during decladding, as will be discussed in Section 4.1.2.1. This leads to the presence of more hydrous uranium oxide after metathesis, which will react rapidly at the start of the acid cut and perhaps cause a reaction that is uncontrolled for at least a brief period. Such a reaction was observed in the acid cut portion of Run 9 , which will be discussed in Section 4.4.2. The high uranium surface area resulting from fuel segmentation also contributes directly to more rapid dissolution of uranium metal in the acid cut (Section 4.4.1.1).

\subsubsection{Reaction of Uranium Fuel Core with Ammonium Fluoride-Ammonium Nitrate Solutions}

The uranium core of $\mathrm{N}$ Reactor fuel elements is also reactive towards the decladding solution. Plant data indicated that more reaction occurred during processing of aged $F G$ fuel than when processing WG fuel. The results of the experimental program verified that major differences can occur, and provided plausible explanations for how they can arise.

Subsections here will address the extent of uranium reaction observed in the flowsheet simulation runs, the potential importance of reactions of uranium with dilute AFAN solutions, an estimation of the importance of the reaction of residual uranium (the acid cut heel) during the subsequent decladding cycle, and the results of other rate studies of uranium in AFAN solutions. Two observations of major importance can be made here: 1) prior 
reaction of the fuel with water, leading to cracking of the fuel, had the greatest impact on the extent of uranium reaction during decladding; and 2) reaction of the uranium core with the decladding solution can continue even after the free fluoride concentration has been reduced to a low level. Also, it was concluded that, when processing intact fue 1 , the exposed uranium heel left at the end of the final acid cut may be the major contributor to the uranium reaction that occurs during decladding of the subsequent charge.

\subsubsection{Uranium Reaction in Flowsheet Simulation Runs}

Because of the insolubility of reacted uranium in the declad solution, the rate of uranium reaction during decladding could not be measured directly. Instead, it was inferred from the ${ }^{137}$ Cs content of the declad solution over time and the ${ }^{137} \mathrm{CS}-$ to-U ratio measured for the particular fuel. The ${ }^{137} \mathrm{CS}$-to-U ratios were obtained in two different ways. One way involved measuring the total ${ }^{137} \mathrm{Cs}$ found in the decladding, metathesis, and acid cut solutions and the weight of uranium reacted, as determined by the total weight loss minus the weight of zirconium found in the declad solution. The second way involved measuring the increases in the ${ }^{137} \mathrm{Cs}$ and uranium concentrations resulting from dissolution of uranium metal during the acid cut.

The extent of uranium reaction during decladding was also determined in two ways. One was from the ${ }^{137} \mathrm{Cs}$ measurements on the final decladding solution, as discussed above. The other method was by summing the results of uranium analyses from the initial acid cut solution and the waste solutions slurped from the dissolver pot, and subtracting the small amount of uranium metal that had reacted in the initial acid cut solution (which was determined by the ${ }^{137}$ Cs method).

Table 4.3 summarizes the ${ }^{137} \mathrm{CS}-\mathrm{to}_{0} \mathrm{U}$ ratios determined by the two methods and compares the values of extent of uranium reaction during decladding determined from the ${ }^{137} \mathrm{Cs}$ contents of the final decladding solutions with those determined by uranium analyses of the initial acid cut solution (corrected by the amounts slurped from the dissolver and the amount that resulted by dissolution of uranium metal in acid by the time the sample was taken). The overall agreement is thought to be excellent; in all cases 
TABLE 4.3. Comparison of 137 Cs-to-Uranium Determinations and of Uranium Reaction During Decladding in Flowsheet Simulation Runs

\begin{tabular}{|c|c|c|c|c|c|}
\hline & & & & Uranium Reacted & ing Decladding, $\mathrm{g}$ \\
\hline & $137 \mathrm{Cs} \mathrm{c/r}$ & $g$ U(a) & Based on $137 \mathrm{C}$ & s in Final Solution & \\
\hline Run & $\begin{array}{l}\text { Based on } \\
\text { Weight Loss }\end{array}$ & $\begin{array}{l}\text { Based on Acid } \\
\text { Cut Analyses }\end{array}$ & $\begin{array}{l}137 \text { Cs-to-U } \\
\text { Based on } \\
\text { Weight Loss } \\
\end{array}$ & $\begin{array}{l}137 \text { Cs-to-U Based } \\
\text { on Acid Cut } \\
\text { Analyses } \\
\end{array}$ & $\begin{array}{l}\text { (U Found in Early Acid Cut Sample) } \\
+ \text { (U Slurped with Waste Solutions) } \\
- \text { (Metal Dissolved in Acid) }\end{array}$ \\
\hline 3 & $3.91 \times 10^{9}(b)$ & $3.15 \times 10^{9}$ & 40 & 50 & $41+3.0-2.0=42$ \\
\hline 4 & $2.93 \times 10^{9}(\mathrm{~b})$ & $3.30 \times 10^{9}$ & 56 & 50 & $62+5.7-6.4=61$ \\
\hline 7 & $1.72 \times 10^{9}(b)$ & $1.74 \times 10^{9}$ & 33 & 32 & $35+5.0-6.1=34$ \\
\hline 8 & (c) & $3.29 \times 10^{9}(d)$ & (c) & 55 & (c) \\
\hline 9 & $3.81 \times 10^{9}(b)$ & $3.87 \times 10^{9}$ & 320 & 318 & $489+7.5-69=428$ \\
\hline $9 B$ & $3.88 \times 10^{9}$ & $3.34 \times 10^{9}(b)$ & 181 & 210 & $250+4.5-16=238$ \\
\hline
\end{tabular}

(a) 137 Cs count ing efficiency $\sim 10 \%$.

(b) The ratio chosen for use in defining reaction rates.

(c) Data not available because of pipettor problems in diluting acid cut samples.

(d) This value should be valid regardless of pipettor problems, because it is based on ratios. 
except one (Run 9) the agreement between at least one of the values determined by the ${ }^{137} \mathrm{Cs}$-to-U ratio is within $13 \%$ of the value determined by analysis of (primarily) the initial acid cut solution.

In Run 9, the amount of uranium found in the initial acid cut solution was appreciably larger than the amount of uranium that reacted during decladding (as measured by the release of ${ }^{137} \mathrm{Cs}$ ). This difference can be explained by postulating that the element section used here, which is known to have reacted extensively with water during storage (Figure 3.7 ), still contained the reaction products from $\sim 100 \mathrm{~g}$ uranium when it was used here. This is thought to be a reasonable explanation.

The ${ }^{137} \mathrm{CS}$-to- $U$ ratios chosen for use in determining the rates of uranium reaction during decladding are identified in Table 4.3. The selection was based on which of the two ratios gave the better agreement of total reaction during decladding with that determined by the uranium measurements on (primarily) the initial acid cut sample. Application of these ratios to the ${ }^{137}$ CS content of the decladding solution over time gives the values of extent of uranium reaction over time shown in Figure 4.8. Also shown in this figure are the final results for Runs 1 and 2 with unirradiated uranium; these results are based only on uranium concentration measurements and may be slightly ( $\leq 15 \%$ ) high relative to the others because of the inability to correct for the amount of uranium metal that had reacted with acid before the first acid cut sample was taken.

These results (Figure 4.8) show that the sections of intact elements of unirradiated, $W G$, and $F G$ fuel reacted to approximately the same extent during decladding. However, the water-reacted FG elements gave greater reaction; this is especially true with the element used in Run 9, which had reacted extensively with water during storage. The percentage of reacted uranium was nearly five times greater in this case than in Run 4, with an intact FG element (it was seen in Table 4.3 that nearly six times as much uranium actually reacted in Run 9; the different factors result from the different sizes of the elements).

The percentages of uranium reaction observed in these experiments are at the low end of the range ( $1 \%$ to $10 \%$ ) normally observed in the plant (except 


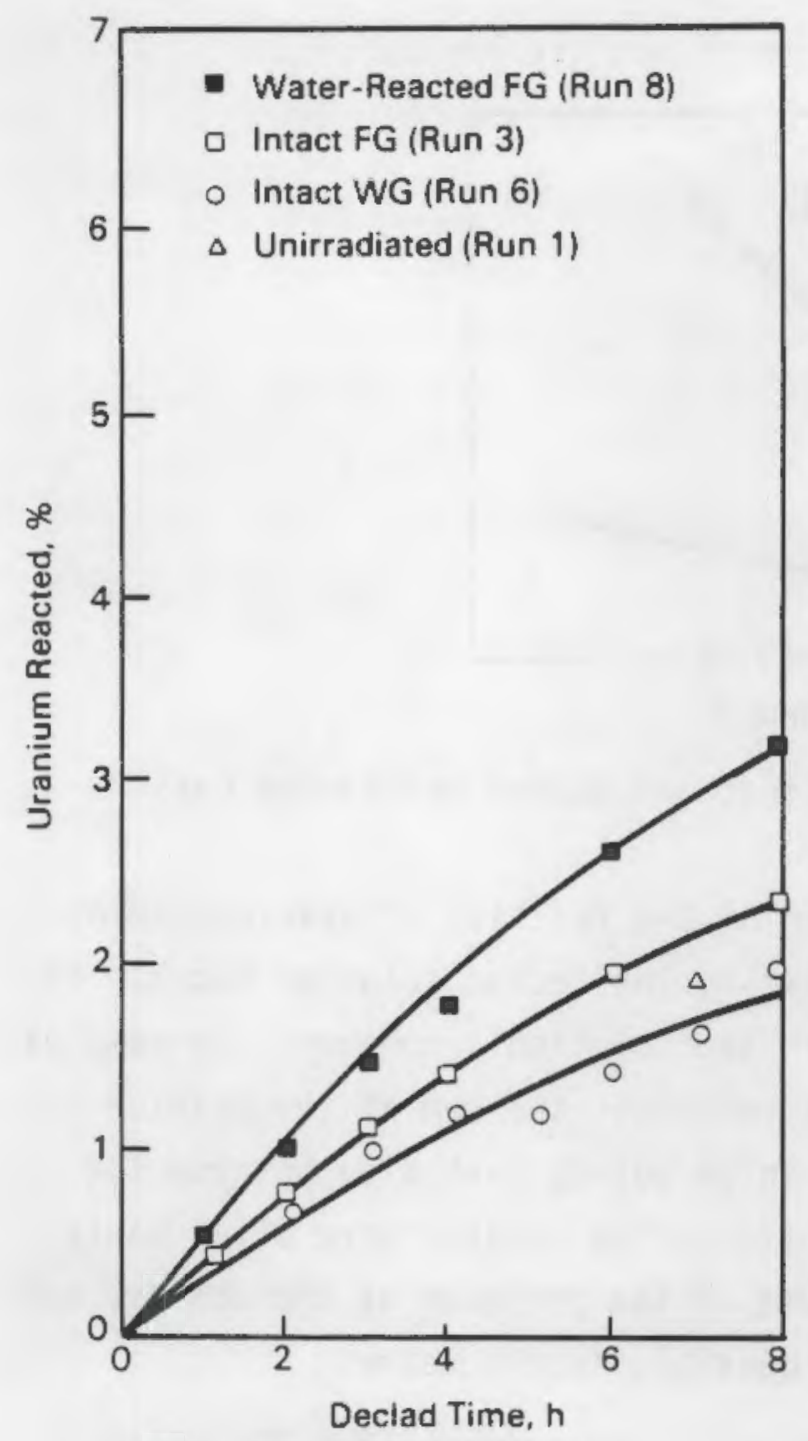

a. Inner Elements

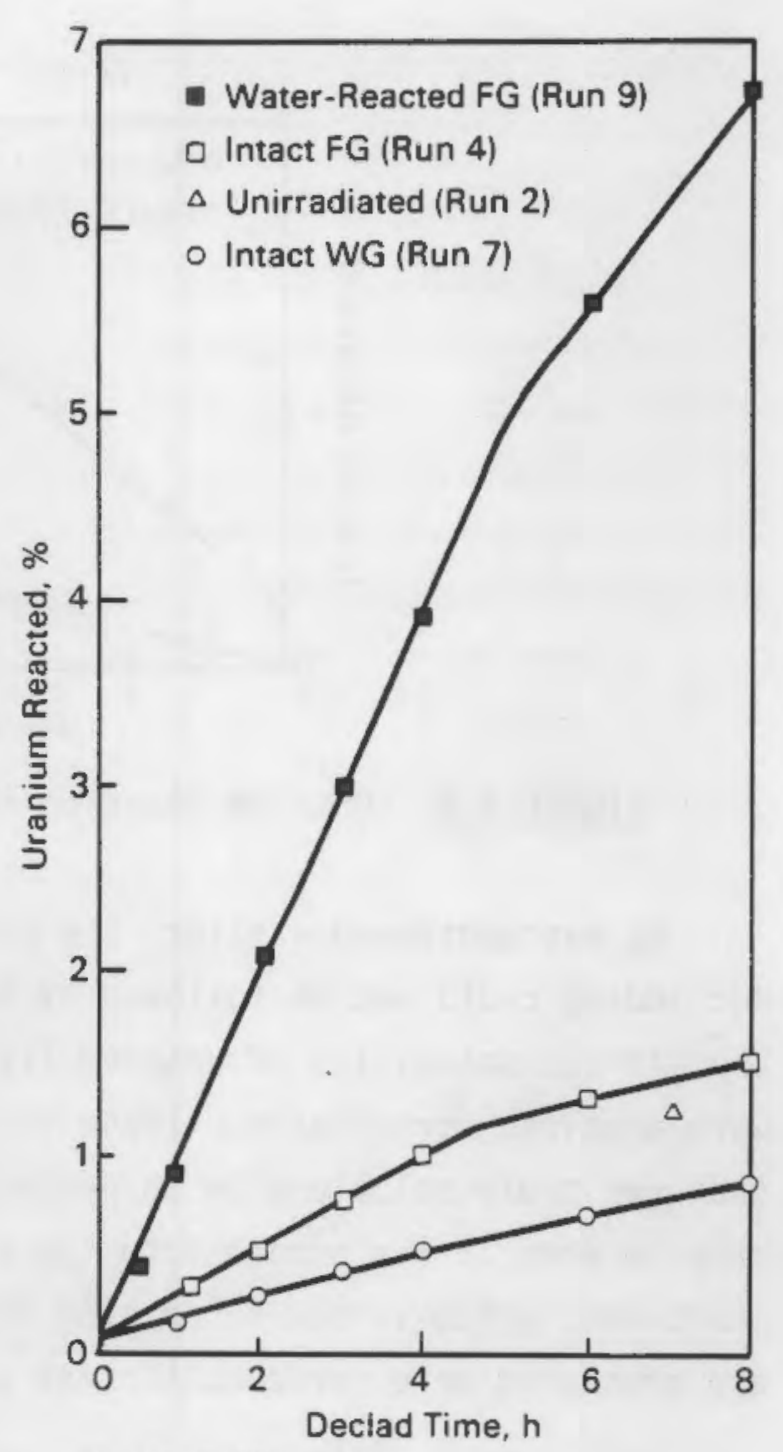

b. Outer Elements

FIGURE 4.8. Uranium Reaction During Decladding

for Run 9). More reaction would have occurred in the outer element runs if there had been enough AFAN present to dissolve all of the cladding. This is illustrated in Figure 4.9 which compares the extent of uranium reaction in a second decladding cut on an outer element with that in the first cut. Higher reaction percentages would also result if an appreciable amount of bare uranium were present at the start of decladding, such as occurs in the plant if the acid cuts on the preceding charge do not dissolve all of the uranium. This will be discussed in Section 4.1.2.3. 


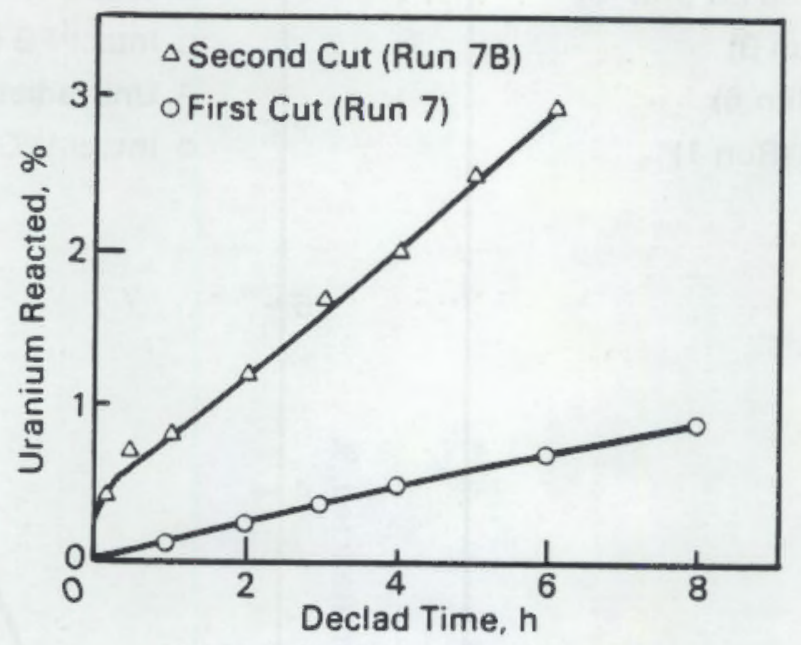

FIGURE 4.9. Uranium Reaction in First and Second Decladding Cuts

As was mentioned earlier, the course of the reaction of uranium during decladding could not be followed by analyzing the declad solution because of the limited solubility of uranium (IV) in the solution. However, the samples were analyzed for uranium. These values represent the sum of the uranium that was truly soluble plus suspended uranium solids that also entered the sampler when it was dipped into the solution. The results were often badly scattered, which is not surprising because of the presence of the solids, but are presented here for completeness and possible future value.

Figure 4.10 contains the data found in one experiment (Run 7B, which used a partially-declad outer element) and compares them with the concentration of soluble uranium (IV) estimated over time. These soluble uranium (IV) values were estimated using the zirconium analyses to calculate the free fluoride concentrations over time, and the uranium (IV) solubility as a function of free fluoride concentration values that were measured in the original Zirflex process development work (Swanson 1958, 1961). This comparison shows that the concentration of uranium in the samples increased until the approximate time that the solution became saturated with respect to uranium (IV) and then decreased markedly before it again began to increase. This late increase in uranium in the samples could result from oxidation of uranium (IV) to uranium (VI), which is more soluble than uranium (IV) at low free fluoride concentrations, or it could result from more solids being 


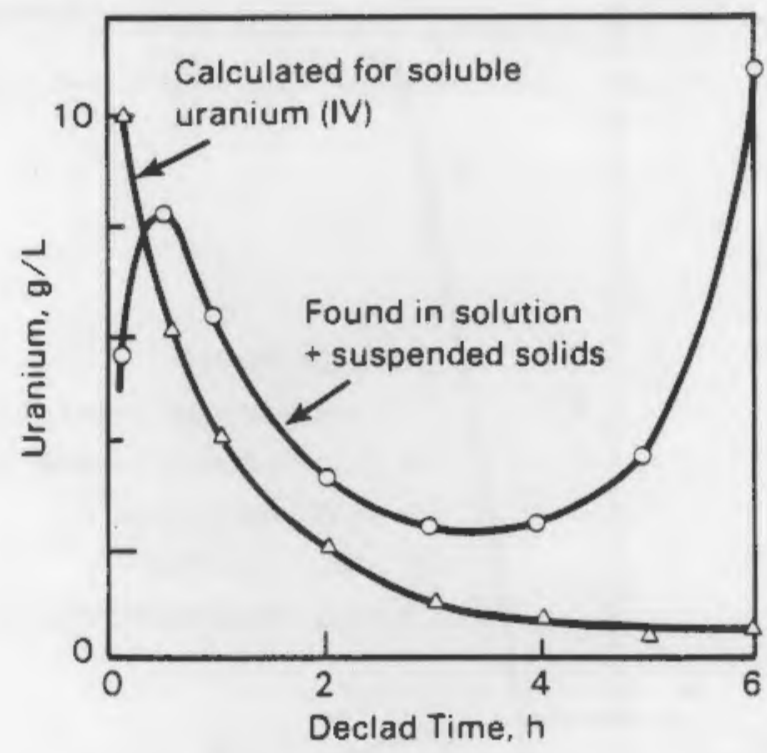

FIGURE 4.10. Comparison of Uranium Content of Dip Samples with That Expected Based on Uranium (IV) Solubility

suspended up into the zone of the solution that was sampled. The latter explanation is preferred because of visual observation of solids in the samples and because analysis of a few filtered declad solutions showed low uranium concentrations.

The uranium concentrations (as suspended solids plus those in solution) found over time in several other experiments are shown in Figure 4.11; a wide variation is apparent. No correlation could be drawn regarding the effect of fuel burnup in these results. There is an indication that a higher concentration of suspended solids occurred in the experiments with waterreacted elements (Runs 8 and 9 ), but it is difficult to be sure because of the wide variability of results.

\subsubsection{Reaction of Uranium with Dilute AFAN Solutions}

The high extent of uranium reaction observed (Figure 4.8 ) in the decladding step of Run 9, with the water-reacted outer element, was quite surprising in that the total quantity of zirconium and uranium that reacted was greater than had been thought possible. At the end of Run 9, the quantity (mole zirconium + mole uranium reacted) per mole total fluoride added was -0.3 . It had previously been thought that this value could not 


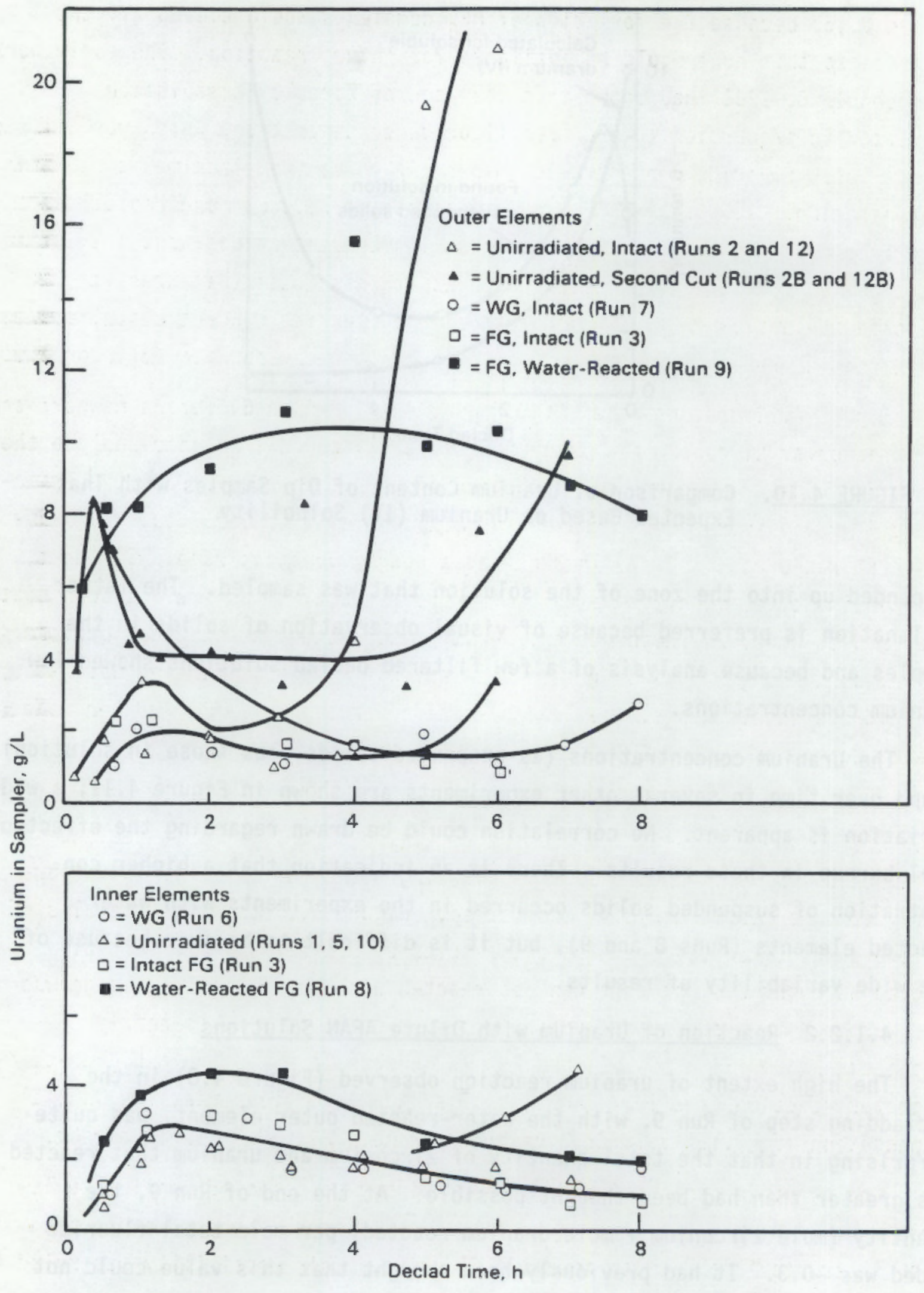

FIGURE 4.11. Uranium Content of Dip Samples During Declad Runs 
exceed 0.167 because the formation of $\mathrm{MF}_{6}^{=}$complexes would tie up all the fluoride so that none would be available for future reaction. The early work (Swanson 1958, 1961) had shown that the rate of Zircaloy dissolution decreased in proportion to the free fluoride concentration, which was defined as the total fluoride concentration minus six times the dissolved zirconium concentration. It was also observed that uranium reacted more rapidly at high free fluoride concentrations than at low concentrations, but the uranium reaction was not studied in detail. It was then assumed that uranium reaction would slow in proportion to the free fluoride concentration, as does the zirconium reaction. This assumption has now been shown to be incorrect.

Figure 4.12 presents the data of Runs 4 and 9 in a different manner; the mole ratios of zirconium and uranium (separately as well as combined) to the added fluoride are plotted as a function of time. In both cases, the $\mathrm{Zr}$-toadded $F^{-}$ratio approaches the expected maximum value of 0.167 but the $U$-toadded $\mathrm{F}^{-}$ratio continues to increase at a nearly constant rate. In Run 4, with an intact element, the extent of uranium reaction was small enough that the $\mathrm{Zr}+\mathrm{U}$-to-added $\mathrm{F}^{-}$ratio was only $\sim 10 \%$ greater than the expected maximum value, so nothing was made of the observation. However, with the waterreacted element in Run 9 , the $\mathrm{Zr}+\mathrm{U}$-to-added $\mathrm{F}^{-}$ratio was $~ 80 \%$ greater than the expected maximum, and it was obvious that something was amiss.

The first check of this unexpected result involved exposure of the fuel rubble from the water-reacted element remaining after the first declad, metathesis, and acid cut to fresh decladding solution to see if the apparently strange result could be duplicated. Figure 4.13 shows the results of this exposure (Run 9B) and also the results of Run 78, where a partially declad WG outer element that had not reacted with water during storage was also exposed to a second decladding cycle. Run $9 B$ is seen to nearly duplicate Run 9 (Figure 4.12) and Run $7 B$ is seen to also give a higher-thanexpected reaction of $\mathrm{Zr}+U$. These results made it obvious that the initial expectation of $\leq 0.167$ mole $\mathrm{Zr}+\mathrm{U}$ reacted per mole $\mathrm{F}^{-}$added was incorrect.

One possible explanation for the continued reaction of uranium at low free fluoride concentrations is that the uranium could simply be reacting with water rather than with ammonium fluoride. This possibility was ruled 

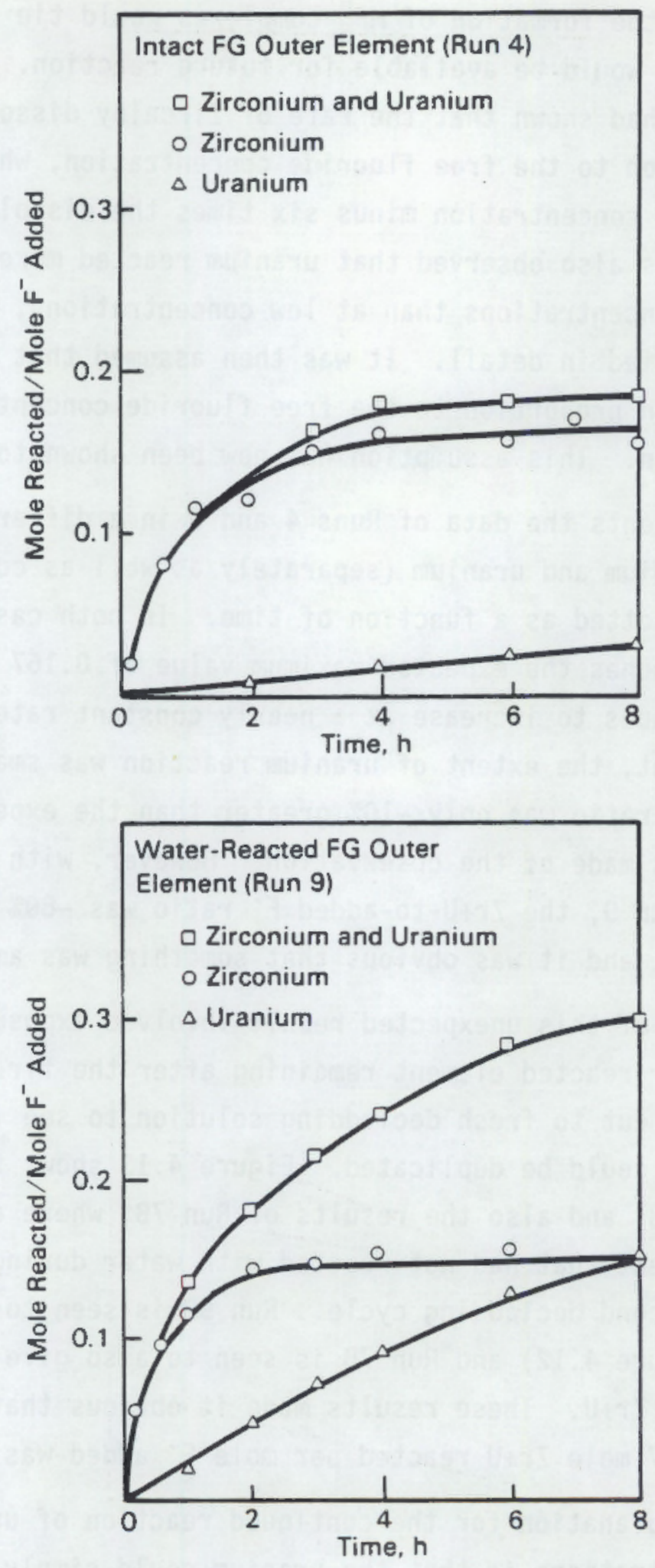

FIGURE 4.12. Comparison of Quantities Reacted During Decladding of Intact and Water-Reacted FG Elements 

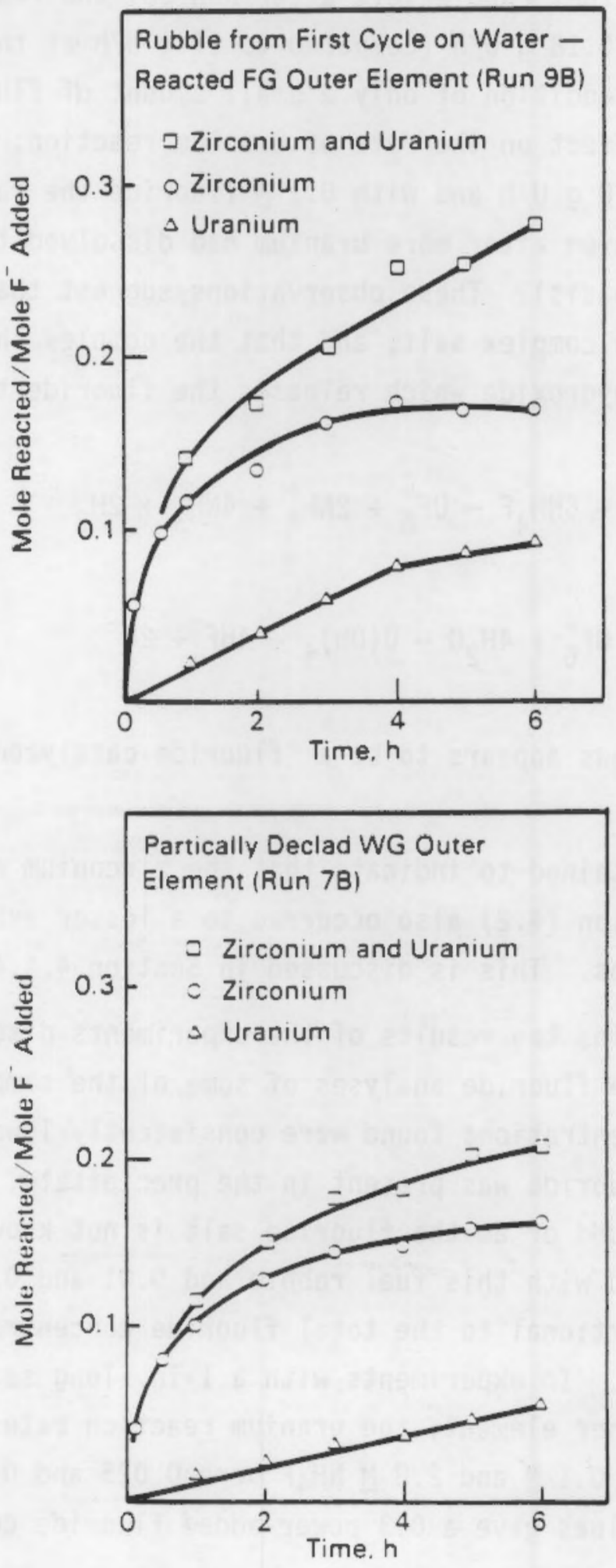

FIGURE 4.13. Quantities Reacted in Other Decladding Steps with Uranium Initially Exposed 
out by a test with the fuel rubble left after Run 98 ; the reaction rate with boiling water was only $0.18 \mathrm{~g} \mathrm{U} / \mathrm{h}$ (compared to $17 \mathrm{~g} \mathrm{U} / \mathrm{h}$ at the end of Run 9B). However, the addition of only a small amount of fluoride to the water had a dramatic effect on the rate of uranium reaction; with $0.01 \underline{M}$ fluoride the rate was $10 \mathrm{~g} \mathrm{U} / \mathrm{h}$ and with $0.1 \mathrm{M}$ fluoride the rate was $26 \mathrm{~g} \mathrm{U} / \mathrm{h}$. These rates persisted even after more uranium had dissolved than fluoride had been added (on a mole basis). These observations suggest that uranium reacts with fluoride to form a complex salt, and that the complex then reacts with water to form uranium hydroxide which releases the fluoride to react again:

$$
\begin{gathered}
U+6 \mathrm{NH}_{4} \mathrm{~F} \rightarrow \mathrm{UF}_{6}^{=}+2 \mathrm{NH}_{4}^{+}+4 \mathrm{NH}_{3}+2 \mathrm{H}_{2} \\
U \mathrm{~F}_{6}^{=}+4 \mathrm{H}_{2} \mathrm{O} \rightarrow \mathrm{U}(\mathrm{OH})_{4}+4 \mathrm{HF}+2 \mathrm{~F}^{-}
\end{gathered}
$$

The overall reaction thus appears to be a "fluoride-catalyzed reaction of uranium with water."

Some data were obtained to indicate that the zirconium reaction corresponding to reaction (4.2) also occurred to a lesser extent at the higher $\mathrm{Zr+U}-\mathrm{U}_{0}-\mathrm{F}^{-}$ratios. This is discussed in Section 4.4.4.

Figure 4.14 contains the results of the experiments discussed above, plus the results of the fluoride analyses of some of the samples. The fact that the fluoride concentrations found were consistently lower than was added indicates that some fluoride was present in the precipitate, whether as a hydroxy-fluoride compound or as the fluoride salt is not known. The uranium reaction rates observed with this fuel rubble and 0.01 and $0.1 \mathrm{M} \mathrm{F}^{-}$indicate that the rate is proportional to the total fluoride concentration raised to the 0.4 power $\left([F]^{0.4}\right)$. In experiments with a 1 -in.-long section of an unirradiated declad inner element, the uranium reaction rates in $3-\mathrm{h}$ exposures to $750 \mathrm{~mL}$ of $0.1 \mathrm{M}$ and $2.8 \mathrm{M} \mathrm{NH}_{4} \mathrm{~F}$ were 0.025 and $0.071 \mathrm{~g} / \mathrm{cm}^{2}-\mathrm{h}$, respectively; these values give a 0.3 power-added fluoride concentration dependence. 


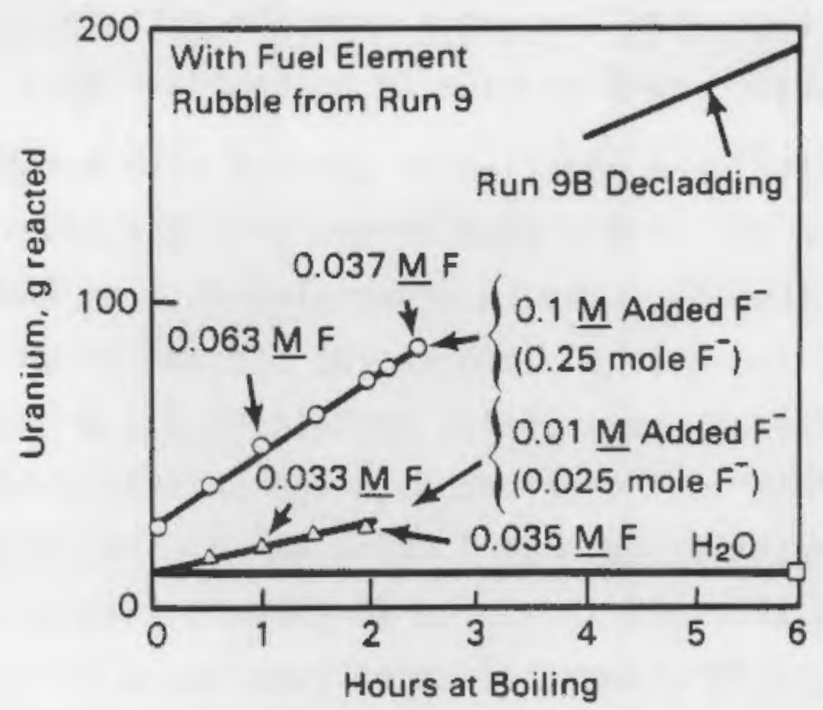

FIGURE 4.14. Reaction Rates of Uranium with Water and with Dilute Fluoride Solutions

The only characterization work on the solids resulting from reaction of uranium with dilute AFAN solutions has been to measure the fluoride-touranium ratio in the solids recovered from the experiment with unirradiated uranium. A value of $0.7 \mathrm{~mole}^{-} / \mathrm{mole}$ uranium was measured in the solution that remained after the solids were dissolved in nitric acid. This reaction was so vigorous that some of the solution and solids were expelled and lost (Section 4.4.2).

One possible effect of a fluoride-catalyzed reaction of uranium with water on the safety of plant operation is the release of hydrogen; [see Equation (4.1)]. Hydrogen release is minimized during decladding by the presence of nitrate (Swanson 1961), but the concentration of nitrate now used in the starting AFAN solution was chosen on the basis that no further reaction could occur after the $\mathrm{Z} r+\mathrm{U}$-to-added $\mathrm{F}^{-}$ratio reached 0.167 . If, as in Runs 9 and 98 , markedly more reaction occurs, there would be no nitrate left to suppress hydrogen formation during much of the decladding cycle. To guard against this eventuality, the nitrate-to-fluoride ratio in the AFAN solution could be increased. The additional ammonium ion concentration resulting from such a change would result in decreased zirconium solubility 
during normal operation when the extra ammonium nitrate is not needed, but other flowsheet changes could be made to accommodate this.

The fluoride-catalyzed reaction of uranium with water was also studied with fuel other than the rubble that formed when the severely water-reacted element was declad (Run 9). The FG inner element from Run 3, the WG inner element from Run 6, and a 1-in.-long declad section of an unirradiated inner element were all exposed (separately) to boiling $0.1 \mathrm{M} \mathrm{NH} \mathrm{N}_{4} \mathrm{~F}+0.01 \mathrm{M} \mathrm{NH}_{4} \mathrm{NO}_{3}$ solutions. The weight loss observed with the unirradiated element section corresponded to a reaction rate of $0.025 \mathrm{~g} / \mathrm{cm}^{2}-\mathrm{h}$. Based on the rates at which ${ }^{137} \mathrm{Cs}$ entered the solutions, the $W G$ element reacted at a rate of $0.032 \mathrm{~g} / \mathrm{cm}^{2}-\mathrm{h}$ and the $F G$ element reaction rate was $0.047 \mathrm{~g} / \mathrm{cm}^{2}-\mathrm{h}$. These data indicate that the rate of the fluoride-catalyzed reaction of uranium with water increases with the burnup of the uranium. This is not consistent with the extents of reaction observed in the flowsheet simulation runs (Figure 4.8), where the free fluoride concentration was higher during most of the runs.

\subsubsection{Reaction of Residual Uranium Heel During Decladding}

The amount of uranium that reacts during a decladding cycle depends not only on the reaction that occurs on the freshly charged fuel elements, but also on the reaction that occurs on the exposed surface area of the uranium that remains in the dissolver after the preceding acid cut cycle. This exposed surface area can be estimated from the criterion used to decide when to terminate the final acid cut and from the rate of dissolution of uranium in the terminal acid cut solution (Section 4.4.1.2). By combining this value with the extent of reaction per unit area of exposed uranium during decladding, the potential contribution of a residual heel can be determined.

The extent of uranium reaction during decladding, per unit area of exposed surface, was determined by measuring the weight loss of a small ring of (unirradiated) uranium that was present during a 6 -h declad cycle (Run 12). The weight loss amounted to $0.45 \mathrm{~g} / \mathrm{cm}^{2}$, which gives an average value of $0.075 \mathrm{~g} / \mathrm{cm}^{2} \mathrm{~h}$ over the 6 -h period. It is not known how the rate varied over time. 
The criterion used by plant personnel in deciding when the final acid cut is "finished" is important for defining the area of exposed uranium that might be carried over to the next decladding cycle. One criterion that has been commonly used is that the cut is "finished" when the specific gravity of the boiling solution fails to rise more than 0.02 units in $1 \mathrm{~h}$. Based on published specific gravity data, which indicate a change of -0.6 units for a uranium concentration increase of $1 \underline{M}$, this rate of change criterion would allow the uranium concentration to increase at a rate of $0.033 \mathrm{M} / \mathrm{h}$ when the acid cut is terminated. With a solution volume of $7700 \mathrm{~L}(2034 \mathrm{gal})$, the rate of reaction allowed by this criterion would be $254 \mathrm{~mole} \mathrm{U} / \mathrm{h}$, or $6.05 \times 10^{4} \mathrm{~g} \mathrm{U} / \mathrm{h}$. With a dissolution rate of $0.12 \mathrm{~g} \mathrm{U} / \mathrm{cm}^{2}-\mathrm{h}$, as was measured with unirradiated elements at terminal acid cut conditions (Section 4.4.1.2), the exposed uranium area would be $5.0 \times 10^{5} \mathrm{~cm}^{2}$. For reference, this area is $-37 \%$ of the surface area of a 10.2 MTU charge of (intact) fuel and is only $-25 \%$ greater than the surface area of the inner elements in such a charge.

Multiplying this area estimate by the previously discussed extent of uranium reaction measured in the laboratory during a 6 -h declad $\left(0.45 \mathrm{~g} \mathrm{U} / \mathrm{cm}^{2}\right)$ gives a value of $2.25 \times 10^{5} \mathrm{~g} \mathrm{U}(2.2 \%$ of a 10.2 MTU charge) reacted during a decladding cycle, due to the uranium heel allowed by the specific gravity change rate criterion. This extent of reaction is greater than that observed on freshly-charged elements in the flowsheet simulation runs with intact fuel (Section 4.1.2.1). Thus, with intact fuel, the exposed uranium heel left at the end of the final acid cut of one cycle may be the major contributor to the uranium reaction that occurs during decladding of the subsequent charge. This contribution could be reduced by changing the acid cut end-point criterion, and could be eliminated by assuring the absence of an exposed uranium heel before the dissolver is charged with a fresh batch of fuel.

This consideration was based on data for unirradiated uranium, and there is some evidence that a greater extent of reaction during decladding would result with irradiated fuel. We have some data indicating that irradiated fuel may dissolve more slowly than unirradiated fuel in nitric acid (Section 4.4.1.2) but at the same rate as unirradiated fuel in AFAN (Section 4.1.2.4). These effects would combine to give more reaction of 
irradiated uranium during decladding because a higher surface area could remain at the end of the preceding acid cut that was terminated based on a given specific gravity change rate criterion. Another factor that would increase the extent of uranium reaction due to the heel left from the preceding cycle is that this consideration was based on the extent of attack observed in $6 \mathrm{~h}$, and the plant has often used longer decladding times.

\subsubsection{0ther Rate Studies of Uranium in AFAN Solutions}

Some simple studies were also done early in this project to compare the rates of reaction of uranium with AFAN solutions under various conditions. Data were obtained to compare the reaction rate before and after the solution became saturated with uranium. The rates of reaction of side-grain and endgrain uranium surfaces, and of inner and outer elements; and the rates of reaction of unirradiated and irradiated uranium.

\section{Reaction Rates Before and After Solution Saturation}

Uranium metal reacts with AFAN solutions to give tetravalent uranium species. Uranium (IV) has only limited solubility in AFAN solutions, so that a mixture of soluble and insoluble species results from this reaction. Under some conditions, insoluble species form a coating on the uranium surface; this coating tends to reduce the rate of the reaction, as shown by the data in Figure 4.15.

The results shown in Figure 4.15 were obtained in stirred, boiling solutions with three different exposure times. The weighed specimen was placed in the boiling solution, where it remained for a predetermined time period before it was removed and placed in a dilute nitric acid/ANN solution to dissolve the adherent uranium (IV)-fluoride coating. The specimen was then reweighed and the nitric acid/ANN solution was analyzed to determine the quantity of uranium in the coating. Under the conditions used, the 44-min exposure gave just enough reaction to reach the uranium (IV) solubility limit, and the rate values based on the concentration of uranium in the solution and on the weight loss were in good agreement. At the longer exposures, however, more uranium reacted than could be soluble and a coating 


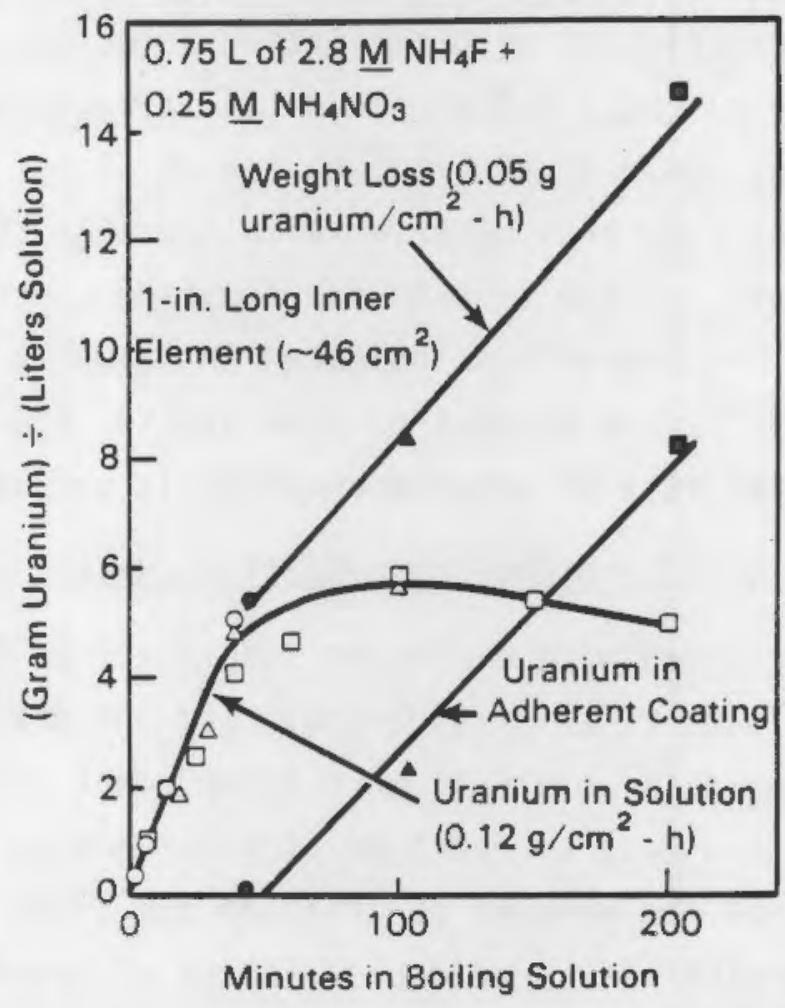

FIGURE 4.15. Uranium Reaction Rates in AFAN Solution Before and After Solution Saturation

formed on the uranium surface. The rate of reaction was $\sim 0.05 \mathrm{~g} \mathrm{U}^{\mathrm{c}} \mathrm{cm}^{2}-\mathrm{h}$ after the surface became coated, compared to $0.12 \mathrm{~g} \mathrm{U} / \mathrm{cm}^{2}-\mathrm{h}$ before the coating formed.

The sum of the uranium found in solution and the uranium found in the adherent coating agreed quite closely with the total uranium weight loss. This indicates that the bulk of the insoluble uranium (IV) species present in this experiment was in the surface coating, rather than being present as loose solids. However, most of the insoluble uranium (IV) species present at the end of the flowsheet simulation runs were as loose solids. The data of Figure 4.15 indicate a uranium (IV) solubility under these conditions of $-6 \mathrm{~g} \mathrm{U} / \mathrm{L}$, which is in good agreement with the $-7 \mathrm{~g} \mathrm{U} / \mathrm{L}$ reported in the initial Zirflex process work (Swanson 1961).

The data shown in Figure 4.15 were obtained with a sample of AFAN solution taken from plant stocks on February 19, 1984; this stock solution 
contained much more iron (150 ppm) than that used in the flowsheet simulation runs $(7 \mathrm{ppm})$. Similar experiments with the latter solution, both with and without added iron, gave slightly different initial dissolution rates; at $100 \mathrm{ppm}$ iron the rate was lower $\left(0.09 \mathrm{~g} / \mathrm{cm}^{2}-\mathrm{h}\right)$ and at $\sim 2 \mathrm{ppm}$ iron the rate was higher $\left(0.15 \mathrm{~g} / \mathrm{cm}^{2}-\mathrm{h}\right)$ than that observed with the 1984 stock solution $\left(0.12 \mathrm{~g} / \mathrm{cm}^{2}-\mathrm{h}\right)$, which gave $-40 \mathrm{ppm}$ iron at the fluoride concentrations used in these experiments. This comparison indicates that, while there are unknown differences in different batches of AFAN stocks, the effect of these differences on the initial rate of uranium reaction is not large.

\section{Comparison of Side-Grain and End-Grain Reaction Rates}

Tests were also performed with different lengths of as-fabricated fuel element sections to evaluate rates of side-grain and end-grain attack by AFAN solutions. The rate results (Table 4.4) were independent of section length, thus demonstrating that the rate of reaction of uranium with AFAN solutions is the same on the ends of the element as it is on the sides. This is in contrast to the results with nitric acid dissolution of uranium, where dissolution proceeds more rapidly from the ends of the element than from the sides (Section 4.4.1.2).

IABLE 4.4. Reaction of Uranium with AFAN Solutions: Rates with Different Unirradiated Sections

\begin{tabular}{ccccc} 
Element Type & $\begin{array}{c}\text { Length of } \\
\text { Section, in. }\end{array}$ & & \multicolumn{2}{c}{ Refoction Rate, (a) $\mathrm{g} / \mathrm{cm}^{2}-\mathrm{h}$} \\
Inner & $1 / 8$ & & $0.15,0.14(\mathrm{~b})$ & (c) \\
Inner & 1 & & 0.12 & 0.053 \\
Inner & 6 & 0.13 & 0.055 \\
Outer & 6 & & 0.14 & 0.066
\end{tabular}

(a) In boiling solution containing $2.8 \mathrm{M} \mathrm{NH}_{4} \mathrm{~F}+0.25 \mathrm{M} \mathrm{NH}_{4} \mathrm{NO}_{3}$ containing 40 to $100 \mathrm{ppm}$ iron (III).

(b) Duplicate run.

(c) Not measured. 
Table 4.4 also contains a comparison of the rates of reaction of outer element and inner element sections. The results show that there is no significant difference.

\section{Effect of Fuel Burnup on Reaction Rate with AFAN Solutions}

Tests were also run with 1/8-in.-long sections of irradiated inner fuel elements to compare reaction rates at different fuel burnups. Rates under conditions comparable to those of Table 4.4 were 0.22 and $0.16 \mathrm{~g} / \mathrm{cm}^{2}-\mathrm{h}$ for WG and FG fuel, respectively, compared to 0.14 to $0.15 \mathrm{~g} / \mathrm{cm}^{2}-\mathrm{h}$ for unirradiated sections. This apparently increased rate of reaction of $2.8 \underline{\mathrm{M} N \mathrm{NH}_{4} \mathrm{~F}}$ solution with WG fuel, but not with $F G$ fuel, is not consistent with the trend observed with $0.1 \mathrm{M} \mathrm{NH}_{4} \mathrm{~F}$ (Section 4.1.2.2), where the $\mathrm{FG}$ fuel dissolved more rapidly. This is also in contrast to the results with nitric acid dissolution of uranium, where dissolution of such sections proceeded more slowly after irradiation (Section 4.4.1.2). Further study of these reactions would be required before definite conclusions can be drawn. However, the available data do indicate that there is no large effect of fuel burnup on the rate of reaction with AFAN solutions.

\subsubsection{Foaming During Decladding}

One of the problems reported during the plant processing of aged $F G$ fuel was excessive foaming during the decladding step. Close attention was therefore given to this phenomenon during the flowsheet simulation runs. These runs included one (Run 5) aimed specifically at evaluating the foamproducing tendency of the sludge present in the storage basin where the aged $F G$ fuel had been stored.

Little sign of reaction was observed in any of the flowsheet simulation decladding runs until the temperature had risen to $-98^{\circ} \mathrm{C}$. At that time, a vigorous reaction would begin and the vapor space of the dissolver would start to fill with foam. In some cases (with the outer element sections), it was necessary to use the cooling coil to prevent foam from overflowing the dissolver. The foam was dissipated easily and rapidly by using the cooling coil or by adding a small portion of dilution water to the decladding solution. 
Figure 4.16a compares the build-up of foam observed over time in the early portions of the flowsheet simulation decladding runs, and Figure 4.16b compares the initial rates of zirconium dissolution in these runs. The two cases where foaming was most severe (Runs 7 and 9) were the two where initial zirconium dissolution was most rapid. However, the next most vigorous foamer (Run 4) had a relatively low zirconium dissolution rate. While it is likely that foaming severity will increase with reaction rate, it appears that other factors can be equally important to the severity of foaming during decladding. However, the results of Run 5 indicate that the sludge present in the basin where the aged fuel had been stored was not such a factor.

Run 5 was performed in the presence of sludge taken from the segregation pit of the KE Reactor basin. As-received samples taken from four different areas were used, in quantities ranging from those corresponding to 0.06 to $0.4 \mathrm{~g}$ of dried sludge. The total quantity used in Run 5 corresponded to $0.9 \mathrm{~g}$ dried sludge, compared to $\sim 1800 \mathrm{~g}$ of uranium in the fuel element section.

\subsubsection{Transfer of Uranium Solids with Declad Solutions}

As was mentioned in Section 3.0, portions of the uranium salts present after decladding accompanied the declad solutions when they were slurped from the dissolver pot. Based on visual observations, some of the settled solids were involved here as well as the solids that remained suspended in the solution. The extent to which solids accompany this solution is important to plant operations from the standpoint of criticality safety, because the solution is transferred to tanks that are not safe by reason of geometry.

Data bearing on this question were obtained in many of the flowsheet simulation runs. The results obtained in the laboratory with unirradiated uranium are summarized in Table 4.5; the data from the runs in the hot cell are judged to be unreliable because of uncertainties in the methods used to sample and to analyze the slurped mixtures, and are not included. They appeared to be roughly comparable to those given in the table.

The contribution of soluble uranium to these values should be low; at low free fluoride concentrations such as resulted in these runs, soluble 


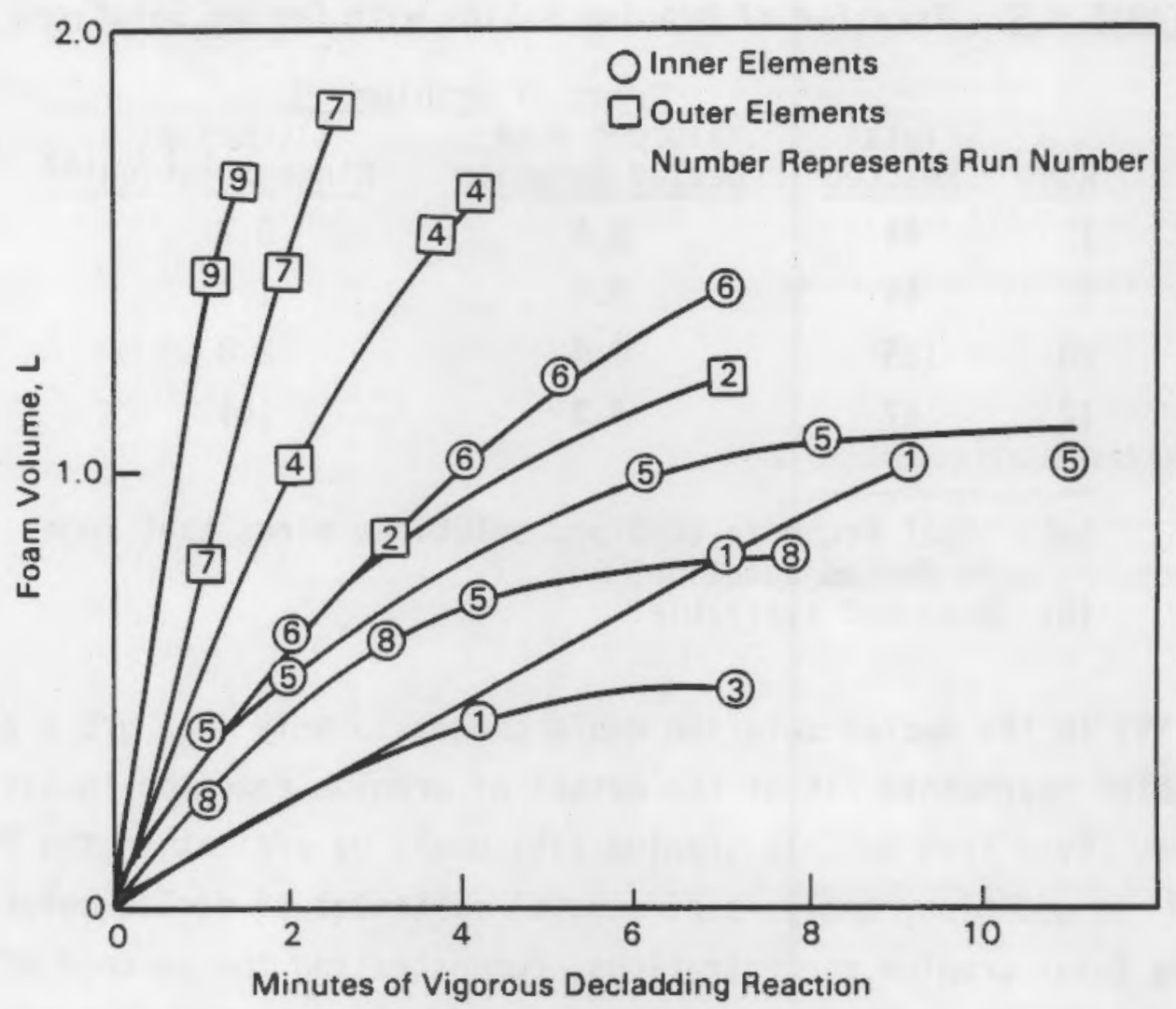

(b)

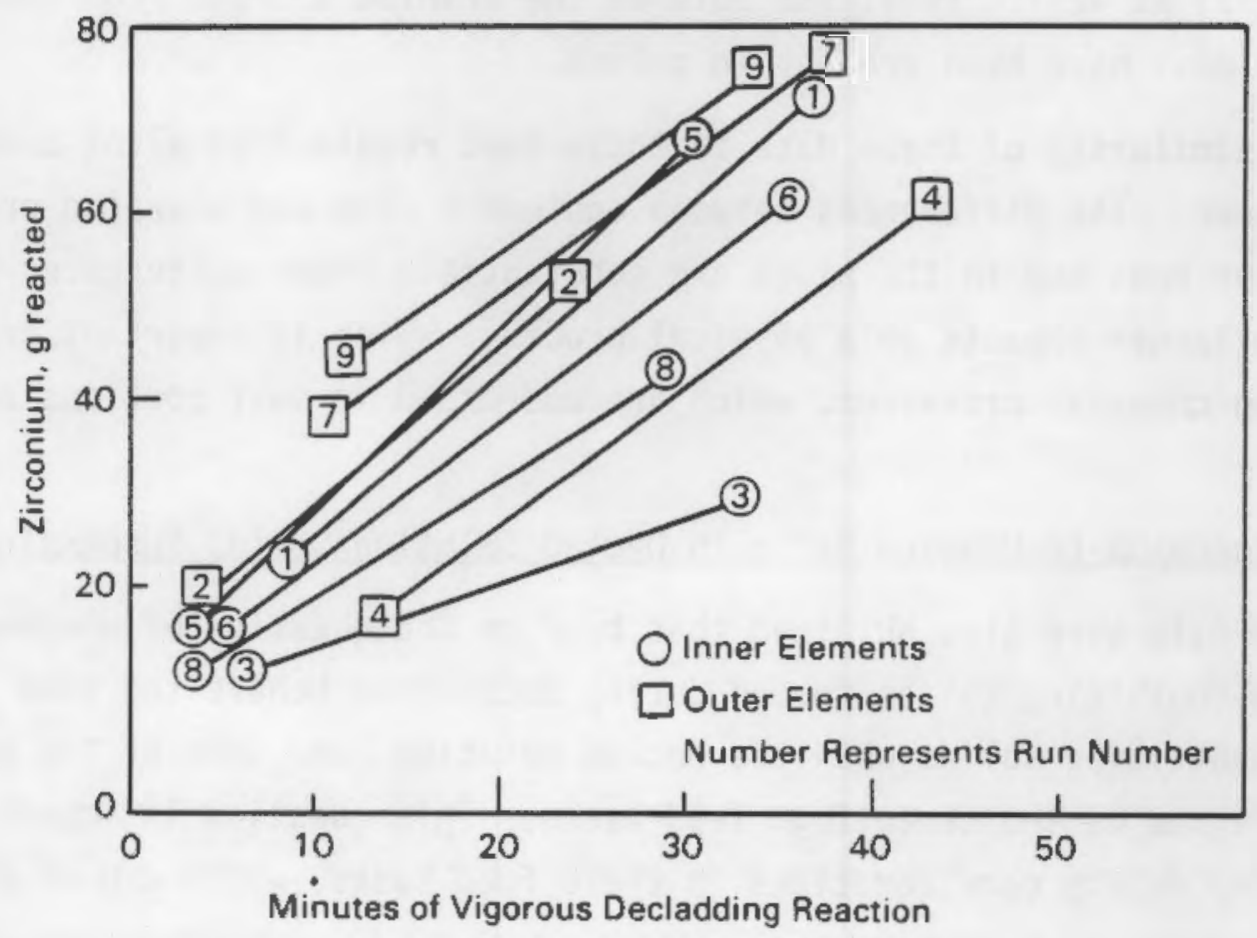

FIGURE 4.16. Foam Volumes and Dissolution Rates During Initial Portions of Decladding in Flowsheet Simulation Runs 
TABLE 4.5. Transfer of Uranium Solids with Declad Solutions Grams of Uranium

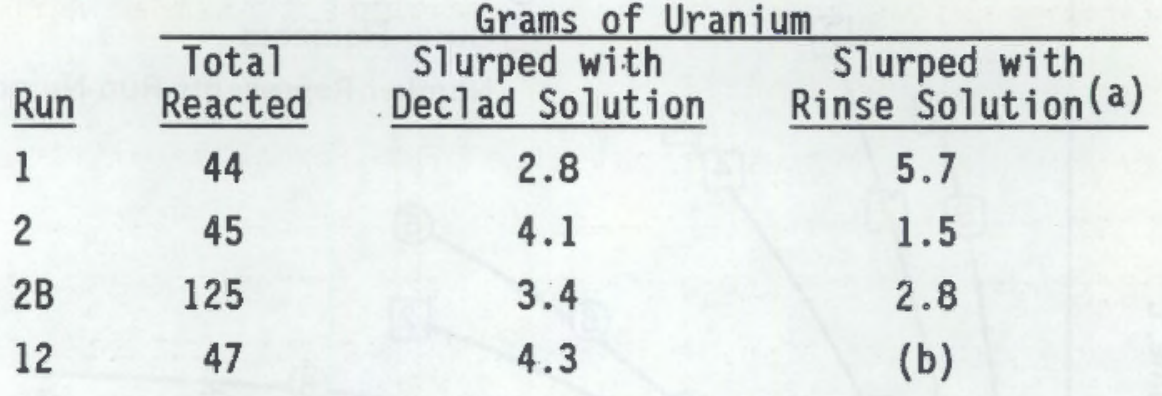

(a) Total found in combined solutions minus that found in declad solution.

(b) Data not available.

uranium (IV) in the declad solution would amount to only $\sim 0.1 \mathrm{~g} / \mathrm{L} \times 2.6 \mathrm{~L}=$ $0.26 \mathrm{~g}$, which represents $<1 \%$ of the extent of uranium reaction in any of these runs. Even less soluble uranium (IV) would be present in the rinse solution. In addition, analys is of several filtrates of declad solutions showed low total uranium concentrations, demonstrating the absence of soluble uranium (VI) as well. Thus, the bulk of the uranium slurped from the dissolver must have been present in solids.

The similarity of these data to those that result from plant operations is not known. The differences between equipment size and slurping procedures used in our runs and in the plant are substantial; these differences could have much larger impacts on a physical process, which is important here, than they do on chemical processes, which are addressed in most portions of this project.

\subsubsection{Plutonium-to-Uranium Ratio in Declad Solution/Solids Suspensions}

Some data were also obtained that bear on the question of whether the plutonium-containing solids formed during decladding behave the same as the uranium-containing solids when the declad solution (and some of the solids) is transferred to the centrifuge feed tanks. This question is important to criticality safety considerations in these feed tanks, which are of different 
geometry than the dissolver. The data that were obtained in this area are not adequate to draw firm conclusions, but they are presented here for completeness.

In several of the flowsheet simulation runs, both the plutonium and uranium contents of some samples were determined in an effort to obtain data bearing on this matter. The samples were 1) the (acidified and dissolved) combined declad and declad rinse solutions, 2) the acid cut solutions after warming to dissolve the metathesized, declad solids, and 3) the acid cut solution after a portion of the uranium metal had also been dissolved. The plutonium-to-uranium ratios in these samples from Runs 3, 4, 6, and 4 are listed in Table 4.6, along with the amounts of uranium present in the solutions that were analyzed. Unfortunately, these values are based on uranium analyses that were done using a system that was shown by experience to be quite erratic, so the results are not of high confidence.

TABLE 4.6. Plutonium-to-Uranium Ratio in Declad and Acid Cut Solutions

\begin{tabular}{|c|c|c|c|}
\hline Run & Solution Sampled & $\begin{array}{l}\text { Adjusted }(a, b) \\
\text { Pu-to-U } \\
\end{array}$ & $\begin{array}{l}U \text { in Sampled } \\
\text { Solution, } g(b)\end{array}$ \\
\hline \multirow[t]{3}{*}{3} & Slurped declad + rinse & 2200 & 0.5 \\
\hline & Dissolved solids & 3300 & 34 \\
\hline & Dissolved (solids + some U) & 3000 & 100 \\
\hline \multirow[t]{3}{*}{4} & Slurped declad + rinse & 7000 & 0.4 \\
\hline & Dissolved solids & 4100 & 46 \\
\hline & Dissolved (solids + some U) & 2200 & 290 \\
\hline \multirow[t]{2}{*}{6} & Slurped declad + rinse & 1100 & 1 \\
\hline & Dissolved (solids + some U) & 700 & 130 \\
\hline \multirow[t]{3}{*}{7} & Slurped declad + rinse & 6100 & 1 \\
\hline & Dissolved solids & 1500 & 26 \\
\hline & Dissolved (solids + some U) & 940 & 140 \\
\hline
\end{tabular}

(a) Dimensionless numbers provided for comparison.

(b) Based on uranium analyses of questionable validity. 
If one accepts these data at face value, which is probably not justified, one can say that in three out of four cases the solids transferred with the declad (and declad rinse) solutions had a higher plutonium-to-uranium . ratio than those in the portion of the element that was dissolved in acid. However, only small fractions of the solids present were transferred, so the amounts of plutonium transferred were still quite small.

A higher plutonium-to-uranium ratio in the solids transferred with the declad solution could result from 1) plutonium-containing solids settling more slowly than uranium-containing solids, or 2) the outer surfaces of the uranium, which reacted with the declad solution, having a higher plutoniumto-uranium ratio (and/or a higher plutonium specific activity) than the more central portions of the element, which reacted with the acid. Data were obtained in another run (7B) bearing on the first possibility but no data bearing on the second possibility were obtained.

In Run $7 \mathrm{~B}$, the plutonium-to-uranium ratio in the declad solution after varying stages of clarification was measured using a more reliable analytical method for low levels or uranium which involved alpha counting following chemical separation. Results of these analyses are summarized in Table 4.7. It is seen that, within the uncertainties of the measurements, the plutoniumto-uranium ratio in the solids suspended near the surface of the declad solution remains constant as $-85 \%$ (based on uranium) of the initially suspended solids settled down. The uncertainties listed in this table are those inherent in the sample counting, which are the most important ones when concentration ratio results are of interest. These results suggest that the plutonium-containing solids settle at the same rate as the uranium-containing solids; however, the uncertainties are large enough that some segregation of the solids could have occurred.

Another point of interest in the data of Table 4.7 is the low uranium concentration in the filtered sample. This is one of the data points that showed that soluble uranium (VI) was not responsible for the high uranium content of declad solution dip samples taken during decladding (Figure 4.11) or of the suspensions slurped from the dissolver (Section 4.1.4). 
TABLE 4.7. Plutonium-to-Uranium Ratio in Declad Solution Suspension (Run 7B)

Found in Sample

\begin{tabular}{|c|c|c|}
\hline Time of Sampling & $U, g / L$ & $10^{-5}(\mathrm{~d} / \mathrm{m}, \mathrm{mL})$ \\
\hline During sparge & $1.18 \pm 0.24$ & $8.48 \pm 0.37$ \\
\hline After 5 -min settle & $0.59 \pm 0.24$ & $2.45 \pm 0.13$ \\
\hline After 10 -min settle & $0.28 \pm 0.16$ & $2.03 \pm 0.07$ \\
\hline Filter $(0.2-\mu \mathrm{m})$ & $0.09 \pm 0.03$ & $0.12 \pm 0.06$ \\
\hline
\end{tabular}

Calculated for Suspended Solids(b)

\begin{tabular}{|c|c|c|}
\hline$U, g / L$ & $\begin{array}{l}\text { Factored } \mathrm{Pu}, \\
10^{-5}\left(\mathrm{~d} / \mathrm{m}_{1} \mathrm{~mL}\right)\end{array}$ & $\begin{array}{c}\left.\text { (Factored } \mathrm{Pu} \times 10^{-5}\right) \\
+\mathrm{U} \\
\end{array}$ \\
\hline $1.09 \pm 0.24$ & $8.36 \pm 0.37$ & $7.7 \pm 1.7$ \\
\hline $0.50 \pm 0.24$ & $2.33 \pm 0.14$ & $4.7 \pm 2.2$ \\
\hline $0.19 \pm 0.16$ & $1.96 \pm 0.09$ & $10.3 \pm 8.7$ \\
\hline-- & -- & -- \\
\hline
\end{tabular}

(a) True Pu content multiplied by a factor.

(b) (Total found in sample) - (found in filtrate). 


\subsubsection{Fission Product Behavior During Decladding}

The presence in the short-cooled WG fuel of ${ }^{95} \mathrm{Zr},{ }^{106} \mathrm{Ru},{ }^{125} \mathrm{Sb}$, and ${ }^{144} \mathrm{Ce}$ (as well as ${ }^{137} \mathrm{Cs}$ ) allowed the behavior of these elements during decladding to be followed. All evidence indicates that cesium was completely soluble, as was expected. This allowed the extent of core reaction to be readily determined from the measured ratio of cesium-to-uranium, as has been discussed earlier (Section 4.1.2.1). The ratios of the other radionuclides to ${ }^{137}$ Cs were used to follow their behavior.

Table 4.8 contains fractions of the expected quantities of the radionuclides that were found in several samples. The expected quantities were based on the extent of uranium reaction, as measured by the ${ }^{137} \mathrm{Cs}$ found, and the ORIGEN-calculated quantities of radionuclides per gram of uranium. In the declad solution samples, only the amount of zirconium found was in agreement with expectations. This indicates that zirconium, like cesium, was soluble in the declad solution--which is as expected. Only small fractions of the expected amounts of ruthenium, antimony, and cerium were found in the declad solution samples, indicating that these elements were present primarily as solid species that were not present in the sample that was

\section{TABLE 4.8. Fission Product Behavior Data}

\section{Sample}

Fraction of Expected (a) Found
$\underline{\mathrm{Zr} \quad \underline{\mathrm{Ru}} \quad \underline{\mathrm{Sb}} \quad \underline{\mathrm{Ce}}}$

Diluted and cooled declad solution (Run 7B)

Sparged

20 -min settled

Filtered $(0.2-\mu \mathrm{m})$
1.1

1.1

1.1
0.06

0.04

0.03

0.06

0.05

0.03
0.02

0.003

0.000

Dissolved metathesis product

Run 6

Run 7

Run 7B

$\begin{array}{lll}1.2 & 1.8 & 0.9 \\ 1.4 & 1.1 & 1.0 \\ 0.8 & 0.5 & 1.0\end{array}$

(a) Based on $C_{S}$ found and the ratios to $C_{s}$ calculated with the ORIGEN code. 
withdrawn. Comparison of these analyses in samples of sparged and of filtered solutions indicates that only $\sim 2 \%$ to $3 \%$ of the reacted amounts of ruthenium, antimony, and cerium were present as suspended solids at the top of the sparged solution (where the sample was taken). The filtered sample result indicates that $\sim 3 \%$ of the reacted ruthenium and antimony, but none of the cerium, was soluble in the declad solution.

These differences in the solubilities of fission products in the declad solution could prove to be useful in providing a relatively simple means of monitoring the effectiveness of techniques for removing solids from the cladding removal waste (CRW) stream before it is neutralized and then discharged to waste. If solids are efficiently removed, the stream should have ruthenium- or cerium-to-cesium ratios markedly lower than in the fuel being processed. Ratios equal to those in the fuel would indicate that all reacted solids had accompanied the solution.

The amounts of reacted ruthenium, antimony, and cerium that had not shown up in the samples of the declad solution were found when the metathesized solids were dissolved in the subsequent acid cut, as shown in Table 4.8. There is not precise agreement in all cases between the quantities expected and those found; however, there can be no question that the vast majority of the ruthenium, antimony, and cerium that react during decladding are present as solids during decladding and metathesis, and then dissolve during the acid cut.

The condensate collected during decladding was analyzed in Run $7 \mathrm{~B}$ and was found to contain only small amounts of the radionuclides. Results of these analyses are contained in Section 4.5.1, where the results of additional studies with this condensate are discussed.

\subsubsection{Ammonium Hydroxide Behavior During Decladding}

Ammonium hydroxide behavior during decladding is of interest because its concentration in the declad solution must be kept low in order to maintain high decladding rates and to minimize precipitation of zirconium hydroxide or hydroxy-fluoride species, especially when the solution is cooled so that it can be jetted out of the dissolver. Past practice in the plant was to add an "ammonia stripping" operation to the end of the decladding operation; this 
involved sparging the boiling, diluted declad solution (for $0.5 \mathrm{~h}$ ) to drive off excess ammonia before the solution was cooled for transfer.

The opportunity was taken in several of the flowsheet simulation runs to analyze samples for ammonium hydroxide $\left(\mathrm{NH}_{4} \mathrm{OH}\right)$. The results of these analyses are shown in Figure 4.17, where the concentrations in both the condensate and the declad solution at various times during the declad period are plotted. The results from the separate runs are seen to be quite comparable, with concentrations in both solutions being much higher initially than they were toward the ends of the runs. This is as expected from the variations in the rates of reaction over time, as illustrated by the data in Figures 4.12 and 4.13 .
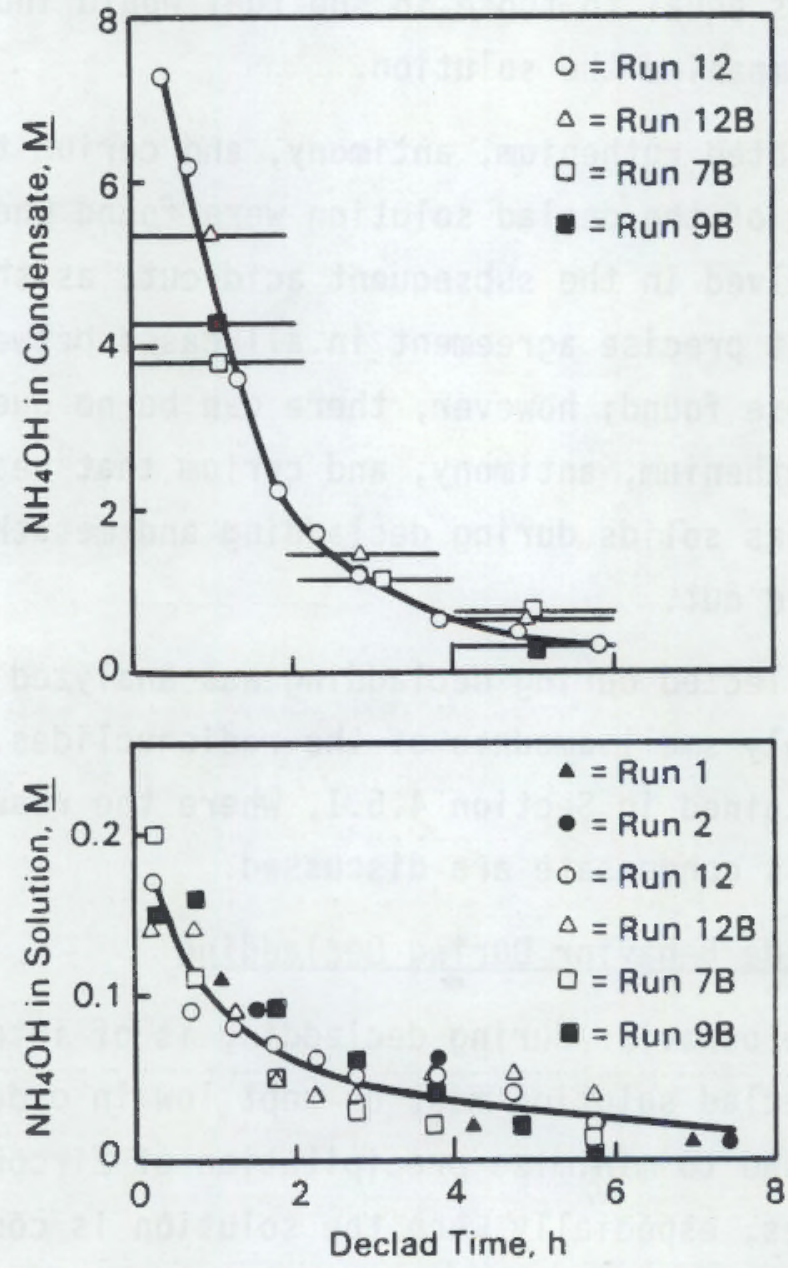

FIGURE 4.17. Ammonium Hydroxide Distribution During Decladding 
Another important conclusion from these results is that little benefit can result from an added "ammonia stripping" period following the declad period, as had been common procedure in the plant. The ammonium hydroxide concentration is already near zero at the end of the declad period and is changing only slowly, so that an additional period would have little effect. This is especially true with metallic Zircaloy and uranium present so that the ammonia-forming reactions (1.1 and 4.1) can continue.

The concentrations of ammonium hydroxide in the declad solutions were estimated by comparison of the $\mathrm{pH}$ values of sample dilutions with the correlation measured using standard solutions (Figure 3.1). Because of the nature of this correlation, the resultant ammonium hydroxide concentrations are not very precise, especially at low concentrations. However, they do provide better values than had been available previously. Table 4.9 contains the $\mathrm{pH}$ data obtained in these runs, along with the ammonium hydroxide concentrations that were estimated from these measurements.

In Run 12, small condensate samples were taken frequently to give a complete profile over time. In the other runs, the condensate was collected in $\sim 2 \mathrm{~h}$ increments, as indicated by the bars shown in Figure 4.17. The total amounts of $\mathrm{NH}_{4} \mathrm{OH}$ condensed in these runs was not as high as expected (based on the reaction stoichiometry of $5 \mathrm{~mole} / \mathrm{mole} \mathrm{Zr}+\mathrm{U}$ reacted). In hot-cell runs $7 \mathrm{~B}$ and $9 \mathrm{~B}, 2.6$ and 2.0 mole $\mathrm{NH}_{4} \mathrm{OH}$ were condensed per mole $\mathrm{Zr}+\mathrm{U}$ reacted, respectively. In Run $12 \mathrm{~B}$, which was done in the laboratory, -3.9 mole $\mathrm{NH}_{4} \mathrm{OH}$ was condensed per mole $\mathrm{Zr}+\mathrm{U}$ reacted (assuming that the extent of uranium reaction was the same there as in Run $2 B$, which was similar). The markedly low ammonium hydroxide recoveries in the hot-cell runs are perplexing; perhaps they resulted from poorer condenser operation in the hot cell (it is likely that the flow of cooling water was not as high as it was in the laboratory), but that was not shown to be the case.

\subsubsection{Precipitation of Unknown Zirconium Compound from Declad Solution}

The initial studies of the Zirflex process (Swanson 1958, 1961) showed that the solubility of ammonium fluorozirconate salts in the declad solution increased as the free fluoride concentration (defined as total fluoride concentration minus six times the zirconium concentration) decreased and as 
TABLE 4.9. Estimated Ammonium Hydroxide in Solution During Decladding

\begin{tabular}{|c|c|c|c|c|c|c|c|c|c|c|c|c|}
\hline \multirow{2}{*}{$\begin{array}{l}\text { Declad } \\
\text { Iime, } h\end{array}$} & \multicolumn{6}{|c|}{$\mathrm{pH}$ of $10-X$ Dilution of Declad Solution } & \multicolumn{6}{|c|}{ Estimated(a) $\mathrm{NH}_{4} \mathrm{OH}$ in Declad Solution, $\underline{M}$} \\
\hline & Run 1 & Run 2 & Run $7 \mathrm{~B}$ & Run 9B & Run 12 & Run 128 & Run 1 & Run 2 & Run $7 \mathrm{~B}$ & Run 9B & Run 12 & Run 12B \\
\hline 0.25 & & & 8.13 & 8.01 & B.29 & 8.19 & & & 0.20 & 0.15 & 0.17 & 0.14 \\
\hline 0.75 & & & 7.48 & 7.62 & 7.64 & 7.87 & & & 0.11 & 0.16 & 0.09 & 0.14 \\
\hline 1.10 & 7.49 & & & & & & 0.11 & & & & & \\
\hline 1.25 & & & & & 7.40 & 7.42 & & & & & 0.08 & 0.09 \\
\hline 1.55 & & 7.27 & & & & & & 0.09 & & & & \\
\hline 1.75 & & & 6.44 & 7.02 & 6.95 & 6.52 & & & 0.05 & 0.09 & 0.07 & 0.05 \\
\hline 2.25 & & & & & 6.61 & 6.22 & & & & & 0.06 & 0.04 \\
\hline 2.75 & & & 5.81 & 6.42 & 6.50 & 6.03 & & & 0.03 & 0.06 & 0.05 & 0.04 \\
\hline 3.75 & & 6.57 & 5.68 & 5.96 & 6.25 & 6.46 & & 0.06 & 0.02 & 0.04 & 0.05 & 0.05 \\
\hline 4.20 & 5.70 & & & & & & 0.02 & & & & & \\
\hline 4.75 & & & 5.68 & 5.55 & 5.96 & 6.42 & & & 0.02 & 0.02 & 0.04 & 0.05 \\
\hline 5.75 & & & 5.32 & 5.18 & 5.54 & 5.75 & & & 0.01 & 0.00 & 0.02 & 0.04 \\
\hline 7.0 & 5.41 & & & & & & 0.01 & & & & & \\
\hline 7.4 & & 5.44 & & & & & & 0.01 & & & & \\
\hline
\end{tabular}

(a) Estimated from the interpolated zirconium concentration and the data of Figure 3.1. 
the temperature increased. At $0.2 \underline{M}$ free fluoride the solubility was $-1 \underline{M}$ at room temperature; on this basis no zirconium precipitation should have occurred in the flowsheet simulation runs. However, slight zirconium precipitation was observed when the diluted declad solutions were cooled; this was investigated further in one run.

A portion of the diluted declad solution from Run $12 \mathrm{~B}$ was used in these tests. White solids formed when this solution was cooled, but redissolved on reheating to $-67^{\circ} \mathrm{C}$. The solids that reformed when a portion of the clear, warm solution was again cooled were collected for (partial) analysis. The filtered solids were air-dried (without being rinsed) over night at room temperature and a portion was then dissolved in 2 M HCl for analysis, which showed a zirconium content of 43 wt\% and a fluorine content of 28 wt\%. These values give a fluorine-to-zirconium mole ratio of 3.1 , which clearly

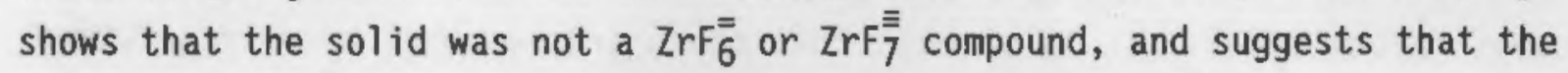
solid might be a mixed zirconium hydroxy/fluoride compound.

The amount of zirconium that was present in this solid was only $-1 \%$ of that which remained in solution; precipitations such as this should therefore not have large process impacts.

\subsection{REACTION DURING LONG STORAGE OF EXPOSED FUEL IN DECLAD RINSE SOLUTION}

In our normal experimental procedure, there was a period of only hours during which the declad fuel stood under the declad rinse solution before proceeding with the metathesis step. However, in two of our late runs (one with irradiated uranium and one with unirradiated), this period was extended for several months while the next action was being considered. Appreciable reaction of the uranium occurred during these long intervals, emphasizing the desirability to avoid such a situation. The available results will be discussed here in the report, in the process sequence, even though the long delay was an abnormal situation.

\section{Long Storage of Irradiated Fuel in Declad Rinse Solution (Run 7B)}

The decladding portion of Run 7B was done to provide timely support to two activities (described in Section 4.5) that were given a high priority. The fuel element section and the solids formed during decladding were then 
stored in the declad rinse solution for 4.6 months, pending decisions regarding possible subsequent use. It was then found that an extensive, and interesting, reaction had occurred during this storage period.

Following the 4.6-month storage period (at the cell ambient temperature of $\sim 35^{\circ} \mathrm{C}$ ), potassium hydroxide was added to the element's storage solution and it was boiled for $1 \mathrm{~h}$ to metathesize the fluoride salts produced during decladding. The ${ }^{137} \mathrm{Cs}$ content of this rinse/metathes is solution indicated that $345 \mathrm{~g}$ uranium had reacted during storage; this uranium must have been present as solid compounds. Addition of nitric acid to these compounds gave a brief "runaway reaction" that is described in Section 4.4.2.

The appearance of this (irradiated) element (after its surface was brightened by exposure to nitric acid) was quite remarkable, as shown by the photographs in Figure 4.18. It is seen that a reaction occurred to produce grooves in the metal. It is thought that these grooves must have been formed during the storage in the declad rinse solution because the ${ }^{137} \mathrm{Cs}$ content of the acid solution indicated that $<100 \mathrm{~g}$ of uranium metal had dissolved in the acid, which is much less than the $345 \mathrm{~g}$ uranium that reacted during storage.

The cause of this "groove-making" reaction is not known, but it is speculated that it might have occurred along lines of stress or of grain imperfections. The fact that the grooves were not parallel indicates that such imperfections were not introduced in the fuel fabrication process. It is difficult to see how they could be induced during reactor irradiation, but the fact that grooves were not found in an unirradiated element that had undergone similar treatment certainly suggests that irradiation played a part.

Long Storage of Unirradiated Fuel in Declad Rinse Solution (Run 12B)

An unplanned long storage of an unirradiated fuel element section in declad rinse solution also occurred in Run $12 \mathrm{~B}$ for the same reasons as with the irradiated fuel. The storage period in the unirradiated fuel case was 5.6 months, at a temperature of $222^{\circ} \mathrm{C}$. Analysis of the solution at the end of this time showed a $\mathrm{pH}$ of 6.3 and a fluoride concentration of $0.017 \mathrm{M}$. 

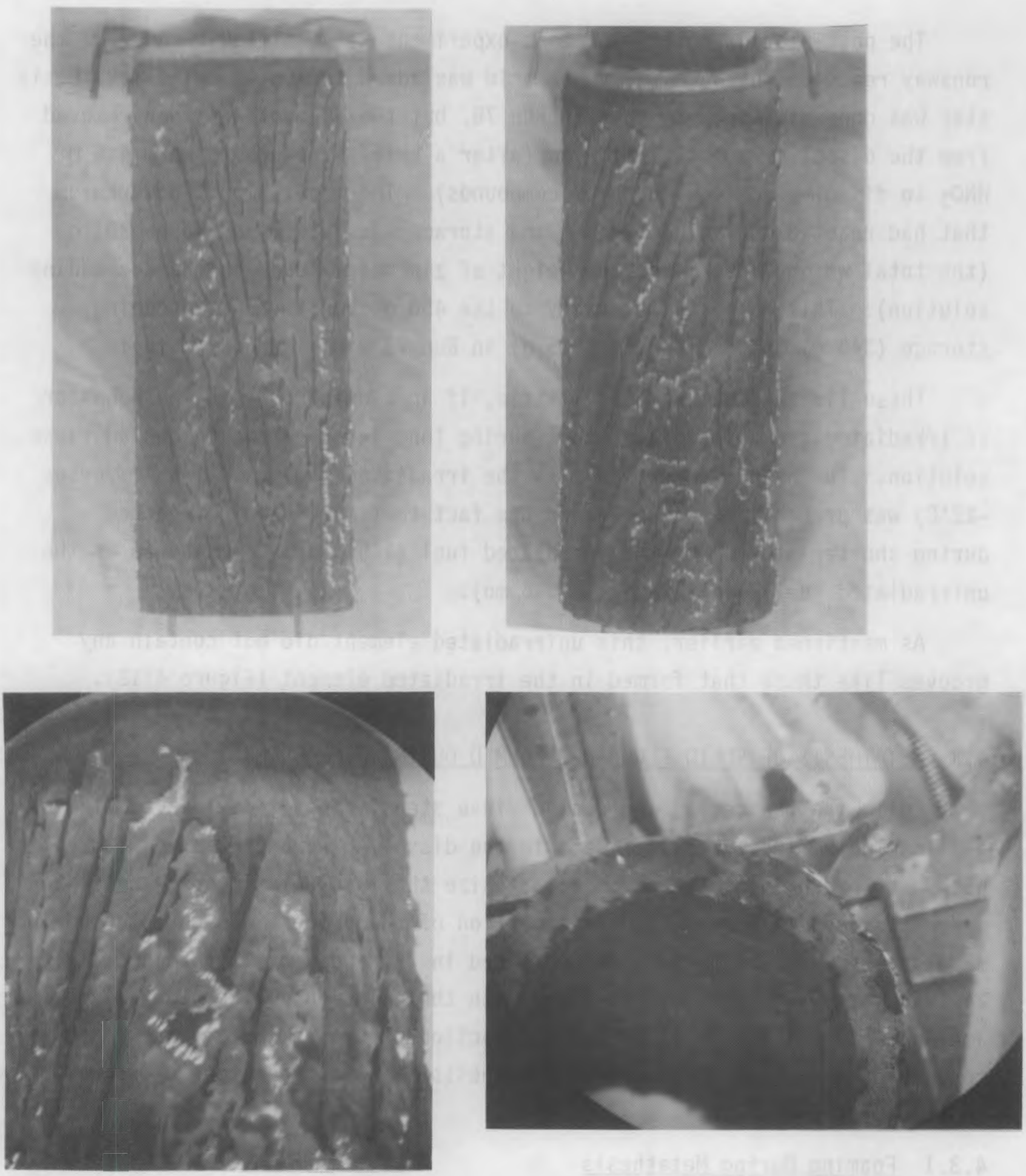

FIGURE 4.18. Photographs of Fuel Following Long Storage in Declad Rinse Solution (plus metathesis and acid cut) 
The post-storage portion of this experiment was modified because of the runaway reaction that occurred when acid was added to Run $7 \mathrm{~B}$. The metathes is step was done similarly to that in Run $7 \mathrm{~B}$, but the element was then removed from the dissolver pot for weighing (after a brief exposure to warm $4.5 \underline{M}$ $\mathrm{HNO}_{3}$ to dissolve residual uranium compounds). The total amount of uranium that had reacted during decladding and storage was determined to be $387 \mathrm{~g}$ (the total weight loss minus the weight of zirconium found in the decladding solution). This compares favorably to the $450 \mathrm{~g}$ uranium reacted during storage $(345 \mathrm{~g})$ and decladding $(105 \mathrm{~g})$ in Run $7 \mathrm{~B}$ with irradiated fuel.

These limited data indicate little, if any, difference in the behavior of irradiated and unirradiated fuel during long-term storage in declad rinse solution. The higher temperature in the irradiated fuel case $\left(-35^{\circ} \mathrm{C}\right.$ versus $-22^{\circ} \mathrm{C}$ ) was probably responsible for the fact that more uranium reacted during shorter storage of the irradiated fuel ( $345 \mathrm{~g}$ in $4.6 \mathrm{mo}$ ) than in the unirradiated fuel case $(280 \mathrm{~g}$ in $5.6 \mathrm{mo})$.

As mentioned earlier, this unirradiated element did not contain any grooves like those that formed in the irradiated element (Figure 4.18).

\subsection{METATHESIS OF SOLID FLUORIDES FORMED DURING DECLADDING}

Following the declad and declad rinse steps, the solids (declad element and insoluble fluoride salts) left in the dissolver were contacted with hot potassium hydroxide solution to metathesize the insoluble fluoride salts to hydrous oxides (hydroxides). This portion of the process was not studied in detai1, but some information was obtained in the areas of 1) foaming, 2) transfer of actinide solids along with the solutions, 3) plutonium and americium solubilities, 4) extent of reaction of uranium metal, and 5) the conditions necessary for complete metathesis. This information is summarized in this section.

\subsubsection{Foaming During Metathesis}

We observed very little foaming during metathesis in most of our flowsheet simulation runs; thus, this is one area where our experimental results were not in agreement with reported plant experience. Most of our 
runs used laboratory chemicals, but one test involved methathesis with a potassium hydroxide solution taken from plant stocks.

The worst foaming observed during metathesis occurred in Run 9B, which was an experiment using the rubble left from the experiment with the extensively water-reacted outer element. This foam was observed when the air sparge that was normally used during metathesis was turned off, and it disappeared when the sparge was resumed. This suggests that our normally used sparge was the reason we observed relatively little foam during metathesis in most of our runs. However, because the plant also normally sparges during metathesis, the discrepancy between our results and the plant results remains. Our sparge was intentionally sufficient to "bounce" the solution quite markedly. Perhaps more vigorous sparging in the plant would help the foaming situation there.

The foam that did form in Run $9 B$ was not nearly as voluminous or as dense as those regularly observed during decladding and nitric acid/ANN dissolution. It looked much like soap suds and it occupied a volume of $<0.5 \mathrm{~L}$. It would never have drawn comment if it had not been known that foaming problems had been reported in the plant.

\subsubsection{Iransfer of Actinide Solids with Metathesis Solutions}

As with the declad solutions, solids were observed to transfer along with the solution when the metathesis and metathesis rinse solutions were slurped from the dissolver. The amounts of uranium and plutonium transferred were comparable to those transferred with the declad solutions; this appears to be in conflict with $\mathrm{plant}$ data, which reportedly indicate that the large majority of these elements present in the combined waste accompanied the declad solution. This apparent discrepancy could result from transfer equipment and procedural differences between the plant and the laboratory (most of the metathesis solution is recycled in the plant), but it could also result from sampling difficulties in the plant. Perhaps more consideration should be given to this matter.

The laboratory data bearing on this matter are summarized in Table 4.10, where the available data on the quantities of transferred uranium and the 
IABLE 4.10. Transfer of Actinide Solids with Metathesis Solutions

Uranium Transferred With

Run Metathesis and Rinse Solutions, $\mathrm{g}$

1

2

$2 B$

3

4

6

7
8.4

3.1

19.0

$2.5(a)$

4.6 (a)

$3.2^{(a)}$

4.0 (a)
Adjusted Pu-to-U In Transferred Solids $(a, b)$

2500

2300

760

2400

(a) Based on uranium analyses of questionable validity.

(b) Dimensionless numbers provided for comparison.

plutonium-to-uranium ratio of the transferred material are 1isted. Comparison of these values with those observed in the declad step (Tables 4.5 and 4.6 ) shows the metathesis values to be very comparable to the declad values.

\subsubsection{Check for Soluble Plutonium and Americium in Metathesis Solution}

In one of the later runs (Run 9), portions of the metathesis solution and the metathesis rinse solution were filtered and then analyzed for plutonium and americium to see if appreciable amounts of these elements were soluble. It had always been thought that their solubilities would be very low, but increasing concern about the higher-than-desired concentrations of these TRU elements in the combined decladding and metathesis waste streams led to this experimental verification.

The metathesis solution filtrate contained only $0.8 \mathrm{nCi} / \mathrm{mL}$ of $239+240 \mathrm{Pu}$ and $0.3 \mathrm{nCi} / \mathrm{mL}$ of ${ }^{241} \mathrm{Am}+{ }^{238} \mathrm{Pu}$, thus verifying the expected low solubility. This plutonium activity corresponds to a concentration of $\sim 10^{-5} \mathrm{~g} / \mathrm{L}$, which is comparable to the values reported by Delegard (1987) for $\mathrm{PuO}_{2} \cdot \mathrm{xH}_{2} \mathrm{O}$ at similar potassium hydroxide concentrations after long aging at room temperature. The metathesis rinse solution filtrate contained only 0.08 and $0.09 \mathrm{nCi} / \mathrm{mL}$, respectively, of plutonium and americium. 


\subsubsection{Check for Reaction of Uranium Metal During Metathesis}

Although the initial perception was that the exposed uranium metal would not react appreciably during the metathesis steps, this potential reaction was examined because the metathesis solutions of the flowsheet simulation runs consistently contained higher concentrations of ${ }^{137} \mathrm{Cs}$ than were expected (based on the concentrations in the preceding rinse solutions). The unexpected importance of the fluoride-catalyzed reaction of uranium with water (Section 4.1.2.2) also added impetus to this examination.

To check the possible importance of this reaction, the element from Run 3 was exposed to boiling $1 \underline{\mathrm{M} K F}+2 \underline{\mathrm{M}} \mathrm{KOH}$ for $2 \mathrm{~h}$. The quantity of ${ }^{137} \mathrm{Cs}$ found in the solution indicated that only $\sim 0.01 \mathrm{~g}$ of the uranium had reacted in this time, for an apparent reaction rate of $<5 \times 10^{-5} \mathrm{~g} / \mathrm{cm}^{2}-\mathrm{h}$. This result verifies the initial perception that uranium does not react appreciably during metathesis, but requires another explanation for the high ${ }^{137} \mathrm{Cs}$ content of the metathesis solutions in the flowsheet simulation runs.

No completely satisfactory explanation for the high ${ }^{137} \mathrm{Cs}$ content of the metathesis solutions in the flowsheet simulation runs has been developed. Because the metathesis steps used a large volume of solution to remove the material deposited on the upper walls during decladding, it was initially thought that the deposited material may have contained the cesium that was later found in the metathesis solution. While such a phenomenon may have played some role, it does not easily account for cesium contents as high as were found in many of the runs. The quantities of ${ }^{137}$ Cs found in the metathesis solutions were $32,70,9,11,5$, and $27 \%$ of the quantities found in the declad solutions in Runs $3,4,6,7,8$, and 9 , respectively.

\subsubsection{Conditions Necessary for Complete Metathesis}

The completeness of fluoride removal from the uranium-containing solids that were formed during decladding was measured at various metathesis conditions in some of the experiments with unirradiated uranium. These tests analyzed the fluoride-to-uranium ratio in the reacted solids remaining in the dissolver pot after 1) reaction of the element sections with diluted AFAN solution, 2) rinsing of the reacted solids with water, 3) metathesis, and 4) rinsing of the metathesized solids. The solutions from each step were 
removed by slurping, which also removed part of the solids present after each step. This should not affect the data insofar as the residual solids are concerned, but some evidence was obtained to suggest that some of the slurped solids could have been incompletely metathesized; when the slurp stream was added to nitric acid, the color of the slurped particles changed from black/brown to green, which suggests that a coating of $\mathrm{UO}_{2} \cdot \mathrm{xH}_{2} \mathrm{O}$ may have dissolved off the surface to leave a kernel of unreacted $\mathrm{UF}_{4}$. However, this observation was not pursued in any more detail.

The reacted solids remaining in the dissolver pot were then dissolved in warm $\left(\sim 60^{\circ} \mathrm{C}\right)$ nitric acid/ANN and the fluoride and uranium quantities were measured. The effectiveness of fluoride removal and the consumption of potassium hydroxide were calculated from these quantities assuming that the initial solids contained four fluorides per uranium (as in $\mathrm{UF}_{4}$ ). This may not be a correct assumption, but plausible variations would have little effect on the conclusions to be drawn from these data. Results of these tests are summarized in Table 4.11 .

These results demonstrate that effective metathesis can be achieved in boiling solutions within $1 \mathrm{~h}$ at potassium hydroxide concentrations as low as $0.5 \mathrm{M}$. No effect of sparging was observed with boiling solutions. However,

\section{TABLE 4.11. Results of Metathesis Efficiency Tests}

Metathesis Conditions $=1 \mathrm{~h}$ in boiling solution unless indicated otherwise

\begin{tabular}{|c|c|c|c|c|}
\hline \multicolumn{2}{|c|}{$\mathrm{KOH}, \mathrm{M}$} & \multirow{2}{*}{$\begin{array}{l}\mathrm{KOH} \text { to } \mathrm{UF}_{4} \\
\text { Mole Ratio } \\
\end{array}$} & \multirow{2}{*}{$\begin{array}{l}\text { Sparge During } \\
\text { Metathesis? }\end{array}$} & \multirow{2}{*}{$\begin{array}{l}\text { Remaining Fluoride, } \\
\% \text { of Initial (a) }\end{array}$} \\
\hline Initial & Final $(a)$ & & & \\
\hline 3.8 & 3.4 & 40 & Briefly & 0.8 \\
\hline 1.0 & 0.5 & 8 & No & $18.0^{(b)}$ \\
\hline 1.0 & 0.8 & 20 & Yes & 0.5 \\
\hline 1.0 & 0.6 & 9 & No & 0.5 \\
\hline 0.5 & 0.4 & 19 & Yes & 0.5 \\
\hline
\end{tabular}

(a) Calculated assuming initial solid was $\mathrm{UF}_{4}$.

(b) Metathesis temperature was 90 to $95^{\circ} \mathrm{C}$. 
poor metathesis efficiency was obtained in a non-sparged test that was also run at a temperature of only 90 to $95^{\circ} \mathrm{C}$. These data indicate that the metathesis time cycle in the plant can be reduced and that high potassium hydroxide concentrations are not required.

\subsection{ACID CUT REACTIONS}

After the metathesis rinse solution had been slurped away, an acid cut solution (generally $6.6 \mathrm{M} \mathrm{HNO} 3+0.6 \mathrm{M}$ ANN) was added to the dissolver pot and the mixture was heated to simulate the initial portion of the first acid cut in the plant. Visual observations of foaming severity were made and samples over time were analyzed to determine the amount of uranium that dissolved near instantaneously, which was primarily the uranium compounds (hydrous oxides) formed by metathesis of the insoluble uranium fluorides formed during decladding, and to determine the rate at which the uranium metal exposed during decladding dissolved in the acid solution.

Also discussed in this section are 1) other data on the rate of dissolution of metallic uranium, 2) the conditions that resulted in "runaway reactions" at the start of some of the acid cuts, 3 ) investigations into some potential causes of foaming during the acid cuts, and 4) the amounts of zirconium found in some of the acid cut solutions.

\subsubsection{Rates of Dissolution of Uranium Metal in Nitric Acid}

Rate data obtained during this project for the dissolution of various specimens of metallic uranium will be summarized here. The major effect observed in this work was the high rate of dissolution observed with a waterreacted fuel element, due to the high exposed surface area resulting from fuel segmentation. The other data are not sufficiently extensive to allow many firm conclusions to be drawn, but they are important with regard to potential differences in processing $F G$ and WG fuel. In general, these data support the major conclusions of an earlier study (Swanson et al. 1985) of the dissolution of uranium from cut sections of $\mathrm{N}$ Reactor fuels similar to those that might result in the shear/leach processing of such fuels. However, the current data do give indication of larger effects of fuel 
irradiation and of direction of grain orientation on the rates of dissolution than were apparent in the earlier study.

\subsubsection{Acid Cut Dissolution Rates in Flowsheet Simulation Runs}

Following the metathesis treatment and rinse, the partially declad fuel element sections were exposed briefly to $6.6 \underline{\mathrm{M} \mathrm{HNO}} \mathrm{H}_{3}+0.6 \underline{\mathrm{M}}$ ANN. This composition corresponds to that present at the start of the first acid cut in the plant during the time that problems with processing FG fuel were most severe. The procedure used in the flowsheet simulation runs was to sample the acid solution after it had been warmed to 50 to $70^{\circ} \mathrm{C}$ and then to take a series of samples after the solution had been heated to (or near) the boiling temperature (in several cases the foaming was too severe to allow operation at the boiling point). Measurement of the uranium content of the warm solution allowed the extent of uranium reaction during decladding to be determined (Section 4.1.2.1). Analys is of the other samples allowed the rate of dissolution of uranium metal to be determined.

Figure 4.19 contains plots of the quantities of uranium in solution in the acid solution over time. These data for irradiated fuels are based on ${ }^{137} \mathrm{Cs}$ counting of samples to determine how much uranium metal had dissolved, plus the amounts of uranium found in the warm acid cut samples (Table 4.3). The data with unirradiated uranium were obtained by liquid scintillation counting of samples.

One of the most striking features of these data is the Targe amount of uranium that dissolved initially in Run 9; this occurred because of the large amount of reacted uranium compounds that was present, as was discussed in Section 4.1.2.1 and will be discussed in Section 4.4.2. Of more interest to the current discussion is a comparison of the rates of dissolution of metallic uranium, as determined from the linear portions of the curves.

Aside from the high dissolution rate observed in Run 9, the data of Figure 4.19 show no large differences in dissolution rates such as would be required to account for some of the differences observed in the plant between 
WG and FG fuels. The high rate observed in Run 9 doubtless resulted from the high surface area of uranium that was exposed by the segmentation that occurred during decladding (Section 4.1.1.3).

In an effort to extract as much information as possible from the results of these experiments, uranium dissolution rates per unit area were also calculated from the results shown in Figure 4.19. These values, which are contained in Table 4.12, are based on visual estimations of the extent of cladding removal and are thus relatively uncertain. This is especially so with the outer element sections, where decladding was < $50 \%$ complete because of the solution volume constraint in these runs.

The inner element rate data shown in this table indicate that the unirradiated element dissolved faster than the irradiated elements, which dissolved at comparable rates. However, this trend was not apparent with the outer element sections, where comparable results were obtained with all three sections. In an earlier limited comparison of the dissolution rates of unirradiated and irradiated $\mathrm{N}$ Reactor fuel element sections, it was concluded that there was little, if any, effect of irradiation and that the effect, if any, was to decrease the dissolution rate (Swanson et al. 1985). The results of this current study add weight to the likelihood that irradiated fuel does indeed exhibit a lower dissolution rate (per unit area). The higher uranium dissolution rate observed with irradiated water-reacted fuel (Figure 4.19) appeared to be due to an increased surface area resulting from segmentation of the fuel.

\subsubsection{Other Uranium/Nitric Acid Rate Data from This Study}

Additional data on the dissolution rates of various uranium specimens in nitric acid solutions of various compositions were obtained during this study and are summarized here. One area of interest was to determine the rate of uranium dissolution in a solution such as is present at the end of a final. acid cut; this rate can affect the size of the uranium heel left at the end 


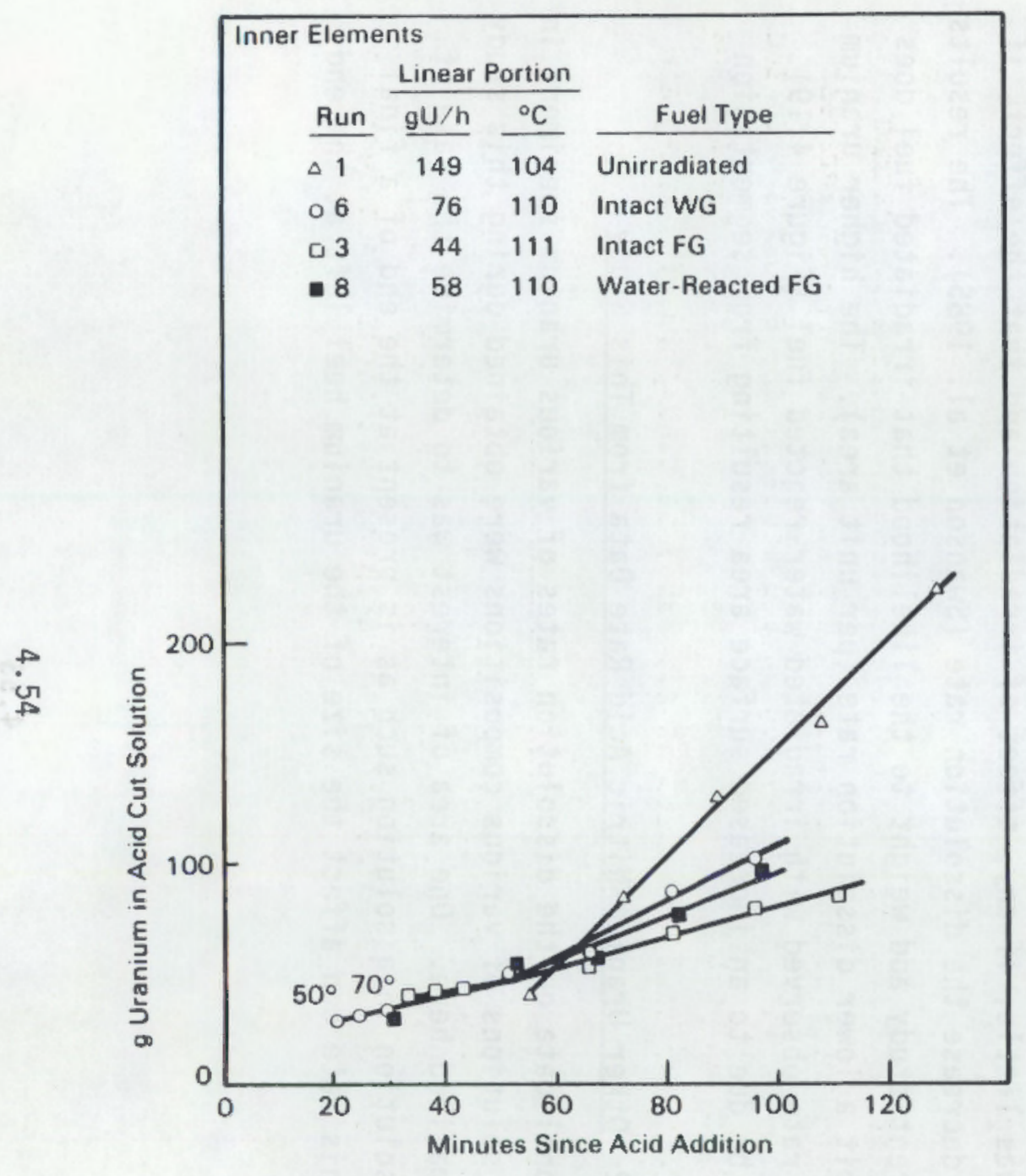

(a)

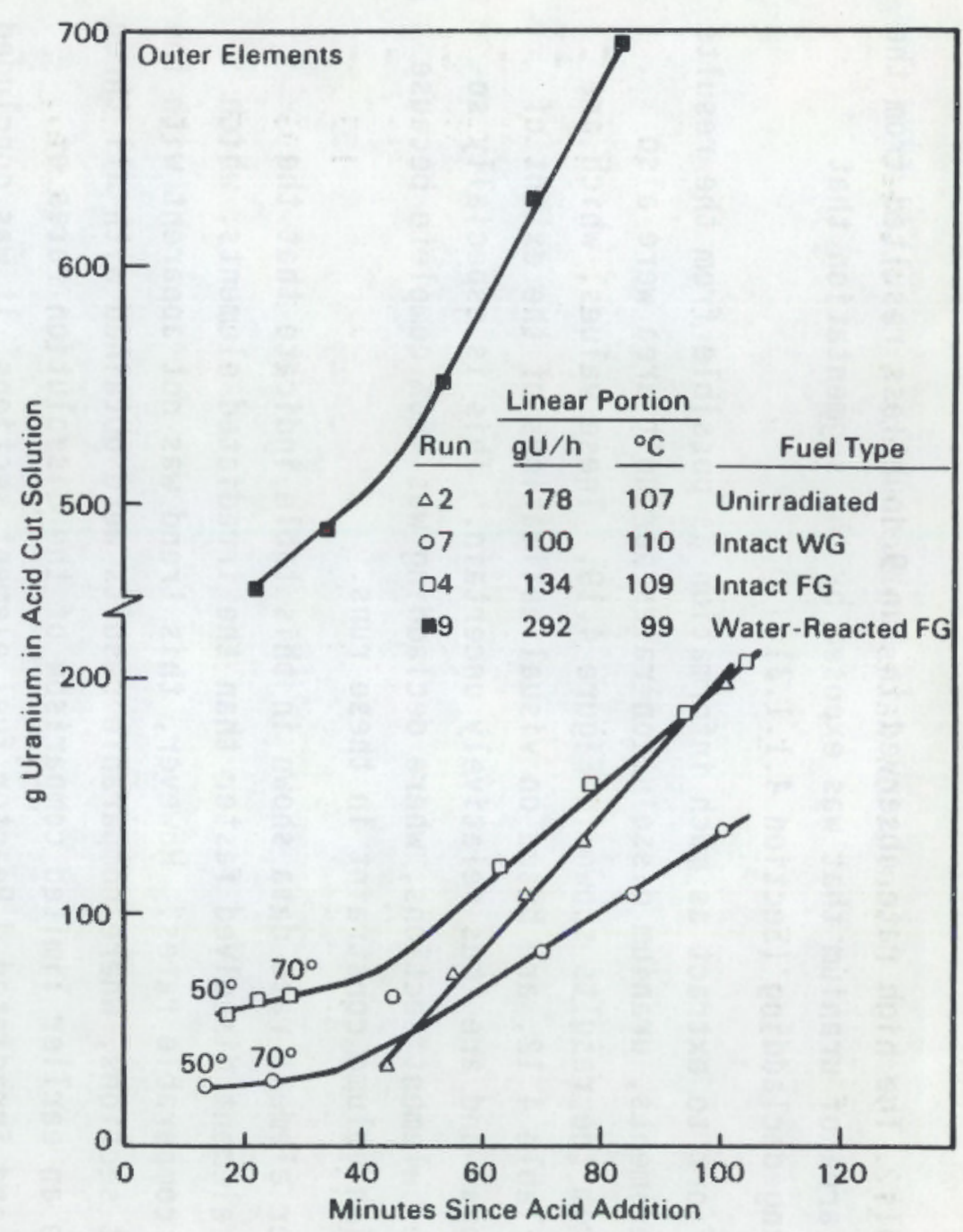

(b)

FIGURE 4.19. Uranium Contents of Acid Cut Solutions Over Time 
TABLE 4.12. Uranium Dissolution Rates in Acid Cuts of Flowsheet Simulation Run

Dissolvent: $\quad 6.6 \underline{\mathrm{M} \mathrm{HNO}} 3+0.6 \underline{\mathrm{M}}$ ANN

\begin{tabular}{|c|c|c|c|c|}
\hline Element Type & Run & $\begin{array}{l}\text { Exposed } 4 \\
\text { Area, } \mathrm{cm}^{2}(\mathrm{a})\end{array}$ & $\begin{array}{l}\text { Dissolution } \\
\text { Rate } \\
\mathrm{g} \mathrm{U} / \mathrm{cm}^{2}-\mathrm{h} \\
\end{array}$ & ${ }^{\circ} \mathrm{C}$ \\
\hline Unirradiated Inner & 1 & 240 & 0.62 & 103 \\
\hline WG Inner & 6 & 205 & 0.37 & 110 \\
\hline \multirow[t]{2}{*}{ FG Inner } & 3 & 145 & 0.31 & 111 \\
\hline & 8 & 170 & 0.34 & 110 \\
\hline \multirow[t]{2}{*}{ Unirradiated Outer } & 2 & 185 & 0.96 & 107 \\
\hline & $2 B(b)$ & 445 & 0.70 & 103 \\
\hline WG Outer & 4 & 125 & 1.1 & 109 \\
\hline FG Outer & 7 & 145 & 0.76 & 110 \\
\hline
\end{tabular}

(a) Based on visual estimation of the extent of cladding removal, plus the calculated total area.

(b) After a second decladding cycle to remove nearly all of the cladding.

of a dissolution cycle, which in turn will affect the extent of uranium reaction during the subsequent decladding cycle. Another area of interest was to compare the rate of dissolution on the sides of the elements with the rate of dissolution on the ends ("side-grain" versus "end-grain" rates); the earlier dissolution study (Swanson et a1. 1985) studied primarily end-grain attack.

\section{Dissolution Rates at Terminal Acid Cut Conditions}

The rate at which (unirradiated) uranium dissolves at the conditions existing at the end of the acid cut was measured to provide part of the data necessary to estimate the total amount of uranium that might react during a 
typical decladding cycle in the plant (Section 4.1.2.3). The results provided other interesting comparisons as well.

The dissolvent for these experiments was a solution containing $2.0 \mathrm{M} \mathrm{U}$ and $0.5 \underline{\mathrm{MHNO}}$. This solution was prepared by dissolving sections of $\mathrm{N}$ Reactor fuel and then adjusting to the final composition. This solution was heated to boiling and the sections were then inserted into the solution and left for measured time periods. The sections were then removed and weighed, after rinsing and drying, to determine the extent of reaction.

In the first set of tests, three specimens were present together. These were 1) a thin ring cut from a (clad) inner element that had previously been exposed to boiling $5 \underline{\mathrm{M} \mathrm{HNO}} 3$, 2) a $\sim 6$-in.-long, completely declad, section of an inner element that been exposed to additional AFAN treatments and then to $5 \underline{M} \mathrm{HNO}_{3}$ after its initial use (in Run 10), and 3) a $\sim 6-$ in.-long, completely declad, section of an outer element that had been exposed to acid attack in Run 2 and to several later exposures to AFAN solutions. The surface of the outer element was quite rough on a macro scale, with hills and valleys resulting from early exposures of the partially declad section to acid solutions. The other sections were smooth (on a macro scale).

These experiments were done in the same type of equipment as was used in the hot-cell tests. The volume of dissolvent was approximately $2 \mathrm{~L}$. Water was added in $25-\mathrm{mL}$ increments to replace condensate as it was collected and $10 \mathrm{M} \mathrm{HNO}_{3}$ was added in $15-\mathrm{mL}$ increments at 5 -minute intervals in an effort to keep the uranium and nitric acid concentrations constant. This nitric acid addition rate did not quite match the actual acid consumption so that concentrations did vary slightly during the runs. However, these variations were small and should not have a marked effect on the results. At the end of the first (one-hour) exposure, the uranium concentration had increased to $2.08 \underline{M}$ and the nitric acid concentration was $0.55 \underline{M}$. This solution was 
diluted to $2.00 \mathrm{MU}+0.53 \mathrm{M} \mathrm{HNO}$ for the second exposure. At the end of the second exposure, which lasted $2 \mathrm{~h}$, the solution composition was about $2.1 \underline{\mathrm{M} U}+0.4 \underline{\mathrm{M}} \mathrm{HNO}_{3}$.

Because of concern about the possible effect of the excessive roughness of the outer element on the rate comparison, a later test was run with a smoother outer element that still contained $5 \%$ of the cladding. This test gave a result in excellent agreement with that first obtained.

The results of these tests are summarized in Table 4.13. Also listed there for comparison are the rate values obtained in preceding exposures of the same specimens to boiling $5.0 \mathrm{M} \mathrm{HNO}$. While the primary reason for obtaining these data was input to a calculation made in Section 4.1.2.3, they are of additional interest. For example, the dissolution rate in the

TABLE 4.13. Rates of Uranium Dissolution at Termina1 Acid Cut Conditions

\begin{tabular}{|c|c|c|c|c|c|}
\hline \multirow[b]{2}{*}{ Specimen } & \multirow[b]{2}{*}{ Area, $\mathrm{cm}^{2}(\mathrm{a})$} & \multicolumn{3}{|c|}{ In $2.0 \mathrm{MU}+0.5 \mathrm{M} \mathrm{HNO}_{3}$} & \multirow{2}{*}{$\begin{array}{c}\text { Rate in Preceding } \\
\text { Exposure to } 5 \text { M } \mathrm{HNO}_{3} \text {, } \\
\mathrm{g} / \mathrm{cm}^{2}-\mathrm{h}\end{array}$} \\
\hline & & $\begin{array}{l}\text { Exposure } \\
\text { Time, } h \\
\end{array}$ & $\begin{array}{l}\text { Weight } \\
\text { Loss, g }\end{array}$ & $\begin{array}{l}\text { Rate, } \\
\mathrm{g} / \mathrm{cm}^{2}-\mathrm{h}\end{array}$ & \\
\hline $\begin{array}{l}\text { Clad } \\
\text { Ring }\end{array}$ & 12 & $\begin{array}{l}1.0 \\
2.0\end{array}$ & $\begin{array}{l}2.23 \\
4.33\end{array}$ & $\begin{array}{l}0.19 \\
0.18\end{array}$ & 0.25 \\
\hline $\begin{array}{l}\text { Declad } \\
\text { Inner }\end{array}$ & 219 & $\begin{array}{l}1.0 \\
2.0\end{array}$ & $\begin{array}{l}24.6 \\
54.4\end{array}$ & $\begin{array}{l}0.11 \\
0.12\end{array}$ & 0.13 \\
\hline $\begin{array}{l}\text { Declad } \\
\text { Outer }\end{array}$ & 474 & $\begin{array}{l}1.0 \\
2.0\end{array}$ & $\begin{array}{r}46.2 \\
119.8\end{array}$ & $\begin{array}{l}0.10 \\
0.13\end{array}$ & \\
\hline $\begin{array}{l}\text { Nearly } \\
\text { Dec1ad } \\
\text { Outer }\end{array}$ & 451 & 1.1 & 66.0 & 0.13 & 0.16 \\
\hline
\end{tabular}

(a) Calculated from specimen dimensions. 
2.0 $\underline{\mathrm{MU}}+0.5 \underline{\mathrm{M} \mathrm{HNO}} 3$ solution, which has a total nitrate concentration of $4.5 \mathrm{M}$, was only slightly lower than the rate in $5.0 \mathrm{M} \mathrm{HNO}_{3}$. This verifies the previously observed importance of nitrate concentration (rather than acidity) to the dissolution rate at a lower acid concentration than had been studied previously (Swanson et a1. 1985).

It is also apparent from the table that the dissolution rate is greater with the clad ring, where all dissolution is by "end-grain" attack, than with the -6 -in.-long sections, where most dissolution is by "side-grain" attack. The rate of end-grain attack was $\sim 60 \%$ greater than the rate of side-grain attack. The rates with inner and outer elements were comparable.

Possible effects of element irradiation on dissolution rates under these conditions were not determined. Results under other conditions indicate that the effect, if any, would be slight (Section 4.4.1.1). It appears that any change would be in the direction of decreasing the rate of acid-cut dissolution.

Other Data on Effect of Irradiation on Side-Grain and End-Grain Dissolution Rates

The first comparison of side-grain and end-grain dissolution rates was made using boiling $5 \underline{\mathrm{M} \mathrm{HNO}} 3$ as the dissolvent. The end-grain specimens were clad rings cut from inner fuel elements and the side-grain specimens were the partially declad elements from the flowsheet simulation runs. Both irradiated and unirradiated specimens were tested. Results of these tests are contained in Table 4.14.

These $5 \mathrm{M} \mathrm{HNO}_{3}$ results support the indication that irradiated fuel dissolves more slowly than unirradiated fuel in both end-grain and side-grain attack with inner element sections, but not with outer element sections. This trend was very strong in the end-grain direction, but was less pronounced in the side-grain direction; this results in the relative rates of end-grain and side-grain attack being different for the three levels of fuel irradiation. The side-grain dissolution rate was markedly lower than the end-grain dissolution rate with unirradiated fuel, but was higher than the end-grain rate with WG fuel. The reasons for these differences are not understood. 
TABLE 4.14. Effects of Specimen Irradiation and of Direction of Attack on Rates of Uranium Dissolution in $5 \mathrm{M} \mathrm{HNO}$

Dissolvent: $5.0 \mathrm{M} \mathrm{HNO} 3$ at the boiling point Dissolution Rate, $\mathrm{g} \mathrm{V} / \mathrm{cm}^{2}-\mathrm{h}$

Side Grain

Rate in

Preceding

Run End Grain Inner Element Outer Element Exposure(a) Unirradiated 0.25

1

0.15

0.62

$10 \mathrm{~B}(\mathrm{~b})$

0.13

2

0.42

0.96

$2 \mathrm{~B}$ (b)

0.22

0.70

12

0.38

${ }_{12 B}(b)$

0.16

WG

0.10

6

0.086

0.37

7

0.06

FG

(a) Exposure to $6.6 \mathrm{M} \mathrm{HNO}{ }_{3}+0.6 \mathrm{M}$ ANN (Table 4.12).

(b) After a second decladding cycle to remove all, or nearly all, of the cladding.

Another facet of the data in Table 4.14 that is not understood is that the dissolution rate (per $\mathrm{cm}^{2}$ ) of partially declad unirradiated outer elements in $5 \underline{M} \mathrm{HNO}_{3}$ became lower as the extent of cladding removal increased. The magnitude of the observed effect was too great to be explained as resulting from uncertainties in estimating the exposed area, and the effect was observed in two instances. However, the effect was observed to a much smaller degree in the preceding exposure (in $6.6 \underline{\mathrm{M} \mathrm{HNO}} 3+0.6 \underline{\mathrm{M}}$ ANN), suggesting that it depends on solution composition.

These observations demonstrate that the effects of all factors on uranium dissolution by nitric acid are still not known. 


\subsection{2 "Runaway Chemical Reactions" During Acid Cut}

One of the important plant indicators of problems associated with processing of aged FG fuel was the occasional occurrence of "runaway reactions" that expelled solution from the dissolvers at the start of the first acid cut. We observed such a reaction on two occasions in our flowsheet simulation runs with irradiated fuel. One was in Run 9, which was a "normal" run except that it employed a fuel element section that had reacted extensively with water during storage; this led to an abnormally high amount of uranium reaction during decladding (Section 4.1.2.1). The other runaway reaction occurred in Run $7 \mathrm{~B}$, which involved an exceptionally long storage period in the declad rinse solution; a large amount of uranium reacted during this period also (Section 4.2). The evidence to be presented here indicates that these runaway reactions at the start of the acid cut were caused by the presence of the large amounts of uranium compounds rather than by reaction of metallic uranium.

A runaway reaction was also observed on a small scale. This occurred when the solids that had been formed during the reaction of unirradiated uranium with dilute AFAN solution (Section 4.1.2.2) were being dissolved for analysis.

In a flowsheet simulation run (12B) employing unirradiated uranium that had reacted appreciably during long storage in declad rinse solution, the acid addition procedure was modified to give a lower initial concentration and no runaway reaction was observed.

\section{Run 9}

The only "runaway" acid cut reaction observed in the normal flowsheet simulation run was in Run 9, where a large amount of uranium had reacted during the decladding cut on the water-reacted outer element (Section 4.1.2.1). This reaction occurred immediately following addition of nitric acid (and ANN) to the rinsed metathesis product; foam built up very rapidly and nearly overflowed the dissolver vessel. However, the addition of water rapidly quenched the reaction and brought the situation back under control. 
The hydrous uranium dioxide resulting from metathesis and the fuel rubble resulting from fuel segmentation during decladding in Run 9 prevented insertion of the slurp line to the bottom of the dissolver vessel, so that an estimated $0.4 \mathrm{~L}$ of metathesis rinse solution was present when the additions for the acid cut were begun. (This residual heel is estimated to have contained $0.57 \mathrm{M} \mathrm{K}$ carried over from the metathesis step.) The possibility of a vigorous reaction occurring when acid was added to these solids was realized, so the cooling coil was turned on before acid addition was begun. The ANN solution ( $0.7 \mathrm{~L}$ of $1.6 \underline{\mathrm{M}}$ ) was added first and $0.8 \mathrm{~L}$ of $15.7 \mathrm{M} \mathrm{HNO}$ was then added; these additions were made at the top of the dissolver pot and the solution was not sparged to mix. When the liquid level first came into view (at about the 2-L level) towards the end of nitric acid addition, a slight amount of foam was observed on the surface. The foam level then increased very rapidly; within seconds it had reached the 4-L level and would have overflowed the dissolver pot if water had not been run in to quench the reaction. The volume of water that was added was only $-0.4 \mathrm{~L}$, as estimated from the final solution volume. This gave a solution composition of $5.5 \underline{M}$ $\mathrm{HNO}_{3}+0.5 \underline{M}$ ANN instead of the $6.6 \underline{\mathrm{M} \mathrm{HNO}} 3+0.6 \underline{\mathrm{M}}$ ANN usually used.

The thermometer was not in place when the acid was added so a temperature reading could not be made during the vigorous reaction. However, a measurement of $60^{\circ} \mathrm{C}$ was made shortly after the reaction was brought under control. That such a vigorous reaction occurred at such a low temperature is indicative of the high reactivity of the solids that were present.

Within 5 min of the time the reaction commenced, no more foam was present in the dissolver, indicating that little (if any) more reaction was occurring. About $5 \mathrm{~min}$ later, the temperature had dropped to $58^{\circ} \mathrm{C}$ and the cooling coil was turned off (and a gentle air sparge was begun). After another 24 min had elapsed, the temperature had risen to $66^{\circ} \mathrm{C}$, and a sample was removed for analysis, which later showed that $489 \mathrm{~g}$ uranium was present in the solution. As shown earlier (Section 4.1.2.1), only $69 \mathrm{~g}$ of this uranium arose from dissolution of the exposed uranium metal so the remainder must have come from dissolution of solid uranium compounds; perhaps $100 \mathrm{~g}$ uranium of this remainder came from uranium compounds formed during water basin storage and the remainder came from metathesis of the uranium compounds 
formed during decladding. Comparison of the ${ }^{137} \mathrm{Cs}$ activity in this acid solution sample with a sample taken 12 min earlier indicated that $25 \mathrm{~g}$ of uranium metal had dissolved in that interval. Extrapolation of this uranium dissolution rate back -22 min to when the acid was added gives a value of the quantity of dissolved metal that is very near zero; this indicates that reaction of the metallic uranium with nitric acid contributed very little, if any, to this runaway reaction.

Shortly after the $66^{\circ} \mathrm{C}$ sample was taken, the heater was turned on (for the first time in this portion of the run). After $15 \mathrm{~min}$, the temperature had reached $97^{\circ} \mathrm{C}$ and the foam level had built up to near the top of the dissolver vessel. The heater was then turned off and the cooling coil was restarted and was run intermittently (as required to maintain a temperature of $99 \pm 1^{\circ} \mathrm{C}$ ) over a period of $-1 \mathrm{~h}$ while the metallic uranium dissolution rate data shown in Figure 4.19 were obtained.

\section{Run 7B}

Another runaway reaction occurred when the normal amount of acid was added to the (metathesized) reaction products resulting from a decladding cycle plus a long storage of the declad element in the declad rinse solution (Section 4.2). Subsequent analysis of the data indicated that uranium compounds containing $\sim 450 \mathrm{~g}$ uranium were present when the acid was added ( $105 \mathrm{~g}$ in the solids formed during decladding and $-345 \mathrm{~g}$ in the solids formed during storage). The reaction that occurred when acid was added to this mixture started more slowly but became more vigorous than that in Run 9; the reaction here could not be brought under control by adding water, and a portion of the reaction mixture spewed out the holes in the 1 id of the dissolver vessel and onto the cell tray. However, the reaction quickly subsided and no damage was done other than to make it impossible to determine the exact extent of reaction with the acid solution.

The metathesis step preceding acid addition was different than usual in this run; it involved adding potassium hydroxide (5.0 moles) directly to the decladding rinse solution, instead of adding a fresh solution after discarding the rinse solution. This change is not thought to have affected the result. 
After the metathesis solution had cooled and settled, it was slurped away and the solids were rinsed with water as usual. The volume reading taken after addition of a known volume of rinse water indicated that $~ 0.4 \mathrm{~L}$ of solution plus reacted solids remained behind after the metathesis solution had been slurped away. The volume of settled rinse solution then slurped out was somewhat greater than the volume that had been added; thus, the volume measurements indicate that $\sim 0.3 \mathrm{~L}$ of solution plus reacted solid was present at the time the acid cut was begun. In retrospect, a volume closer to $0.5 \mathrm{~L}$ would be expected for the $-450 \mathrm{~g}$ of reacted uranium that were present.

As in Run 9, the cooling coil was turned on and $0.7 \mathrm{~L}$ of $1.6 \mathrm{M}$ ANN was added to the wet solids (and unreacted uranium) in the dissolver. Nitric acid ( $1.2 \mathrm{~L}$ of $10.4 \underline{\mathrm{M}}$ ) was then added to the (unmixed) dissolver contents. Little, if any, sign of reaction was observed for several minutes. Then a slight foaming action began and shortly thereafter the foam level began to increase very rapidly. Water was added in an effort to quench the reaction, but the foam continued to build and a portion of the reacting mixture spewed out the top of the dissolver and onto the cell tray. This loss continued for perhaps up to a minute and the foam level then subsided nearly as rapidly as it had built.

The induction period in this reaction could have occurred because of the time necessary for the solution to self-mix so that the acid could contact the solids. However, an induction period that was not related to self-mixing was observed in the experiment to be discussed next. The suggested reason for that induction period, an autocatalytic reaction involving nitrous acid, could also have been important here in Run 12B.

About 20 min after the reaction had occurred, the remaining solution was slurped from the dissolver pot and combined with the spewed solution that had been slurped from the cell tray. The ${ }^{137} \mathrm{Cs}$ content of the combined solution indicated that $\sim 70 \mathrm{~g}$ of uranium metal had reacted during the acid exposure. There is considerable uncertainty to this value, because of uncertainties regarding completeness of recovery of the spewed solution from the cell tray and of the initial cleanliness of the cell tray. However, it does indicate 
that relatively little metallic uranium reacted during the "runaway reaction," which is in agreement with the observations of Run 9.

The element was dark in appearance after it was removed from the acid solution (and rinsed). It appeared to be even darker after standing overnight. Closer examination revealed what were first thought to be cracks in the fuel, but which were later found to be grooves that had been "chemically milled" into the metal (Section 4.2.1). As part of this examination, the element surface was brightened by brief exposure to near-boiling $5 \underline{M}$ $\mathrm{HNO}_{3}$. Based on the ${ }^{137} \mathrm{Cs}$ found in the solution, $-10 \mathrm{~g}$ of uranium metal dissolved in this exposure. This amount is too small to have contributed to the overall appearance of the element.

Vigorous Reaction During Dissolution of Solids for Analysis

A vigorous reaction also occurred when a small amount of the solid material that had formed during reaction of unirradiated uranium with dilute AFAN solution (Section 4.1.2.2) was being dissolved for analysis. Approximately $2 \mathrm{~mL}$ of these wet solids (containing 2 to $3 \mathrm{~g}$ uranium) were recovered and washed with water in a $15-\mathrm{mL}$ centrifuge tube. Five $\mathrm{mL}$ of $5 \underline{\mathrm{M}} \mathrm{HNO}_{3}$ was then added and the mixture was observed closely. After there was no evidence of reaction for many seconds, the solids and acid were mixed with a small spatula. There was still no evidence of reaction for perhaps a minute or two, but then the solution began to foam; it quickly foamed out the top of the centrifuge tube, and colored nitrogen dioxide fumes were also observed. The reaction then rapidly subsided, leaving $4.8 \mathrm{~mL}$ of clear yellow solution in the tube (indicating that $2.2 \mathrm{~mL}$ of solution had foamed out).

The fact that the vigorous reaction did not begin for an appreciable time after mixing suggests that an autocatalytic reaction involving nitrous acid occurred. Nitrous acid is a product of the reaction of uranium dioxide with nitric acid; nitrous acid speeds the reaction of uranium dioxide with nitric acid. Thus, a slow reaction can rapidly become a rapid reaction.

\section{Dissolution of Reactive Solids Without a Runaway Reaction}

A modified initial acid cut procedure was successfully used to avoid a vigorous reaction when the uranium solids from Run $12 \mathrm{~B}$, most of which were 
formed during extended storage in declad rinse solution (Section 4.2), were dissolved in acid. The major modification was simpiy to reduce the concentration of acid. Another change was to sparge the mixture during acid addition to suspend (some of) the solids and distribute the reacting material throughout a larger volume.

The hydrous uranium dioxide present in the dissolver vessel at the time the acid was added in Run 12B contained only $260 \mathrm{~g}$ of uranium; this is appreciably lower than the amount of uranium that reacted in the preceding steps because the loss during slurping of the metathesis and metathesis rinse solutions amounted to $>100 \mathrm{~g}$ uranium. Thus, less hydrous uranium dioxide was present in this flowsheet simulation run than in those where runaway reactions did occur; this fact doubtless also helped to avoid such a reaction in Run $12 B$.

Before this acid cut step, the element was returned (it had been removed for weighing) to the dissolver pot containing the hydrous uranium dioxide, and the metathesis rinse solution was slurped out. Based on subsequent volume readings, it is estimated that a $\sim 0.2 \mathrm{~L}$ heel of wet solids remained after this slurping. The cooling coil was turned on, $0.3 \mathrm{~L}$ of $1.6 \mathrm{M}$ ANN and $0.99 \mathrm{~L}$ of water were added, and a gentle air sparge was begun. The acid $(0.55 \mathrm{~L}$ of $10.4 \underline{\mathrm{M} \mathrm{HNO}} 3)$ was then added, giving a solution composition of $3 \underline{\mathrm{M}}$ $\mathrm{HNO}_{3}+0.3 \mathrm{M}$ ANN.

Three minutes after the acid was added the temperature was $28^{\circ} \mathrm{C}$ and, after another three minutes, it was $26^{\circ} \mathrm{C}$; the cooling water flow was then stopped. Seven minutes later the temperature was sti11 $26^{\circ} \mathrm{C}$ and the heater was turned on. Three minutes later it was observed that the solution was lighter in appearance, indicating that many of the solids had dissolved. When the temperature reached $54^{\circ} \mathrm{C}$, the heater was turned off as foam was beginning to build, but it never reached a volume of $>0.3 \mathrm{~L}$. The temperature continued to rise to $-68^{\circ} \mathrm{C}$ but the foaming gradually subsided and finally stopped -40 min after the acid had been added.

The procedure followed here to avoid a runaway reaction is very similar to that adopted in the plant to avoid and/or minimize problems when 
processing FG fuel. This thus provides another instance of close correlation between the behavior observed in our experiments and that observed in the plant.

\subsubsection{Foaming During Acid Cut}

In addition to the rapidly forming and subsiding foams that occurred in the "runaway reactions" discussed in the preceding section, another type of foaming was also observed. This foam formed gradually as the uranium metal dissolution conditions stabilized and then remained at a constant level under the stable conditions. The severity of this type of foam was found to increase with increasing ANN concentration and with the presence of oil like that used in the plant air compressors.

A photograph (taken during Run 4) of this type of foaming is shown in Figure 4.20. The liquid level before foaming began was $2.3 \mathrm{~L}$; thus, $-1.5 \mathrm{~L}$ of foam was present when this photograph was taken. Dark-colored solids that result from materials left over from decladding are apparent in three places; some have been deposited on the walls above the top of the foam, some still float atop the foam, and others are contained in the lower portion of the foam (which is darker than the top portion of the foam).

With foam such as that shown in Figure 4.20--a normal situation in our runs--it would not be difficult to have foam loss from dissolvers being run with minimal freeboard above the solution. Such "foaming incidents" are entirely different from those discussed in Section 4.4.2; they could result from a slight increase in temperature or dissolution rate, rather than involving anything approaching a "runaway reaction."

\subsubsection{Foaming During Flowsheet Simulation Acid Cuts}

During the uranium metal dissolution portions of the flowsheet simulation runs, the volume of foam in the dissolver pot increased markedly as the temperature approached boiling, as shown in Figure 4.21. The foam volumes shown in this figure were obtained by reading the volume at the top of the foam level and subtracting the volume occupied by the warm solution and the element section. 


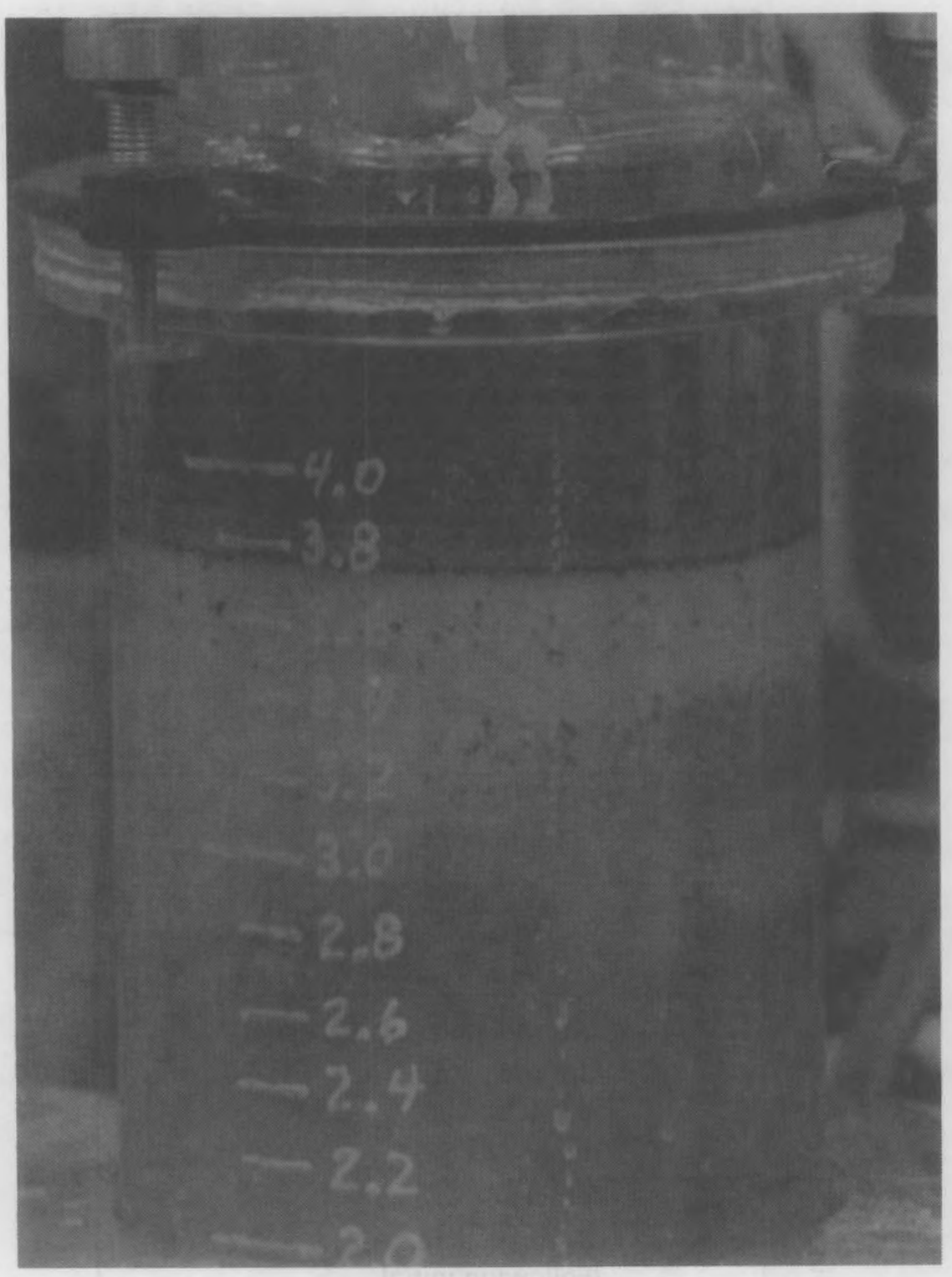

FIGURE 4.20. Photograph of Foaming During Acid Cut

Also listed in this figure are the uranium dissolution rates that were measured after the dissolution conditions had stabilized, which was generally at the highest temperature plotted in the figure. These values are shown for comparison because the foam level must depend on the reaction rate to some degree. However, the strong dependence of foam volume on temperature must be 

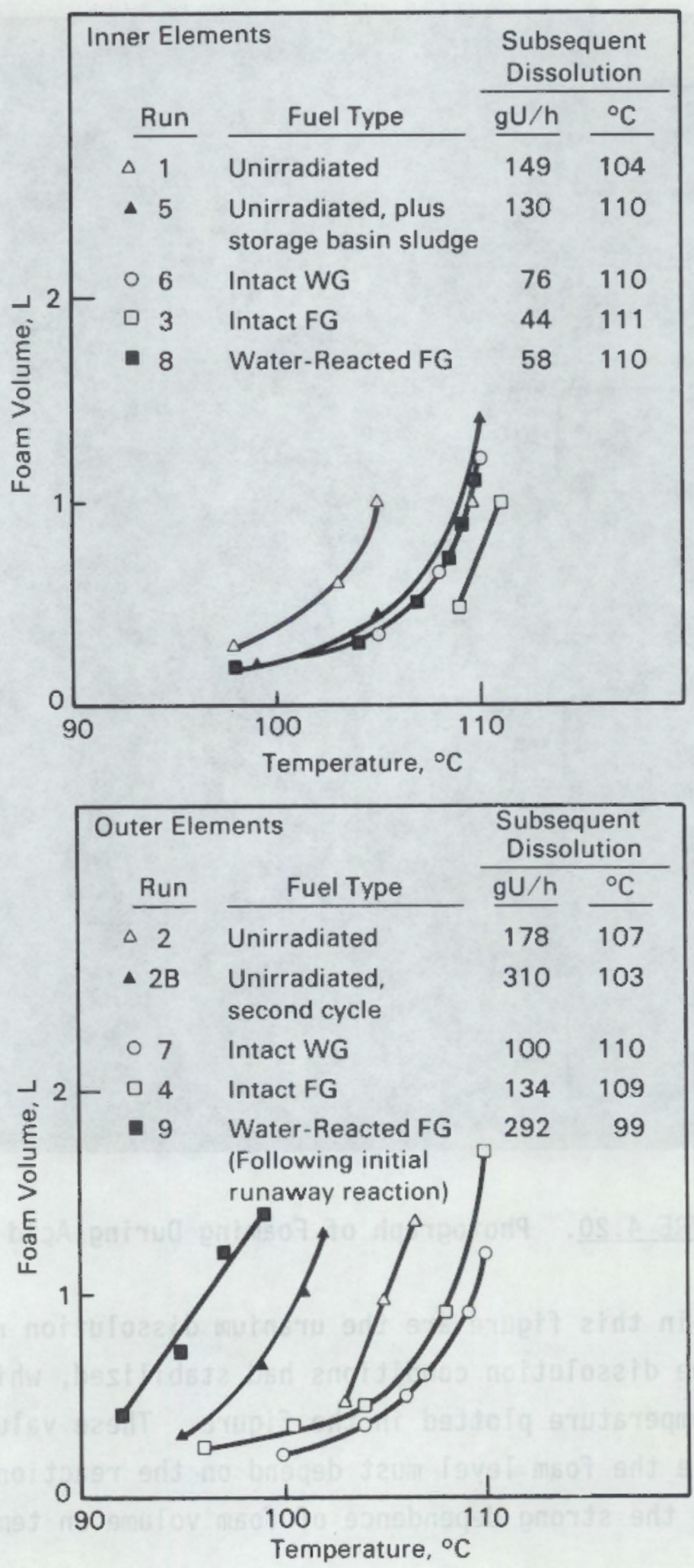

FIGURE 4.21. Foaming During Heat-Up of Acid Cuts 
largely independent of the reaction rate. This is because the uranium dissolution rate does not increase very markedly with temperature (Swanson et al. 1985).

By far the most severe foaming in the flowsheet simulation runs was in Run 9, which involved the outer element that had reacted extensively with water during storage. This run was also unique in that the foam level decreased over time at $\sim 99^{\circ} \mathrm{C}$. After $-0.5 \mathrm{~h}$ it had decreased to a level typical of the other runs at that temperature. This behavior suggests that a consumable foaming agent may have been present, but no speculation as to its nature can be given.

The run made to test the possible foam-inducing properties of sludge from the storage basin (Run 5) showed no such property of this sludge. In fact, the reverse may have been true; foaming was less severe in Run 5 than in Run 1 with unirradiated uranium without the storage basin sludge. An unresolved uncertainty in this comparison is that Run 5 was done in the hot cel1 while Run 1 was not; it is not known what effect, if any, this may have had.

The data of Figure 4.21 show comparable foaming in runs involving intact $W G$ and $F G$ elements. Differences in the plant in dissolver foaming incidents between $W G$ and $F G$ fuels thus appear to have resulted from the presence of some water-reacted fuel in (some of) the $F G$ fuel charges.

Tests were a1so performed to test the effect of air sparging on the volume of the acid cut foam. Introducing an air sparge to a foaming mixture did give a decrease in foam volume; this effect seemed to result simply from lowering of the temperature. An identical effect was observed when the temperature was lowered slightly with the cooling coil.

An anti-foaming agent (DB-110A), of ten used in the plant, was also tested in the acid cut foam. A positive effect was obtained, but it was transitory; addition of $1.0 \mathrm{~mL}$ of the anti-foaming agent to $2 \mathrm{~L}$ of $8.4 \mathrm{M}$ $\mathrm{HNO}_{3}$ in contact with an inner element (Run 1) at $\sim 106^{\circ} \mathrm{C}$ reduced the foam volume by perhaps $50 \%$, but within a minute the foam had returned to its previous level. Thus, successful use of this material to suppress foaming during the acid cut would require that it be added continuously. 


\subsubsection{Effect of ANN Concentration on Foaming}

The foaming observed in the $6.6 \underline{M} \mathrm{HNO}_{3}+0.6 \underline{M}$ ANN solutions used in the flowsheet simulation runs of this project was much worse than had been observed previously under similar conditions except that ANN was absent (Swanson et al. 1985). To further investigate this point, the element from Run 1 was used in a series of runs at different ANN concentrations. These runs were made at a constant total nitrate concentration so that the dissolution rate would be the same at a given temperature (Swanson et al. 1985). Results are shown in Figure 4.22.

It is readily apparent that acid cut foaming is much worse in nitric acid/ANN mixtures than it is in nitric acid alone. The reason for this is unknown; the first thought was that it was because of an impurity in the plant ANN that was used in these experiments, but an experiment with ANN crystals from the laboratory gave a similar result.

\subsubsection{Effect of Compressor $0 i 1$ on Foaming}

Compressed air is fed into the plant dissolvers through instrument dip legs as well as through the sparge ring. It was thought that compressor oil entrained in this air might, if it were not efficiently removed, contribute to foaming problems. To test this possibility, some oil taken from a plant compressor on April 10, 1987 was spiked into the dissolver during a $5 \underline{\mathrm{M} \mathrm{HNO}}$ dissolution (in Run 12B). Addition of 5 to $10 \mu \mathrm{L}$ of oil (to $2 \mathrm{~L}$ of solution)

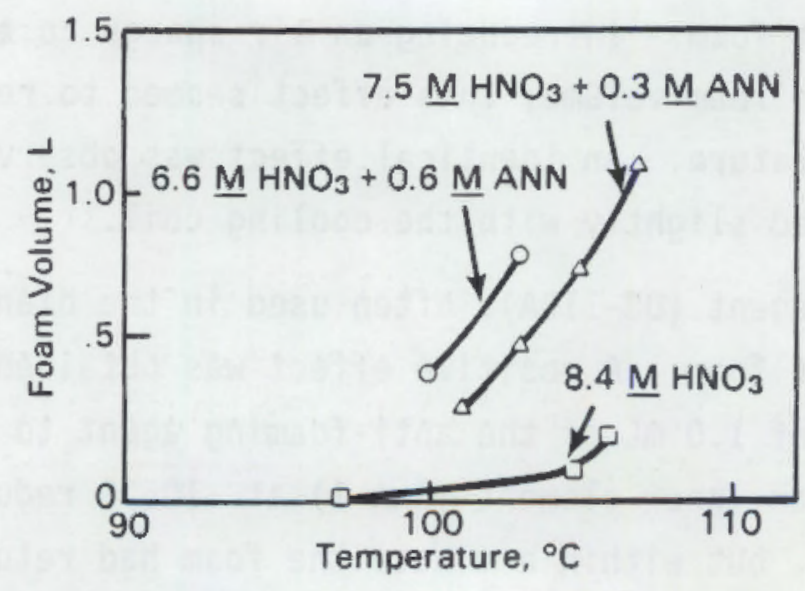

FIGURE 4.22. Effect of ANN Concentration on Foaming 
increased the foam volume from -0.1 to $-0.3 \mathrm{~L}$. Addition of another 15 to $20 \mu \mathrm{L}$ further increased the foam volume to $-0.7 \mathrm{~L}$. The foam volume then remained constant for $-0.5 \mathrm{~h}$, when the experiment was terminated. Thus, it was shown that compressor oil does indeed give increased acid cut foaming; this points out the need to ensure that the oil is removed from the air before it enters the dissolver.

\subsubsection{Zirconium in Acid Cut Solutions}

Although not needed in the pursuit of any of the major areas of study for this project, the opportunity was taken to obtain some information on another PUREX head-end problem area--the presence of excessive quantities of zirconium in the acid cut solution. According to the current plan for highlevel waste treatment, this zirconium will be included in the high-level waste glass, thus probably increasing the disposal cost. Zirconium compounds that are present as solids in the acid cut can also cause difficulties in accountability analyses and in solvent extraction column operation.

The quantity of zirconium found in samples taken during the warm-up of the acid cut solutions in our flowsheet simulation runs was generally only 1 to $2 \mathrm{~g}$. This corresponded to 1 to $2 \%$ of the total zirconium dissolved, and gave a zirconium concentration in the acid solution of $-0.01 \underline{M}$. However, much more zirconium was found in the acid cut in Run 9, which involved the element that had reacted extensively with water during storage.

During Run 9, it was observed that the primary (-thirteenfold) dilutions of the samples taken during the acid cut solution warm-up phase became progressively more murky. Subsequent analyses of the clear supernates of these dilutions showed that the zirconium concentration in the dissolver solution had decreased over time, indicating that zirconium precipitation had occurred as dissolution proceeded. The initial zirconium concentration in the acid solution $(-0.15 \underline{M})$ was much higher than in the preceding runs, which may have caused the precipitation. Zirconium precipitation in this case may have also been enhanced by the very high uranium concentration in this acid cut solution (Figure 4.19).

This abnormally high carry-over of zirconium to the acid cut in Run 9 is felt to have been caused by the presence of a water-insoluble zirconium 
precipitate at the end of the decladding cycle. This is based on the fact that -tenfold less zirconium was found in the declad rinse solution than in the acid cut solution; if the zirconium carry-over had been caused by leaving a large heel of declad solution or by the presence of a water-soluble solid, the amount of zirconium found in the declad rinse solution should have been greater than that found in the acid cut solution.

The indicated water-insoluble zirconium compound is hypothesized to be a mixed hydroxy/fluoride or a hydroxide formed by analogy to reaction (4.2), which allows the reactions to proceed to higher $\mathrm{Zr}+\mathrm{U}$ to added $\mathrm{F}^{-}$ratios than was previously thought to be possible (Section 4.1.2.2). The quantity of zirconium found in this form in Run 9 was $-30 \mathrm{~g}$, which indicates that $\sim 145 \mathrm{~g}$ zirconium dissolved in Run 9 instead of $\sim 115 \mathrm{~g}$ as indicated by analysis of the declad solution.

Somewhat similar results were obtained in Run $9 \mathrm{~B}$, where the moles zirconium+uranium reacted per mole added fluoride was also higher than usual, but not as much as in Run 9 (compare Figures 4.12 and 4.13). In this case, approximately half as much $(-15 \mathrm{~g})$ zirconium was found in the acid cut solution; again, only $\sim 3 \mathrm{~g}$ zirconium was found in the declad rinse solution.

These results indicate that increased carry-over of zirconium to the acid cut solution results from the processing of extensively water-reacted fuels. This is an additional problem in the processing of such fuels.

\subsubsection{Potassium in Acid Cut Solutions}

The quantity of potassium found by analysis of the acid cut solutions was in the range from 3 to $8 \mathrm{~g}(0.1$ to 0.2 mole) in most of the flowsheet simulation runs, but was $30 \mathrm{~g}$ in Run 9 and $20 \mathrm{~g}$ in Run 98 . Even these lower values are an order of magnitude higher than expected on the basis of simple dilution and washing of solids; this indicates that a water-insoluble salt of potassium is present after metathesis.

Unpublished observations by operating contractor personnel had led to the suggestion that a reaction such as

$$
\left(\mathrm{NH}_{4}\right)_{3} \mathrm{UF}_{7}+8 \mathrm{KOH} \rightarrow 0.5 \mathrm{~K}_{2} \mathrm{U}_{2} \mathrm{O}_{7}+7 \mathrm{KF}+\mathrm{H}_{2}+3 \mathrm{NH}_{3}+4.5 \mathrm{H}_{2} \mathrm{O}
$$


could be important during metathesis, in addition to the simple metathesis reaction described by Equation 1.5. The potassium-to-uranium mole ratio found in the flowsheet simulation runs when the metathesized product was dissolved in nitric acid was generally 0.5 . This indicates that Equation 4.3 could not represent the entire metathesis reaction, but that it could be an important contributor. More work is necessary before a firm conclusion can be made in this area.

\subsubsection{Tin in Acid Cut Solutions}

A few data were obtained regarding the behavior of tin, which is present to $-1.5 \%$ in Zircaloy, in the head-end simulation runs. These results indicate that a substantial fraction of the tin does not dissolve in the declad solution as desired, but instead stays behind in the dissolver and ends up in the acid cut solution.

Approximately one-third of the tin calculated to have been reteased from the Zircaloy dissolved in Run 1 was found dissolved in the warm $-3 \underline{M} \mathrm{HNO}_{3}$ solution that was used to dissolve the hydrous uranium dioxide present after metathesis. In Run 12, the solids present after a normal acid cut were found to contain $\sim 60 \%$ of the tin calculated to have been released from the Zircaloy; these solids contained an approximately equal weight of zirconium. In Run 12B, it was observed that many more solids were present after boiling a (dilute nitric) acid cut solution than were present after it had been warmed to only $-60^{\circ} \mathrm{C}$ to dissolve hydrous uranium dioxide; this indicates that some soluble tin species were converted to insoluble ones when the solution was boiled.

The reason for the incomplete dissolution of tin in the declad solution is not known, but is thought likely to be caused both by a slow dissolution rate in the declad solution and by the fact that the early foaming action deposited undissolved tin on the vessel walls above the liquid level, where it was not contacted by the declad solution during most of the declad period.

Some dissolution of the residual tin in the metathesis solution is likely. However, no data were obtained in this area. 


\subsection{OTHER STUDIES RELATED TO HEAD-END PROCESSING}

Head-end related studies were also performed in two other areas where plant operation was not as good as desired. One of these areas was the volatilization of ${ }^{106} \mathrm{Ru}$ when the ammonia scrubber solution is distilled to give a decontaminated ammonia stream to be discharged to the ground; tests were made of several additives that decreased this volatilization. The other area was the entrainment of plutonium- and americium-containing solids in the decladding waste solution to the extent that this waste stream might have to be vitrified for disposal in a deep geologic repository; solids characterization data were obtained on declad and metathesis solids and tests were made of the use of flocculating agents to improve the removal of such suspended solids.

\subsubsection{Suppression of Ruthenium Volatilization when Ammonia Scrubber Solution is Distilled}

In the PUREX plant, the off-gas stream generated during decladding is scrubbed with water (to remove ammonia) before it is routed to the normal off-gas treatment system. This ammonia-containing scrub solution is combined with the (downdraft) condenser condensate, and with other ammonia-containing solutions, and is then treated for disposal.

At the time this study was done, the treatment involved evaporation to concentrate the contained radionuclides (and volatilize the ammonia) before the concentrated stream, called the ammonia scrubber waste (ASW), was sent to waste tanks for storage/disposal. The resulting ammonia scrubber distillate (ASD) contained low concentrations of radionuclides and could be discharged to the ground under then-existing regulations. These discharges were regularly limited by the concentration of contained ${ }^{106} \mathrm{Ru}$, so experimental testing of possible ways of reducing ${ }^{106}$ Ru volatilization was of interest. Since this study was completed, regulations were changed so that a question now exists as to whether discharge of this stream at the normal rate would be allowed because of the quantity of contained ammonia. This may require a modification of plant operation such that our experimental results would be of no value to the plant. However, the results will be discussed here for completeness. 
The decladding condensate from one of our hot-cell runs (7B) was used to study the distillation of ruthenium with the ASD, and to investigate means of decreasing ruthenium volatilization.

The chemicals tested here for suppression of ruthenium volatilization with ASD (permanganate, alkaline permanganate, and hydrogen peroxide) were chosen based on earlier work by operating contractor personnel in which actual plant ASD was redistilled. Those tests indicated that alkaline permanganate was very effective in suppressing ruthenium volatilization and that permanganate alone or peroxide were somewhat effective. Our results verified the effectiveness of these additives but pointed out a drawback to the use of alkaline permanganate.

Suppression of ruthenium volatilization by reaction with oxidizing agents is the reverse of what is usually done in nitric acid solutions; the observed effectiveness of oxidants indicates that the volatile species present in ammonia scrubber solution is not ruthenium tetraoxide, which is the species that normally volatilizes from nitric acid solutions.

\section{Feed for Ammonia Scrubber Waste Distillation Study}

The decladding condensate collected in Run $7 \mathrm{~B}$ provided the feed solution for the study of ruthenium volatilization during ASW evaporation. This condensate was collected in three cuts; the volumes, ammonia concentrations, and radionuclide contents of these cuts are given in Table 4.15. Except for the high ${ }^{144} \mathrm{Ce}$ content of the first cut, the radionuclide content of the cuts did not vary much over the course of the decladding operation. Many of these radionuclides must have been carried to the condensate by entrainment, as no volatile compounds are known. The quantity of ${ }^{137} \mathrm{Cs}$ found in the condensate amounted to $\sim 0.1 \%$ of that dissolved during the decladding operation.

The decladding condensate cuts were observed to contain solids when they were first sampled, which was one day after they were collected. These solids were mixed with the solutions when the first samples were withdrawn for analysis. The condensate cuts were subsequently sampled and analyzed after the solids had settled out; these results are also given in Table 4.15. Comparison of the analyses for the mixed and the settled cuts shows that the solids contained none of the cesium, $-20 \%$ of the antimony, $-60 \%$ of the 
TABLE 4.15. Analys is of Declad Condensate Samples (from Run 7B)

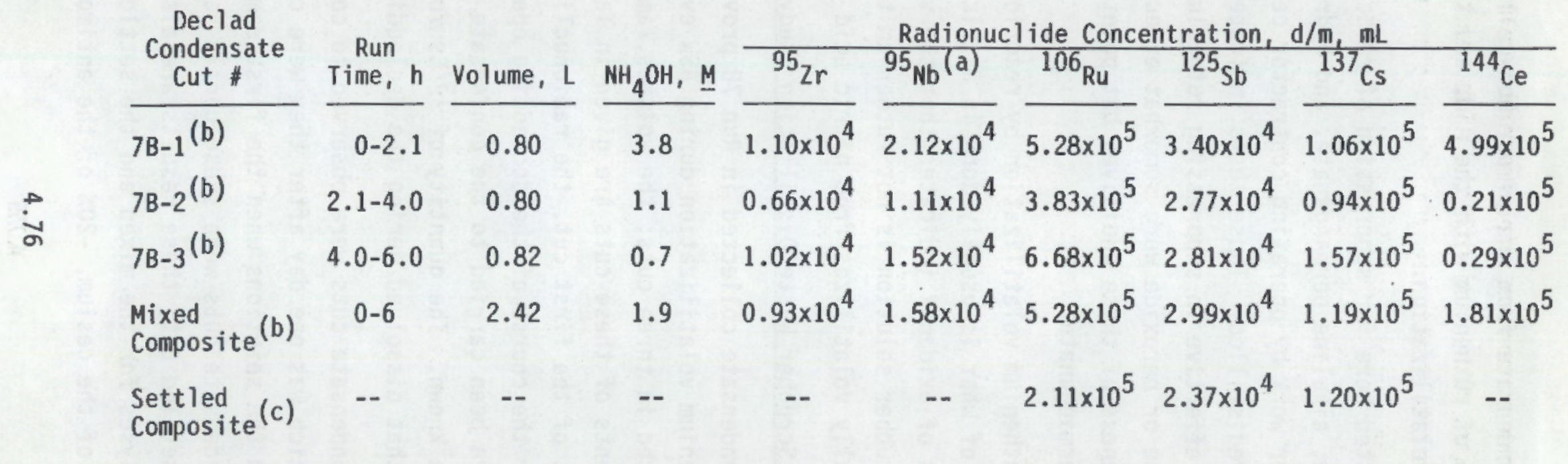

(a) Samples were counted 7 days after collection.

(b) Cuts were mixed to suspend solids before dilutions were made for analysis.

(c) Cuts were allowed to settle before portions were composited. 
ruthenium, and all of the zirconium, niobium, and cerium that was found in the mixed condensate cuts. The feed solutions used in our distillation studies did not contain the solids found in the decladding condensate cuts; those feed solutions were composites of the settled supernatant solutions, and were diluted fivefold to give an ammonium hydroxide concentration equivalent to that given in the plant flowsheet for the evaporator feed stream $(\sim 0.4 \underline{M})$.

Table 4.16 lists the ratios of other fission products to ${ }^{137} \mathrm{Cs}$ in the deolad condensate, in the filtered final declad solution, and in the fuel (as calculated by the ORIGEN code). Cesium is a good reference for use here because it is both soluble and nonvolatile. The concentrations (relative to ${ }^{137} \mathrm{Cs}$ ) of ${ }^{106} \mathrm{Ru}$ and ${ }^{125} \mathrm{Sb}$ in the declad condensate are seen to have been higher than in the fuel, indicating that some volatilization of these two elements occurred during decladding. The data indicate that only $\sim 0.1 \%$ of the ruthenium and antimony that were released by attack of the uranium were present in the declad condensate. For comparison, $\sim 0.03 \%$ of the released cesium was found in the declad condensate. The low ratios of ${ }^{106} \mathrm{Ru}$ and ${ }^{125} \mathrm{Sb}$ to ${ }^{137} \mathrm{Cs}$ in the filtered declad solutions reflect the fact that most of the ruthenium and antimony that react during decladding are insoluble in the decladding solution, as was discussed in Section 4.1.6.

The concentrations of fluoride in the declad condensate samples used in this study were also determined, but not until after the condensate samples had stood for 10 mo in glass bottles. The concentrations found in the three

TABLE 4.16. Fission Product Ratios in Declad Condensate, in Declad Solution, and in Irradiated Fuel

\begin{tabular}{|c|c|c|c|c|}
\hline & \multicolumn{4}{|c|}{ Activity Relative to That of ${ }^{137} \mathrm{Cs}$} \\
\hline & $95 \mathrm{Zr}$ & $106 \mathrm{Ru}$ & $\underline{125} \mathrm{Sb}$ & ${ }^{144} \mathrm{Ce}$ \\
\hline Declad Condensate (Mixed Composite) & 0.08 & 4.4 & 0.25 & 1.5 \\
\hline Final Declad Solution (Filtered) & 0.32 & 0.053 & 0.004 & 0.00 \\
\hline Irradiated Fuel(a) & 0.27 & 1.7 & 0.11 & 7.7 \\
\hline
\end{tabular}

(a) Based on output of the ORIGEN code. 
cuts at that time were $0.0040,0.0021$, and $0.0016 \underline{M}$. In a later run $(7 \mathrm{C})$, where the fluoride analyses were done after the condensate samples had stood only one day in glass, concentrations of $0.0095,0.0017$, and $0.0014 \mathrm{M}$ were found in the three successive declad condensate cuts.

\section{Procedures for Ammonia Scrubber Distillations}

Our tests were run in a way that simulated plant operation; a large volume of ammonia scrubber solution feed (ASF) was processed through a small evaporator, with feed being added semicontinuously to maintain a nearconstant volume of bottoms solution in the evaporator. Our runs involved -25 mL of bottoms solution, with ASF being added in $5 \mathrm{~mL}$ increments whenever another $5 \mathrm{~mL}$ increment of distillate had been collected. However, we shut down our operation every day instead of running continuously as in the plant; this different procedure did give some effects that would probably not be observed in the plant, but it is felt that it did not affect the major conclusions of the study.

The evaporator used here was really a distillation flask $(100-\mathrm{mL}$ capacity) fitted with a simple condenser attached to the neck $-13 \mathrm{~cm}$ above the surface of the liquid. Distillate cuts were collected in open graduated cylinders. The results of the distillations were followed by analysis of selected distillate cuts. The size of the cuts that were analyzed was generally $20 \mathrm{~mL}$, although sometimes the larger intervening cuts were also analyzed.

Most of the analyses in the distillation study were performed with our in-lab gamma counter, which is a well-counter using a sodium-iodide detector, in 5-mL portions at 20-to-50-min count times. This allowed us to obtain nearly "real-time" data at a low cost. However, the high background in the laboratory gave significant counting uncertainties at the low count rates encountered in the ASD, and the combinations of low count rate and high background made it impractical to measure ${ }^{125} \mathrm{Sb}$ concentrations in ASD. Qualitative examination of the spectra of selected samples indicated that antimony was not highly volatile. No antimony peaks were seen in ASD samples, and the ratios of the antimony and ruthenium peaks in samples of the pot bottoms solution (ASW) were approximately the same as in the feed (ASF). 
One radionuclide that was observed at relatively high concentrations in ASD samples was ${ }^{113} \mathrm{~S} n$, which presumably arises by neutron activation of the tin in Zircaloy. This radionuclide was detected by counting the $113 \mathrm{~m} I n$ daughter $\left(t_{1 / 2}=1.7 \mathrm{~h}\right)$. The fact that this activity was very low when distillate cuts were analyzed immediately, but grew to a significant (and constant) value on standing overnight, demonstrates that the volatile material was ${ }^{113} \mathrm{Sn}$ rather than ${ }^{113 \mathrm{~m}} \mathrm{In}$.

Comparison of our in-lab counting results with the results obtained in an analytical laboratory under optimum counting conditions gave the following factors to use in converting our counts to actual disintegrations: $\sim 20 \mathrm{~d} / \mathrm{c}$ for ${ }^{106} \mathrm{Ru},-7.5$ for ${ }^{137} \mathrm{Cs}$, and $\sim 4.5$ for ${ }^{113} \mathrm{Sn}$. We counted the ${ }^{106} \mathrm{Ru}$ peak at $513 \mathrm{keV}$, the ${ }^{137} \mathrm{Cs}$ peak at $662 \mathrm{keV}$, and the ${ }^{113} \mathrm{Sn}$ peak at $392 \mathrm{keV}$. The activities at the cesium and tin peaks were corrected for ruthenium interference using factors measured with a ${ }^{106} \mathrm{Ru}$ standard; the ruthenium activity in the cesium location was $-32 \%$ of that in the ruthenium peak, and the ruthenium activity in the tin location was $-18 \%$ of that in the ruthenium peak.

\subsubsection{Ammonia Scrubber Solution Distillation Without Additives}

The results of a long-term distillation run of 1.2-mo-01d ASF without additives (Run R2) are summarized in Figure 4.23, where the concentrations of ${ }^{106} \mathrm{Ru},{ }^{113} \mathrm{Sn}$, and ${ }^{137} \mathrm{Cs}$ in the distillate are plotted against the total volume of distillate collected. Each of these three radionuclides behaved differently.

The ${ }^{137}$ Cs content of the distillate was initially zero and increased gradually as the distillation progressed (and the concentration in the evaporator bottoms increased). Within the scatter of the experimental data, the ${ }^{137} \mathrm{Cs}$ concentration in the distillate was represented by the equation:

$$
\left[{ }^{137} C s\right]_{D}=\frac{\left[{ }^{137} C s\right]_{B}}{2 \times 10^{5}}
$$


Initial pot solution $=\mathrm{H}_{2} \mathrm{O}(25 \mathrm{~mL})$

Feed contains $2200{ }^{106} \mathrm{Ru} \mathrm{c} / \mathrm{m}, \mathrm{mL}$ and $3200{ }^{137} \mathrm{Cs} \mathrm{c} / \mathrm{m}, \mathrm{mL}$

Distillation Rate $=\approx 1 \mathrm{~mL} / \mathrm{min}$

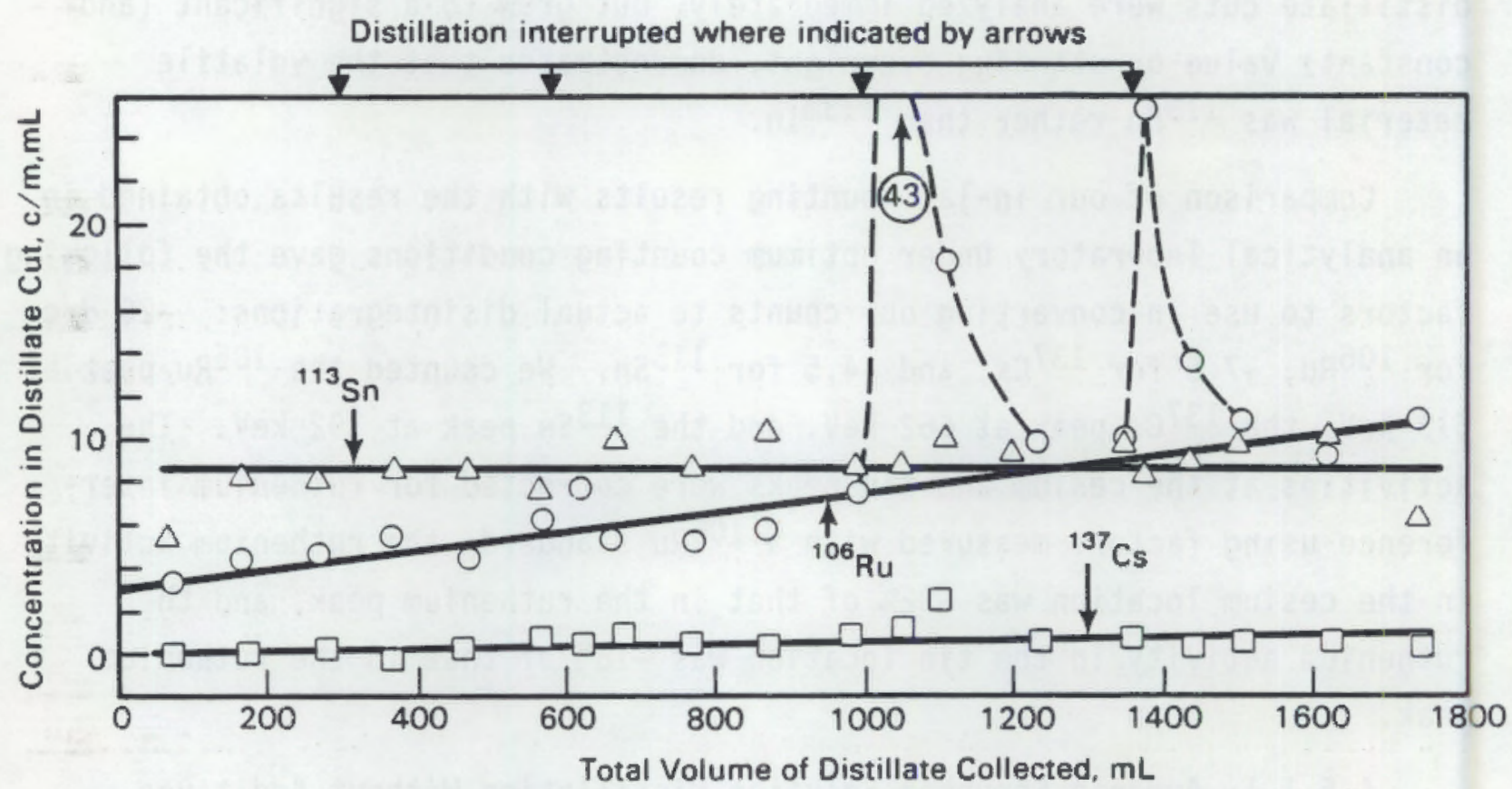

FIGURE 4.23. Radionuclide Concentrations in ASD from Distillation Without Additives (Run R2)

where the subscripts $D$ and $B$ refer to the concentrations in the distillate and the bottoms solution, respectively. This behavior is as expected for a nonvolatile element such as cesium in an evaporator operating with a de-entrainment factor of $2 \times 10^{5}$.

The ${ }^{113}$ Sn behavior was completely different than the ${ }^{137} \mathrm{Cs}$ behavior; the ${ }^{113} \mathrm{Sn}$ concentration in the distillate was constant throughout the run. This behavior is represented by the equation:

$$
\left[{ }^{113} S n\right]_{D}=k\left[{ }^{113} S n\right]_{F}
$$

where the subscript $D$ refers to the concentration in the distillate (as before), the subscript $F$ refers to the concentration in the feed, and $k$ represents a constant. That is, the ${ }^{113} S n$ concentration in the distillate is 
a constant fraction ( $k$ ) of that in the feed (the ASF). Our data do not allow us to give a value of $k$, but it is thought that it might be unity (e.g., all of the ${ }^{113} \mathrm{Sn}$ is volatilized). Analysis of a feed sample by high resolution gamma spectroscopy gave a reported ${ }^{113}$ Sn concentration of $84 \pm 82 \mathrm{~d} / \mathrm{m}, \mathrm{mL}$, which converts to $19 \pm 18 \mathrm{c} / \mathrm{m}$, mL for our in-lab counter. This range certainly includes the $-9 \mathrm{c} / \mathrm{m}, \mathrm{mL}$ concentration that was found in the distillate in the experiment.

The behavior exhibited by ${ }^{106}$ Ru was different than that exhibited by either ${ }^{137} \mathrm{Cs}$ or ${ }^{113} \mathrm{Sn}$. For one thing, high ${ }^{106} \mathrm{Ru}$ volatilization occurred when distillation was restarted after some (but not al1) shutdown periods. Such a restart phenomenon is obviousiy of interest, but it does not really affect the plant situation because the plant evaporator is not run in the frequent stop/restart mode. The further discussion of ${ }^{106} \mathrm{Ru}$ behavior will center on the trends observed aside from this restart phenomenon.

The concentration of ${ }^{106} \mathrm{Ru}$ in the ASD of Run R2 (Figure 4.23) was appreciable from the beginning (as was the concentration of ${ }^{113} \mathrm{Sn}$ ), and increased gradually over the course of the run (as did ${ }^{137} \mathrm{Cs}$ ). These data are fit quite well by the equation

$$
[R u]_{D}=\frac{[R u]_{F}}{730}+\frac{[R u]_{B}}{1.9 \times 10^{4}}
$$

that is, the concentration in the distillate results from both a portion of that in the feed $(\sim 0.14 \%)$ and a portion of that in the bottoms solution. The contribution from the bottoms solution is -tenfold greater than in the ${ }^{137} \mathrm{Cs}$ case discussed earlier; therefore, a factor other than entrainment must be important in the ${ }^{106} \mathrm{Ru}$ case. Such a factor could be the presence in the feed of a ${ }^{106}$ Ru species having a low volatility, or it could be the gradual conversion of a small fraction of the nonvolatile species in the bottoms solution to volatile species.

To further investigate the volatile species, some of the (2-wk-aged) distillate cuts from Run R2 were combined and used as feed for a second distillation run (Run R4). For this run, the initial pot solution was a 
portion of an early distillate cut (containing $4.3 \mathrm{c} / \mathrm{m}$, mL ${ }^{106} \mathrm{Ru}$ ) while the feed was a composite of three later distillate cuts and contained $6.7 \mathrm{c} / \mathrm{m}, \mathrm{mL}$ ${ }^{106} \mathrm{Ru}$. In this run, $100 \mathrm{~mL}$ of feed were processed and four distillate cuts were collected. The ${ }^{106} \mathrm{Ru}$ concentrations in these cuts were essentially constant at $2.2 \pm 0.4 \mathrm{c} / \mathrm{m}$, mL, which is $-33 \%$ as high as the feed concentration [giving a ruthenium decontamination factor (DF) of 3.0 ]. The ${ }^{113} \mathrm{Sn}$ concentrations in two of these cuts were $4.2 \pm 0.5 \mathrm{c} / \mathrm{m}$, mL, which is $-75 \%$ as high as the feed concentration (giving a tin DF of 1.3). Comparison of these data with the results of Run R2 shows that the second distillation was much less effective than the first distillation in reducing the ${ }^{106} \mathrm{Ru}$ concentration. The ${ }^{106}$ Ru DF observed here was comparable to that observed by earlier workers with actual plant ASD, which indicates that our results were indeed comparable to those obtained in the plant.

Run R8 also addressed radionuclide volatilization during ASF evaporation in the absence of additives. This run employed raw water from the PUREX plant, as is used in the ammonia scrubber there, for the fivefold dilution of the (3.5-mo-01d) declad condensate to the desired ASF composition and for the initial pot solution, instead of distilled water as was used in Run R2. The ${ }^{106} \mathrm{Ru}$ concentrations in the distillate over the first $300 \mathrm{~mL}$ were essentially identical to those observed under the same conditions in Run R2, demonstrating that neither the source of the water nor the aging of the declad condensate had an effect (or that they had offsetting effects, which is not considered to be likely). There was also no effect of water source on ${ }^{113} \mathrm{Sn}$ volatilization; the lower ${ }^{113} \mathrm{Sn}$ concentrations observed in Run $\mathrm{R} 8$ were as expected for the decay of ${ }^{113} \mathrm{Sn}\left(t_{1 / 2}=118 \mathrm{~d}\right)$ in the interval between Runs R2 and R8.

Another point addressed in Run R8 was the effect of boil-up rate on radionuclide volatilization. Lowering this rate from 1.0 to $0.4 \mathrm{~mL} / \mathrm{min}$ had no effect on the radionuclide concentrations in the distillate over the brief (75 mL of distillate) period of study.

\subsubsection{Use of Permanganate to Reduce ${ }^{106} \mathrm{Ru}$ Volatilization}

The use of permanganate to suppress ${ }^{106}$ Ru volatilization when ammonia scrubber solution is distilled was tested both in the presence and absence of 
sodium hydroxide. Reduced ${ }^{106}$ Ru volatilization was obtained initially in both cases, but the presence of sodium hydroxide had a markedly deleterious effect after the permanganate had been destroyed/consumed.

\section{Tests with Alkaline Permanganate}

Two experiments were done to assess the use of alkaline permanganate in the evaporator bottoms to reduce the volatilization of ${ }^{106} \mathrm{Ru}$; one (Run R3) used a potassium permanganate concentration of $0.01 \underline{\mathrm{M}}$ and the other (Run R5) used a concentration of $0.1 \mathrm{M}$. The results are summarized in the plots shown in Figure 4.24. The dotted lines on these plots represent the results that were obtained in Run R2 in the absence of any additive, corrected for ${ }^{113} \mathrm{Sn}$ decay that occurred since Run R2 was done.

The presence of alkaline permanganate resulted in significant decreases in the concentrations of both ${ }^{106} \mathrm{Ru}$ and ${ }^{113} \mathrm{Sn}$ in the distillate, and had little or no effect on the ${ }^{137}$ Cs concentration. However, the effect was rather short-lived, lasting only $\sim 9$ pot volumes of throughput in the $0.01 \underline{M}$ $\mathrm{KMnO}_{4}$ case and 28 pot volumes of throughput in the $0.1 \mathrm{M} \mathrm{KMnO}{ }_{4}$ case. Very importantly, the concentration of ${ }^{106} \mathrm{Ru}$ in the distillate then became higher than it was when no additive was used. This appears to be a significant drawback to the use of alkaline permanganate if many pot volumes of throughput are desired, as was the case when this work was done.

The point at which alkaline permanganate ceased to be effective appeared to coincide quite well with the point at which the permanganate color had disappeared. The fact that the permanganate lifetime was only -threefold longer in the experiment at a tenfold higher permanganate concentration indicates that factors other than reaction with something in the ASF are important to the disappearance of the permanganate (e.g., thermal decomposition). If thermal decomposition is indeed the major factor that limits the permanganate lifetime, then operation at lower throughput rates would allow processing of even fewer pot volumes of throughput than was achieved in these runs.

The manganese dioxide solid formed by the reduction/decomposition of the permanganate was readily dispersable and slurpable. The volume occupied by the settled solids amounted to $\sim 5$ to $10 \%$ of the pot solution volume. These 
Initial Pot Solution $=0.01 \mathrm{M} \mathrm{KMnO}_{4}(25 \mathrm{~mL})$

Feed Contains $\sim 2200{ }^{106} \mathrm{Ru} \mathrm{c} / \mathrm{m}, \mathrm{mL}$ and $\sim 3200{ }^{137} \mathrm{Cs} \mathrm{c} / \mathrm{m}, \mathrm{mL}$

Distillation Rate $\sim 1 \mathrm{~mL} / \mathrm{min}$

Dashed lines indicate results expected without additive

(Figure 4.23, corrected for Sn decay)

$$
\text { Run A3 Run R5 }
$$

Initial pot solution $=0.1 \underline{\mathrm{M}} \mathrm{KMnO}_{4}+\quad$ Initial pot solution $=0.1 \underline{\mathrm{M}} \mathrm{KMnO}_{4}+$
$0.1 \mathrm{M} \mathrm{NaOH}(25 \mathrm{~mL})$
$0.1 \underline{\mathrm{M}} \mathrm{NaOH}(25 \mathrm{~mL})$

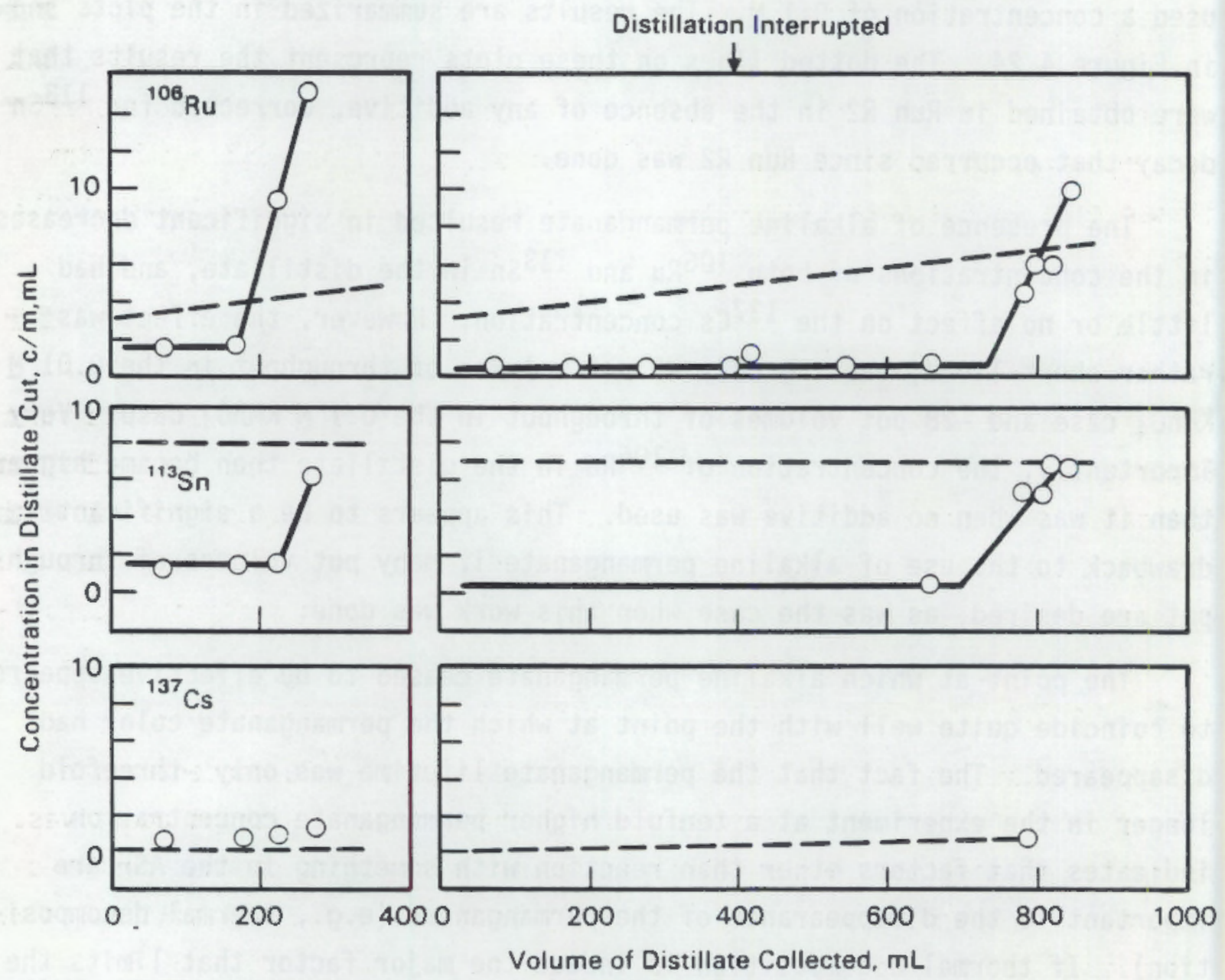

FIGURE 4.24. Radionuclide Concentrations in ASD with Alkaline Permanganate Added to Evaporator Bottoms 
solids contained appreciable amounts of the added radionuclides; the settled supernatant solution from Run R5 contained only $35 \%$ of the expected ${ }^{106} \mathrm{Ru}$ and $70 \%$ of the expected ${ }^{137} \mathrm{Cs}$. A sample of this stirred slurry showed $92 \%$ of the expected ${ }^{106} \mathrm{Ru}$ and $95 \%$ of the expected ${ }^{137} \mathrm{Cs}$, demonstrating that the overall material balance in this run was very good.

\section{Tests with Neutral Permanganate}

The effects of doing the ASF distillation from a bottoms solution containing neutral permanganate were initially similar to the effects observed with alkaline permanganate, but were different in an important respect after the permanganate had been reduced/decomposed. With neutral permanganate, the concentration of ${ }^{106} \mathrm{Ru}$ in the distillate did not become higher than in the no-additive case, as it did in the alkaline permanganate case just discussed.

Results of the first neutral permanganate run (R6) are shown in Figure 4.25. Throughout the first day's operation, the concentration of ${ }^{106} \mathrm{Ru}$ in the distillate ran $-1.5 \mathrm{c} / \mathrm{m}$, mL, which is a factor of two to three lower than was measured without additives (Figure 4.23). Visual observations indicated that the permanganate had been completely reduced/decomposed by the end of the first day, but that some permanganate remained until near the end of the day. Thus, the period required to give complete reduction/decomposition of permanganate was - twofold greater here with neutral permanganate than it was in Run R3 with alkaline permanganate at the same concentration.

When distillation was resumed the next day, the ${ }^{106} \mathrm{Ru}$ concentration stayed below (except for a start-up burst) that measured without additives. As mentioned earlier, such behavior is in marked contrast to that observed with alkaline permanganate, where markedly increased ${ }^{106} \mathrm{Ru}$ volatilization was observed after the permanganate had disappeared.

Shortly after distillation was again resumed (after a 4-day interval), potassium permanganate was added to the pot solution to make its concentration $0.01 \mathrm{M}$ again. The ${ }^{106} \mathrm{Ru}$ concentration in the distillate decreased rapidly to $-1.5 \mathrm{c} / \mathrm{m}, \mathrm{mL}$ before beginning a gradual increase. This behavior indicates that prolonged evaporator operation with 10 w ${ }^{106} \mathrm{Ru}$ volatilization 
Initial Pot Solution $=0.01 \underline{\mathrm{M} \mathrm{KMnO}} 4(25 \mathrm{~mL})$

Feed Contains $\sim 2100{ }^{106} \mathrm{Ru} \mathrm{c} / \mathrm{m}, \mathrm{mL}$ and $\sim 3200{ }^{137} \mathrm{Cs} \mathrm{c} / \mathrm{m}, \mathrm{mL}$

Distillation Rate $\sim 1 \mathrm{~mL} / \mathrm{min}$

Dashed lines indicate results expected without additive

(Figure 4.23, corrected for Sn decay)

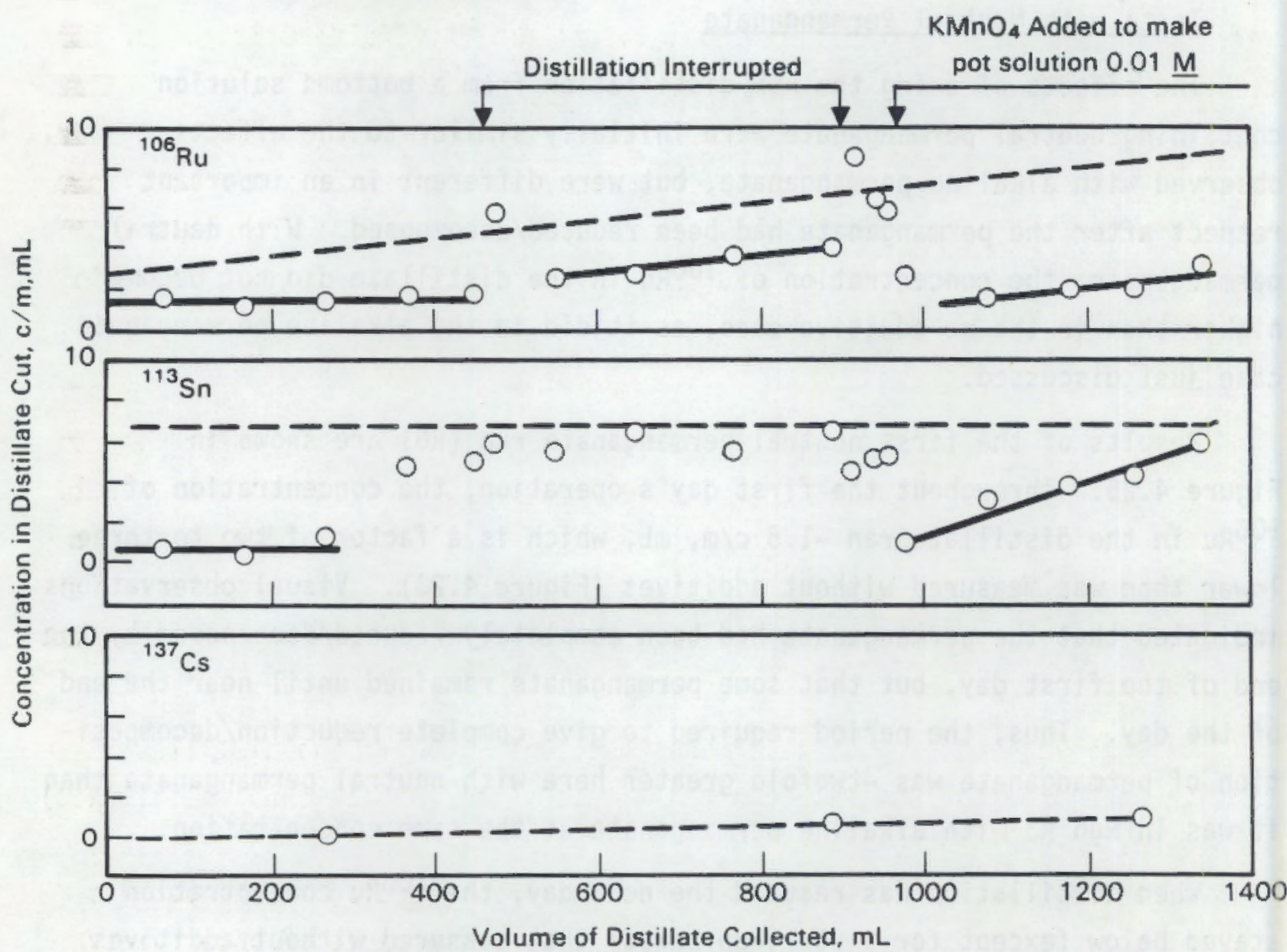

FIGURE 4.25. Radionuclides in ASD with Neutral Permanganate Added to Evaporator Bottoms (Run R6, with distilled water)

could be achieved by periodically adding fresh potassium permanganate so that its concentration never drops to zero.

The behavior of ${ }^{113} \mathrm{Sn}$ in Run $R 6$ is also of interest. Its concentration in the distillate was initially markedly lower than in the no-additive case, but it increased to the no-additive level before the end of the first day and remained near there during the operation with no residual permanganate. The 
${ }^{113} \mathrm{Sn}$ concentration dropped dramatically when fresh potassium permanganate was added but then gradually climbed back to near the no-additive level.

The ${ }^{137} \mathrm{Cs}$ behavior in Run $\mathrm{R} 6$ was essentially identical to that in Run R2 with no additive.

Another run (R7) was made with neutral permanganate, but this time the water used in the initial pot solution and in the (fivefold) dilution of declad condensate to ASF was raw water from the PUREX plant instead of distilled water as in Run R6. This test was made to determine if such water, which is used in the ammonia scrubber in the plant, contains impurities that would adversely affect permanganate effectiveness. The data from this run are shown in Figure 4.26; the ${ }^{106} \mathrm{Ru}$ and ${ }^{113} \mathrm{Sn}$ results were quite comparable to those in the neutral permanganate run with distilled water (Figure 4.25), but an important difference in ${ }^{137}$ Cs behavior was observed.

The fact that much more ${ }^{137} \mathrm{Cs}$ was found in the distillate during the last half of this run indicates that entrainment was more severe than usual. The data at the time the ${ }^{137} \mathrm{Cs}$ content of the distillate was highest give a de-entrainment factor of $2.5 \times 10^{4}$, which is reightfold lower than that normally observed. The reason for this is not known; no bumping or excessive foaming was observed.

This higher entrainment also means that the ${ }^{106} \mathrm{Ru}$ in the distillate contains a higher-than-normal fraction of entrained (rather than volatilized) ruthenium. The ${ }^{106} \mathrm{Ru}$ concentration due to entrainment cannot be estimated with certainty because the ${ }^{106} \mathrm{Ru}$-to- ${ }^{137} \mathrm{Cs}$ ratio in solution in the pot was not the same as the total ${ }^{106} \mathrm{Ru}-\mathrm{to}_{0}-{ }^{137} \mathrm{Cs}$ ratio, and because of uncertainty about the mechanism of entrainment.

The ${ }^{106} \mathrm{Ru}$-to- ${ }^{137} \mathrm{Cs}$ ratio in the pot solution and the material balances were addressed at the end of this run. The final pot solution slurry (27 mL) was mixed and slurped into a bottle, to which was added a 5 -mL water rinse of the pot. Analysis of a sample of this stirred mixture showed $92 \%$ of the added ruthenium and $96 \%$ of the added cesium. After the solids had been allowed to settle overnight, analys is of the supernatant solution showed only $23 \%$ of the added ruthenium and $73 \%$ of the added cesium; subtraction of these results from the others leads to the conclusion that $69 \%$ of the ruthenium and 
Initial Pot Solution $=0.01 \mathrm{M} \mathrm{KMnO}_{4}(25 \mathrm{~mL})$

Feed Contains $\sim 2300{ }^{106} \mathrm{Ru} \mathrm{c} / \mathrm{m}, \mathrm{mL}$ and $\sim 3200{ }^{137} \mathrm{Cs} \mathrm{c} / \mathrm{m}, \mathrm{mL}$

Distillation Rate $\sim 1 \mathrm{~mL} / \mathrm{min}$

Dashed lines indicate results expected without additive

(Figure 4.23, corrected for Sn decay)

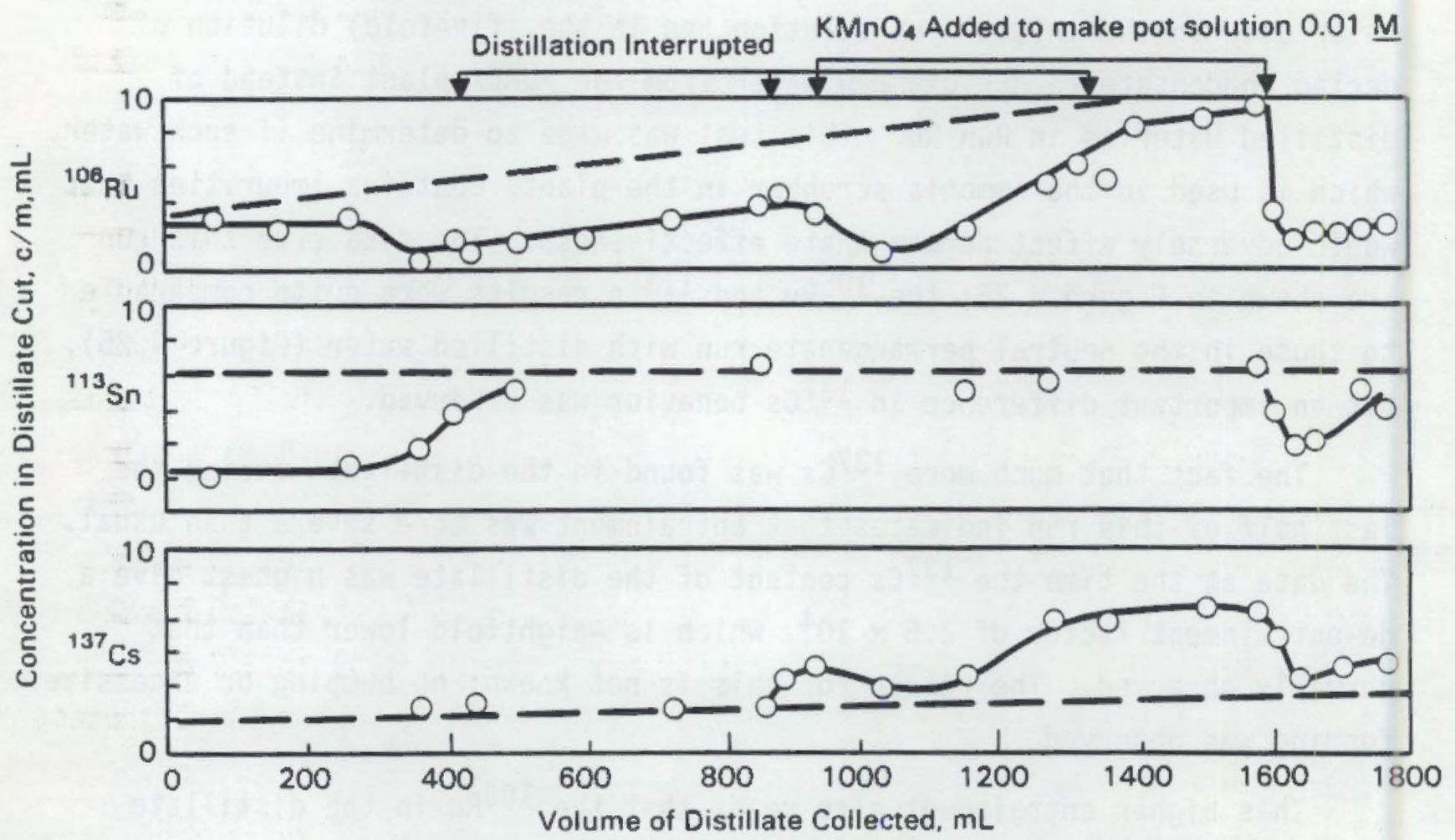

FIGURE 4.26. Radionuclides in ASD Made with PUREX Raw Water, with Neutral Permanganate Added to Evaporator Bottoms (Run R7)

$23 \%$ of the cesium were associated with the suspendable solids. The evaporator pot was then cleaned by heating in $0.2 \underline{M}$ oxalic acid; this solution contained $3 \%$ of the added ruthenium and $1 \%$ of the added cesium. The overa 11 material balances in this experiment were thus $95 \%$ for ruthenium and $97 \%$ for cesium.

\subsubsection{Use of Peroxide to Reduce ${ }^{106}$ Ru Volatilization}

Hydrogen peroxide was tested next as an additive to suppress ruthenium volatilization during distillation of ammonia scrubber solution. This material was tested in an effort to suppress volatilization using a chemical 
that would not add solids to the evaporator bottoms. Earlier work by others had indicated that hydrogen peroxide suppresses ruthenium volatilization, al though not to the extent achieved with potassium permanganate.

Because of the thermal instability of hydrogen peroxide, it was added semicontinuously during the course of the experiments. In the first experiments, it was added to the ASF but later was added in a separate stream. Peroxide was added to $50-\mathrm{mL}$ portions of the ASF when that method of addition was used.

The first test of peroxide addition (Run R9) involved testing of several different conditions. As is indicated in Figure 4.27, this run was begun with a $0.1 \mathrm{M} \mathrm{H}_{2} \mathrm{O}_{2}$ solution in the pot and the ASF also contained $0.1 \mathrm{M} \mathrm{H}_{2} \mathrm{O}_{2}$. Raw water from PUREX was used in preparing these solutions. Only a slight improvement in the ruthenium concentration of the ASD was initially observed, so the hydrogen peroxide concentration in the feed was increased to $0.4 \mathrm{M}$. This move was counterproductive; the ruthenium content of the ASD increased to above where it had been in the no-additive experiment. Return to $0.1 \mathrm{M}$ $\mathrm{H}_{2} \mathrm{O}_{2}$ in the feed then led to a decrease of ruthenium in ASD to a low level that remained relatively constant for an extended period (300 to $850 \mathrm{~mL}$ of $A S D$ ). No effect of boil up rate (between 1 and $0.5 \mathrm{~mL} / \mathrm{min}$, which corresponds to approximately 2 and 1 pot volumes/h) was observed during this period. These results look very good, but it was felt that a lower peroxide concentration might be more desirable from a cost standpoint. Before testing a lower peroxide concentration in this experiment, it was necessary to assure that there was no residual effect from the peroxide added earlier.

Operation was thus continued without peroxide addition to the feed; low ruthenium in ASD was observed unti1 the apparent concentration of peroxide in the pot solution decreased to $\leq 0.005 \underline{M}$ (as determined by adding a portion of the solution to $0.5 \mathrm{M} \mathrm{H}_{2} \mathrm{SO}_{4}$ and titrating with potassium permanganate solution). Continued operation with no hydrogen peroxide in the ASF led to an increase to -3 ruthenium $\mathrm{c} / \mathrm{m}, \mathrm{mL}$ in ASD (which is that observed initially in runs with no additive).

The peroxide concentrations in the feed and pot solutions were then (after $-1270 \mathrm{~mL}$ of ASD) adjusted to $0.005 \underline{M}$ and $0.02 \underline{M}$, respectively, to 
Initial Pot Solution $=0.1 \underline{\mathrm{M}} \mathrm{H}_{2} \mathrm{O}_{2}(25 \mathrm{~mL})$

Feed Contains $\sim 2100{ }^{106} \mathrm{Ru} \mathrm{c} / \mathrm{m}, \mathrm{mL}$ and $\sim 3200{ }^{137} \mathrm{Cs} \mathrm{c} / \mathrm{m}, \mathrm{mL}$

Dashed fines indicate results expected without additive

(Figure 4.23, corrected for Sn decay)

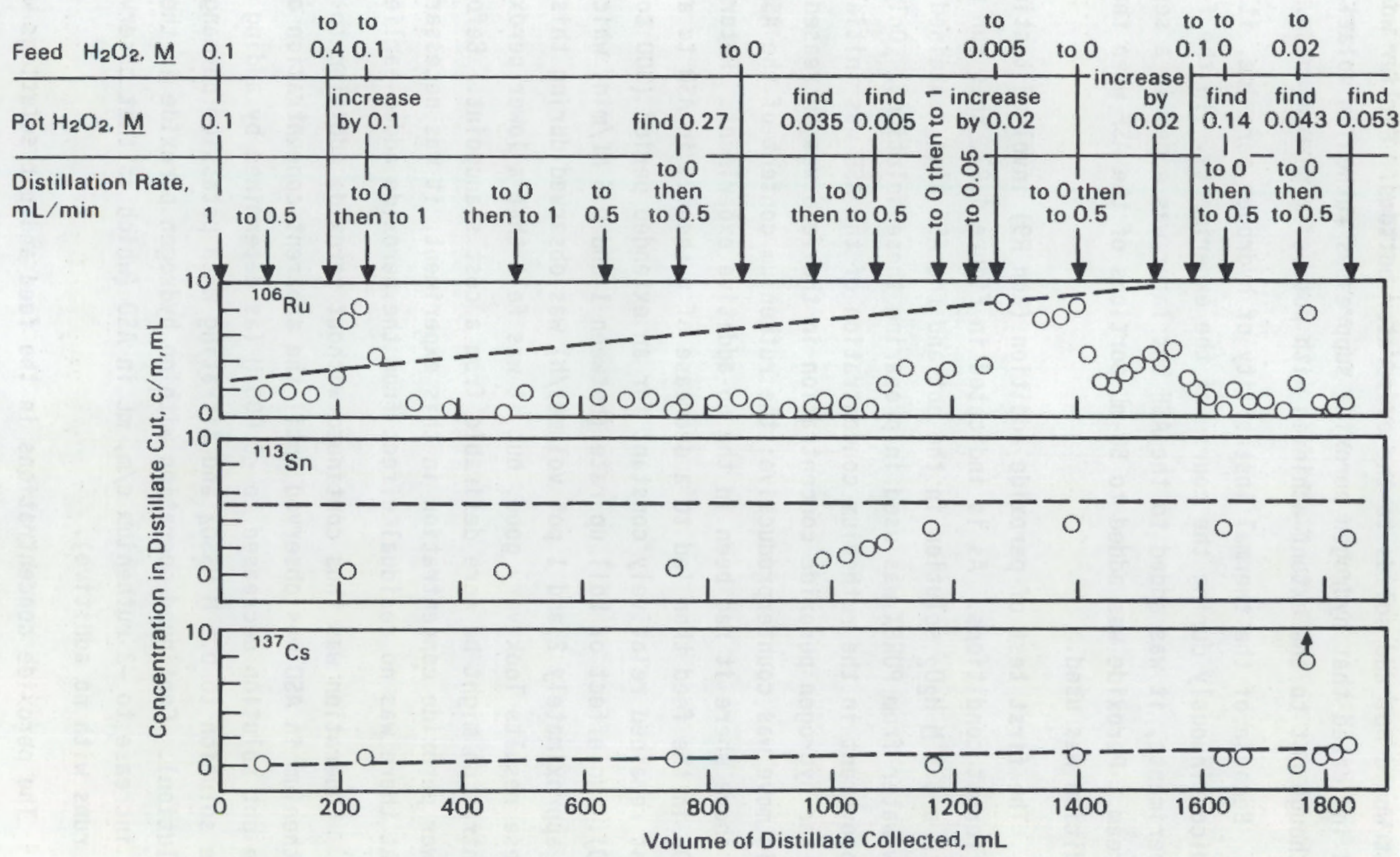

FIGURE 4.27. Radionuclides in ASD Distilled with Peroxide Present (Run R9) 
maintain $\sim 0.02 \mathrm{M} \mathrm{H}_{2} \mathrm{O}_{2}$ in the pot solution in anticipation that the ruthenium in ASD would drop to the level observed earlier at that apparent pot solution concentration. However, this change resulted in increased ruthenium in the ASD instead. The reason for the apparent discrepancy between this result and that observed earlier is not known. The chemical system is obviously complex.

After several minor adjustments were not successful in returning ruthenium in the ASD to the low level, the feed peroxide concentration was again increased to $0.1 \underline{\mathrm{M}}$ (at $1590 \mathrm{~mL}$ of ASD) and low ruthenium in ASD was attained rapidly. After a period of operation without hydrogen peroxide in the ASD, to again reduce the peroxide concentration in the pot solution, operation was resumed with $0.02 \underline{\mathrm{M} \mathrm{H}} \mathrm{H}_{2}$ in the ASF. We then observed a "restart blip" (that appeared to be due to entrainment), but low ruthenium in the ASD was soon re-established.

The behaviors of ${ }^{113} \mathrm{Sn}$ and ${ }^{137} \mathrm{Cs}$ during this run with peroxide addition are also of interest. Near-zero concentrations of ${ }^{113} \mathrm{Sn}$ were maintained throughout the first half of the run, but the concentration then increased to near where it would have been without an additive. Entrainment (as measured by the ${ }^{137}$ Cs content of the distillate) was very low in this run, except for one sample inmediately following a resumption of boiling.

Material balance measurements at the end of Run R9 gave $76 \%$ of the expected ruthenium and $109 \%$ of the expected cesium in the slurry of solution and solids in the pot at the end of this run (the quantities found in the supernatant solution amounted to $38 \%$ for ruthenium and $90 \%$ for cesium). The caked solids in the pot were found to contain 19\% of the added ruthenium, but $0 \%$ of the added cesium. Overall balances were thus $95 \%$ for ruthenium and $109 \%$ for cesium.

In summary, the results of Run R9 pointed out that the addition of hydrogen peroxide can be very effective in lowering the concentration of ruthenium in ASD but that things occur that are not understood. A peroxide concentration of $0.1 \underline{M}$ in ASF gives very good results, concentrations of $0.4 \underline{M}$ or $0.005 \underline{M}$ do not give good results, and a concentration of $0.02 \underline{M}$ might be sufficient to give low ruthenium in ASD. 
Run R10 was made to get more data at low peroxide concentrations. In this run, we also investigated the effects of 1) adding the peroxide as a separate stream instead of premixing it with ASF, and 2) having a higher ammonium hydroxide concentration in ASF. These results are shown in Figure 4.28. Raw water from PUREX was used in this experiment, as in the previous run.

The initial pot solution in Run $\mathrm{R} 10$ was $0.05 \mathrm{M} \mathrm{H}_{2} \mathrm{O}_{2}$, which was the apparent concentration measured at the end of Run R9. We used $0.01 \mathrm{M} \mathrm{H}_{2} \mathrm{O}_{2}$ in ASF because we planned to run at $1 \mathrm{~mL} / \mathrm{min}$ initially and this feed addition rate would give the same hydrogen peroxide addition rate as was used at the end of Run R9. This set of conditions did give low ruthenium in ASD; however, when the boil-up rate was decreased to $0.5 \mathrm{~mL} / \mathrm{min}$ and hydrogen peroxide in ASF was increased to $0.02 \mathrm{M}$ (the same hydrogen peroxide addition rate), ruthenium in ASD increased dramatically. This is another instance where a surprising and unexplained result occurred.

As operation continued at these conditions, ruthenium in ASD gradually decreased and eventually became very low. A ruthenium spike then occurred (at $310 \mathrm{~mL}$ ) when an equipment malfunction resulted in an interval at a low boil-up rate; ruthenium in ASD returned rapidly to a low value when the normal boil-up rate was reestablished. Another ruthenium spike occurred (at $370 \mathrm{~mL}$ ) on restarting following a shutdown but, again, ruthenium in ASD soon returned to a low value following establishment of stable conditions. The reasons for these ruthenium spikes during off-standard operation are not known. They were taken to indicate that operation with $0.02 \mathrm{M} \mathrm{H}_{2} \mathrm{O}_{2}$ in the feed gave conditions near a "ragged edge" where a fine 1 ine exists between good and bad results.

Accordingly, hydrogen peroxide in ASF was then increased to $0.04 \mathrm{M}$. This gave even lower ruthenium in ASD and less severe spikes resulting from off-standard conditions. For example, when the low distillation rate condition that gave a ruthenium spike to $7 \mathrm{c} / \mathrm{m}$, mL with $0.02 \mathrm{M} \mathrm{H}_{2} \mathrm{O}_{2}$ in ASF was duplicated (as best we could) with $0.04 \mathrm{M} \mathrm{H}_{2} \mathrm{O}_{2}$ in ASF, a ruthenium spike to only $\sim 3 \mathrm{c} / \mathrm{m}$, mL was observed (at $530 \mathrm{~mL}$ ). Also a much smaller ruthenium 
Initial Pot Solution $=0.05 \underline{\mathrm{M} \mathrm{H}} \mathrm{H}_{2} \mathrm{O}_{2}(25 \mathrm{~mL})$

Feed Contains $\sim 2000{ }^{106} \mathrm{Ru} \mathrm{c} / \mathrm{m}, \mathrm{mL}$ and $\sim 3100{ }^{137} \mathrm{Cs} \mathrm{c} / \mathrm{m}$, $\mathrm{mL}$

Dashed lines indicate results expected without additive

(Figure 4.23, corrected for Sn decay)

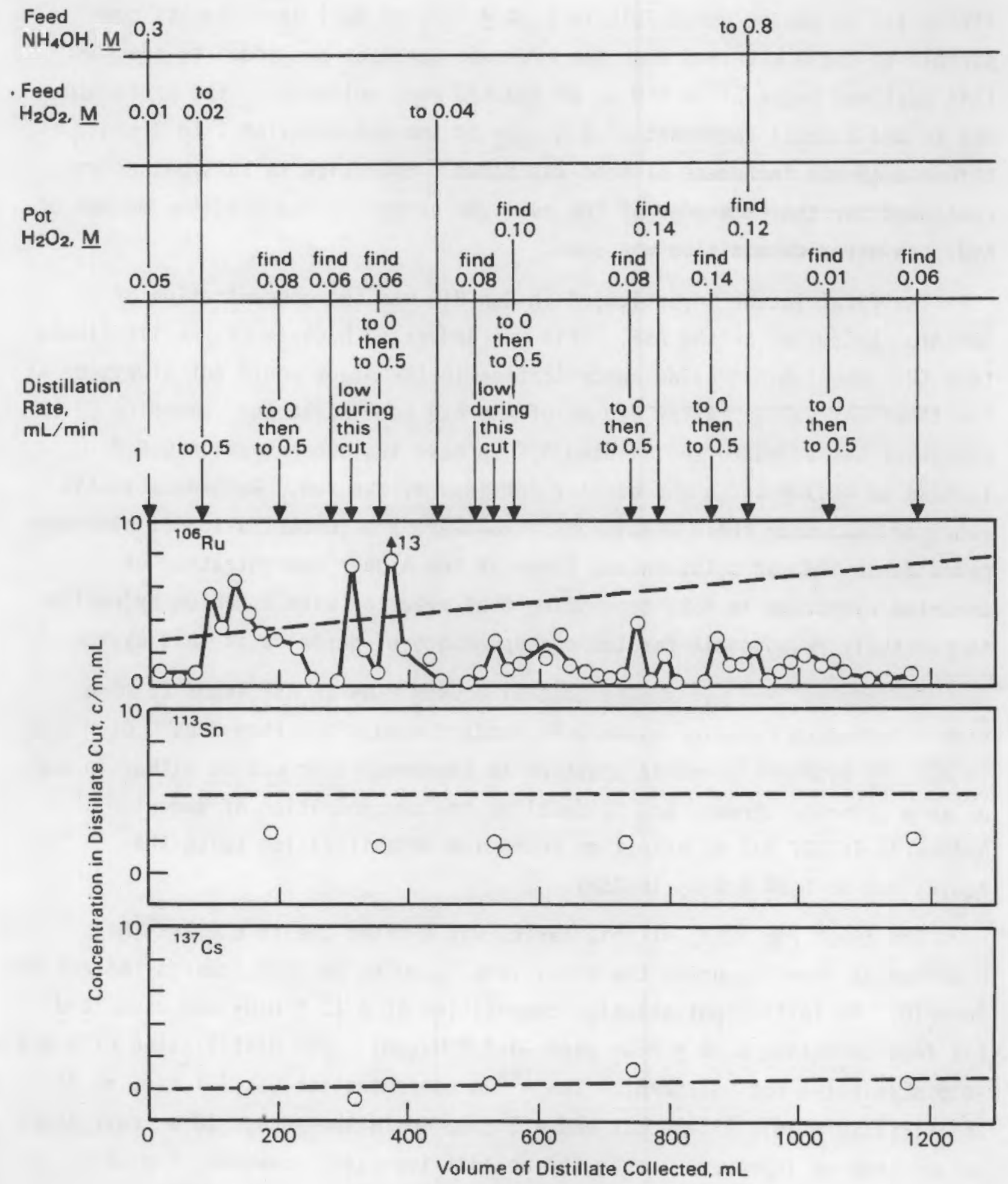

FIGURE 4.28. Second Run on Use of Peroxide to Suppress Ruthenium Volatilization (Run 10) 
spike was observed on subsequent shutdown and restart with $0.04 \mathrm{M} \mathrm{H}_{2} \mathrm{O}_{2}$ in ASF than had been observed with a $0.02 \mathrm{M} \mathrm{H}_{2} \mathrm{O}_{2}$ in ASF.

A test was then made to see if adding hydrogen peroxide in a separate stream (in an amount comparable to $0.04 \mathrm{M} \mathrm{H}_{2} \mathrm{O}_{2}$ in ASF) gave results comparable to those obtained when the hydrogen peroxide was added to the ASF; this test was begun after $660 \mathrm{~mL}$ of ASD had been collected. The procedure was to add a small increment of $5 \mathrm{M} \mathrm{H}_{2} \mathrm{O}_{2}$ to the pot solution 1 to $2 \mathrm{~min}$ before a $(5-\mathrm{mL})$ increment of feed was added. Operation in this manner was continued for the remainder of the run. No effect of changing the method of hydrogen peroxide addition was seen.

The final factor investigated in Run R10 was the concentration of ammonium hydroxide in the ASF. This was addressed because of the likelihood that the ammonium hydroxide concentration in the plant would not always be at the flowsheet value. After $920 \mathrm{~mL}$ of ASD had been collected, ammonium hydroxide was added to the diluted ASF to make its concentration $0.8 \underline{M}$ instead of $\sim 0.3 \underline{M}$ as in the earlier portions of the run. Ruthenium in ASD remained low under these conditions. However, the concentration of hydrogen peroxide in the pot solution was lower at the higher concentration of ammonium hydroxide in ASF, suggesting that reaction with ammonium hydroxide is partially responsible for the disappearance of peroxide in this system.

In summary, Run $\mathrm{R} 10$ showed that 1) $0.04 \mathrm{M} \mathrm{H}_{2} \mathrm{O}_{2}$ in ASF leads to more stable ruthenium behavior under off-standard conditions than does $0.02 \mathrm{M} \mathrm{H}_{2} \mathrm{O}_{2}$ in ASF, 2) hydrogen peroxide addition to the evaporator can be either in ASF or as a separate stream, and 3 ) doubling the concentration of ammonium hydroxide in ASF had no effect on ruthenium volatilization (with the equivalent of $0.04 \mathrm{M} \mathrm{H}_{2} \mathrm{O}_{2}$ in ASF).

The final run (R11) of this series was a brief one to check ${ }^{106} \mathrm{Ru}$ behavior at start-up under the conditions found to be good towards the end of Run R10. An initial pot solution composition of $0.12 \mathrm{M} \mathrm{H}_{2} \mathrm{O}_{2}$ was used, and the feed contained $0.04 \mathrm{M} \mathrm{H}_{2} \mathrm{O}_{2}$ (and $\sim 0.3 \mathrm{M} \mathrm{NH}{ }_{4} \mathrm{OH}$ ). The distillation rate was $\sim 0.5 \mathrm{~mL} / \mathrm{min}(\sim 1$ pot volume $/ \mathrm{h})$. The ${ }^{106} \mathrm{Ru}$ concentration was $2.1 \mathrm{c} / \mathrm{m}, \mathrm{mL}$ in the first $20 \mathrm{~mL}$ distillate cut and $4.5 \mathrm{c} / \mathrm{m}, \mathrm{mL}$ in the second $20-\mathrm{mL}$ cut; these values show no improvement over the no-additive case. However, the next 
$20-\mathrm{mL}$ cut contained only $0.7 \mathrm{c} / \mathrm{m}$, mL and the ${ }^{106} \mathrm{Ru}$ concentration stayed low for another six $20-\mathrm{mL}$ cuts, when the experiment was ended. These results show that these conditions give good suppression of ${ }^{106_{\mathrm{Ru}}}$ volatilization near the start of a run, as well as after an appreciable period of operation, as was demonstrated in Run R10.

\subsubsection{Comparison of Permanganate and Peroxide Treatments}

The choice of whether to use permanganate or peroxide to suppress the volatilization of ruthenium with ASD is not clear cut. Either additive can give a large decrease in ruthenium volatilization under properly controlled conditions, but both peroxide and alkaline permanganate gave increased ruthenium volatilization under some off-standard conditions. Neutral permanganate did not give increased ruthenium volatilization, but increased entrainment was observed in one test; increased entrainment increases the concentration of all fission products in ASD. Peroxide additions must be done continuously or at frequent intervals, while permanganate additions would be required only about once per shift. The required amount of peroxide would cost about 5 to 10 times as much as the required amount of permanganate, but these chemical costs are relatively low (hundreds of dollars per day) and are only a fraction of the total cost of implementing either option. The use of permanganate leads to the formation of manganese dioxide solids; some of these solids would probably deposit on equipment surfaces and would have to be removed periodically. The use of alkaline permanganate would require using a different type of water in the ammonia scrubber; the calcium content of raw water is high, and precipitation of calcium hydroxide would become a problem if use of raw water were continued in conjunction with the addition of alkaline permanganate.

The choice of which additive to use in the plant would probably be based on the perceptions of the plant operating staff regarding the ease of operations.

\subsubsection{Characterization of Declad and Metathesis Solids}

Improved solid/liquid separation in declad and metathesis solution slurries is desired so that the quantity of TRU-containing solids that accompany the solutions will be low enough that the waste mixture can be 
grouted for disposal as low-level waste. Earlier studies (Hodgson et al.

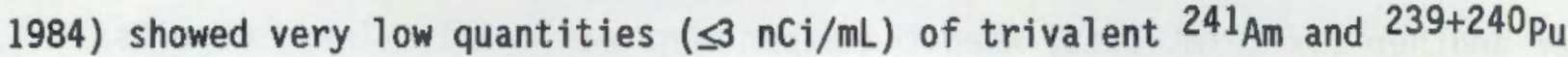
to be soluble in a fresh declad solution; however, extended contact of the solution and solids (in the presence of air) led to an increase in the plutonium solubility, presumably because of oxidation to more highly soluble plutonium (IV). Those workers also showed that the soluble plutonium (IV) content of the declad solution could be reduced to a low level by carrier precipitation on a rare earth fluoride precipitate (e.g., lanthanum fluoride). As was discussed earlier (Section 4.3.3), the solubilities of both americium and plutonium in metathesis solutions are low.

In support of this effort, characterization tests were run on the following: 1) the solids present after the decladding step, 2) the solids resulting from metathesis of a portion of the declad solids, and 3 ) the solids present after rare earth nitrate had been added (to $0.004 \underline{M}$ ) to a portion of the declad solution in order to precipitate rare earth fluorides. The solids used in these tests were obtained during flowsheet simulation Run 12. The characterization tests included measurement of densities, examination by scanning electron microscopy (SEM), and particle size measurements. Applicability of these results is uncertain, but they are presented for completeness and for possible future use.

\subsubsection{Solids Density Measurements}

Two types of density values were obtained; one was the "cake density" and the other was the "displacement density." The cake density is important to evaluating the volume occupied by the solids (and trapped liquid) after settling in a tank or in a centrifuge bowl, while the displacement density is important to evaluating settling rates.

Table 4.17 contains the raw data obtained in these tests, plus the values calculated from the data. The procedure used in these tests was to transfer the solids, along with a small portion of associated solution, to a pre-weighed $15-\mathrm{mL}$ centrifuge tube having a conical bottom. The solids were suspended by pipetting and their settled volume was measured over time. Weighings were then made before and after removing most of the solution above the solids. The solids were settled further by centrifugation and weighings 


\section{TABLE 4.17. Declad and Metathesis Solids Densities}

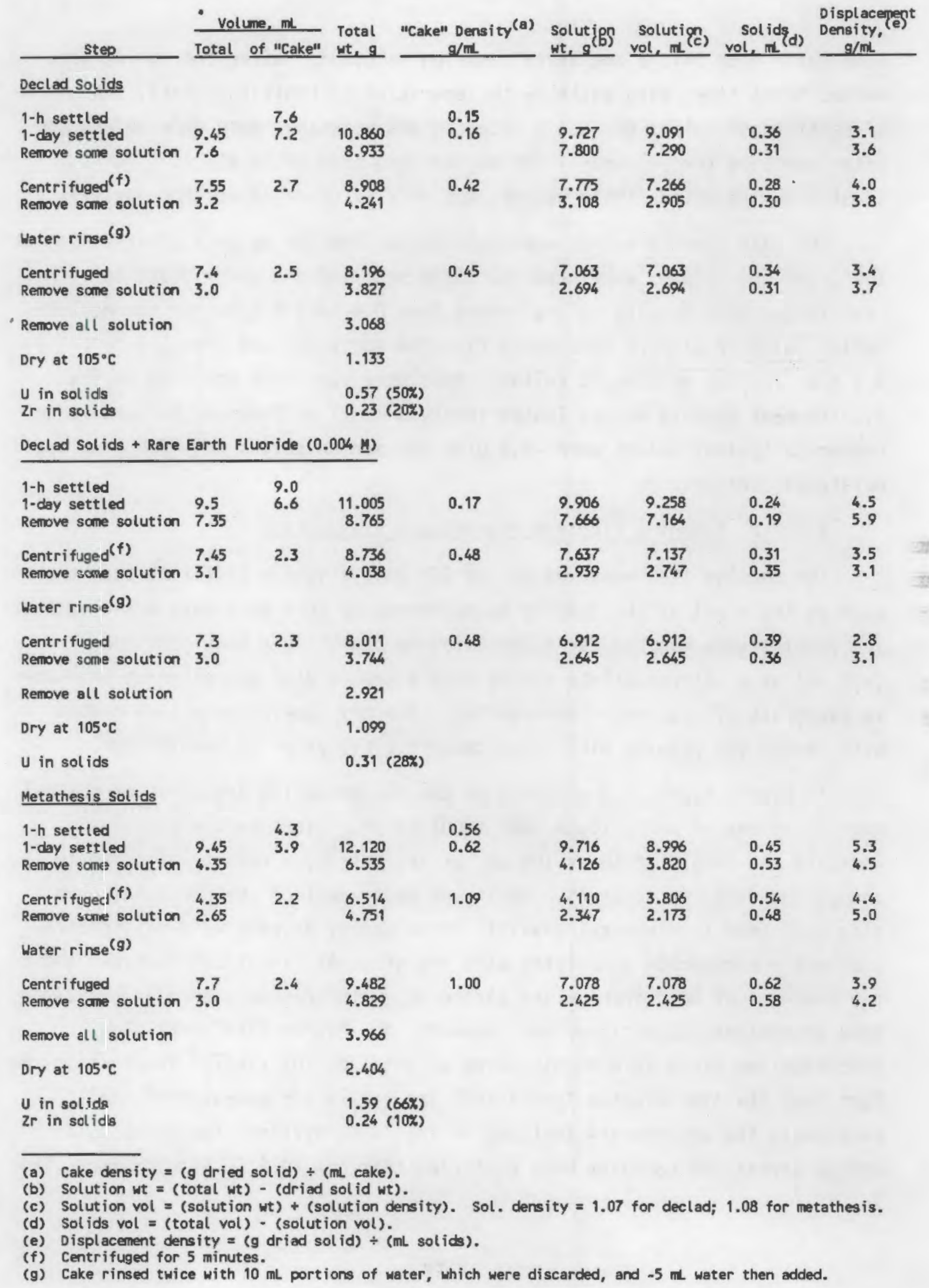


were again made before and after removing solution. After the solids were washed three times with water (with separation by centrifugation), the volume of centrifuged solids was again recorded and weighings were made before and after removing the solution. The solids were then dried at $105^{\circ} \mathrm{C}$ for at least 1 day to obtain their weight, and were later dissolved for analysis.

The cake density values were calculated from the weights after drying at $105^{\circ} \mathrm{C}$ and the volumes were measured after settling and centrifugation. The centrifuged cake density values ranged from 0.4 to $0.5 \mathrm{~g} / \mathrm{mL}$ for the declad solids (with or without rare earth fluoride addition) and from 1.0 to $1.1 \mathrm{~g} / \mathrm{mL}$ for the metathesis solids. Much more variation occurred in the displacement density values (which involved small differences between large numbers); typical values were $-4.0 \mathrm{~g} / \mathrm{mL}$ for declad solids and $-5.0 \mathrm{~g} / \mathrm{mL}$ for metathesis solids.

\subsubsection{Scanning Electron Microscopic Examination}

The samples that were run on the SEM were slightly different than those used at the start of the density measurements in that they were water-washed. The samples were mounted for examination by pipetting a small portion $(\sim 25 \mu \mathrm{L})$ of a stirred dilute slurry onto a smooth disc and allowing the water to evaporate off (at room temperature). The dry samples were then coated with carbon (to provide electrical conductivity) prior to examination.

In Figure 4.29a, SEM pictures of the declad solids are shown at nominal magnifications of $300 \mathrm{X}, 1000 \mathrm{X}$, and $3000 \mathrm{X}$ (marker lines on the pictures indicate the length of 10 or $100 \mu \mathrm{m}$, as indicated); a variety of particle shapes and sizes is apparent. Locations on several of the particles were also subjected to elemental analysis by an energy dispersive $x$-ray spectrophotometry microprobe associated with the SEM. All locations examined showed the presence of both uranium and zirconium, with uranium generally ten times more predominant than zirconium. However, the "straw-like" particles contained ten times as much zirconium as uranium. of special interest is the fact that the high-uranium "particles" are really agglomerates of small particles; the agglomerate featured in the $3000 x$ picture, for example, is $\sim 20 \mu \mathrm{m}$ across but contains many particles that are $\sim 0.3 \mu \mathrm{m}$ in diameter. The 
(a)
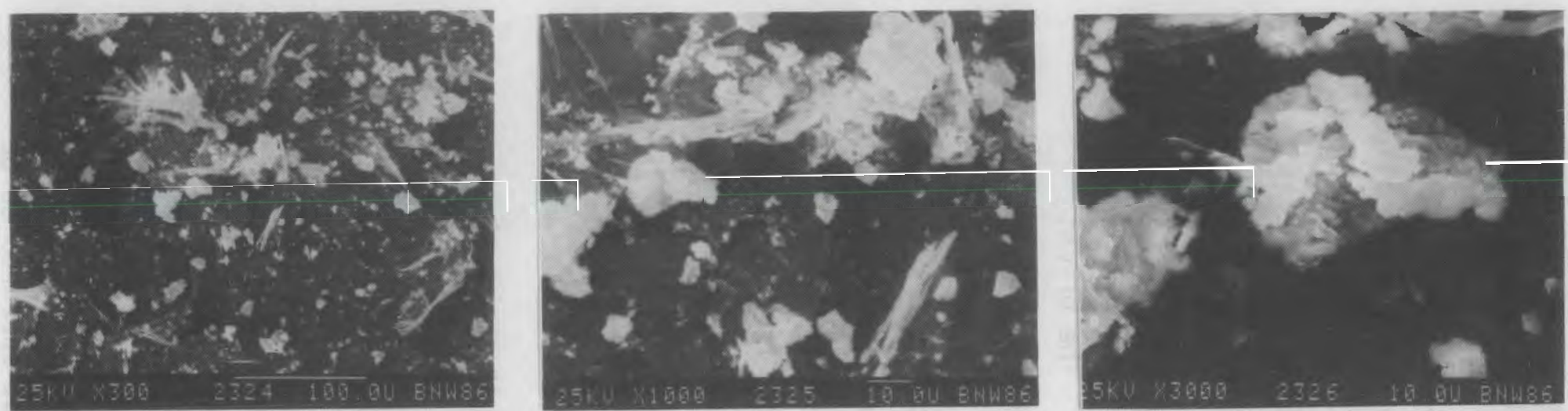

io
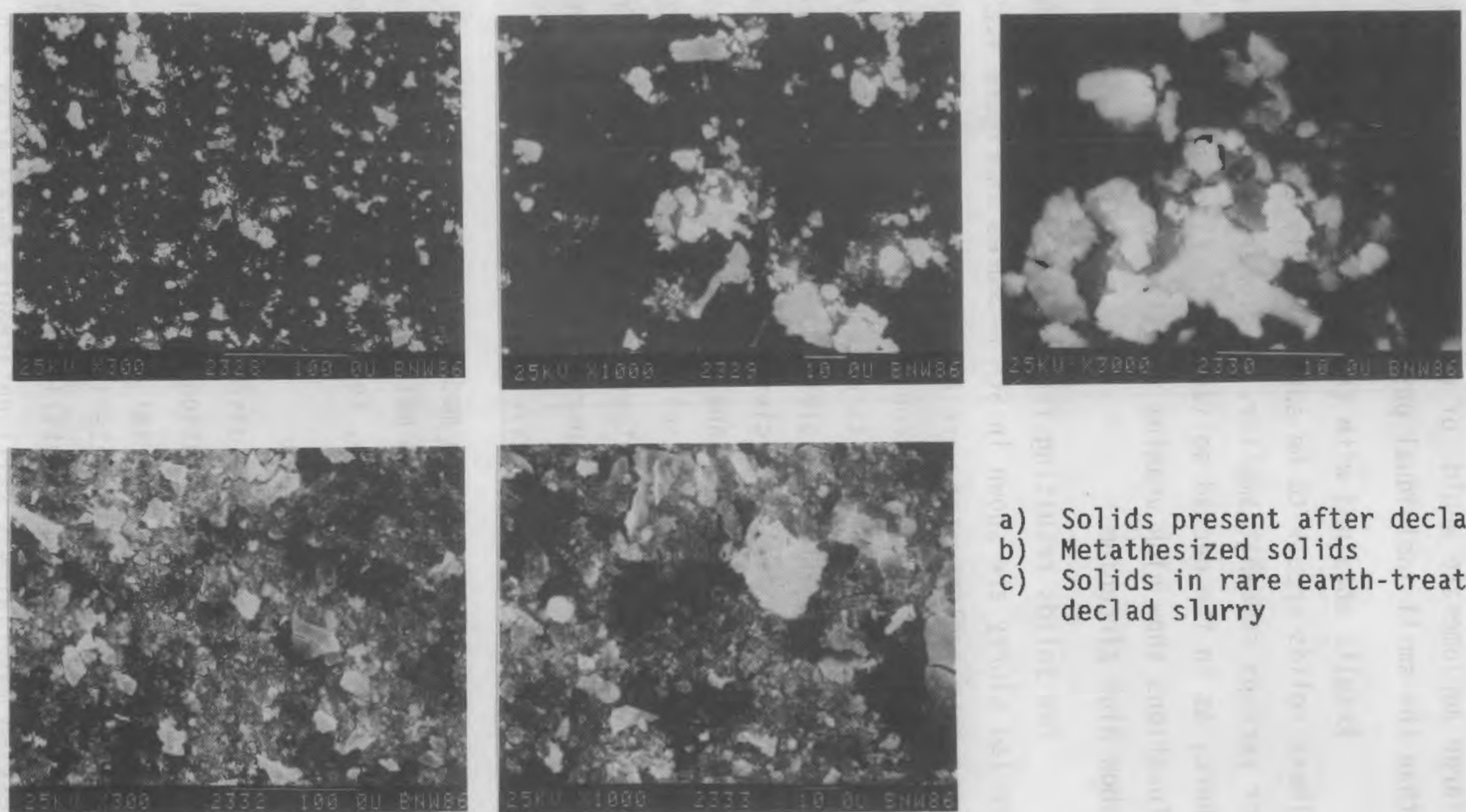

a) Solids present after declad

b) Metathesized solids

c) Solids in rare earth-treated

declad slurry

(c)

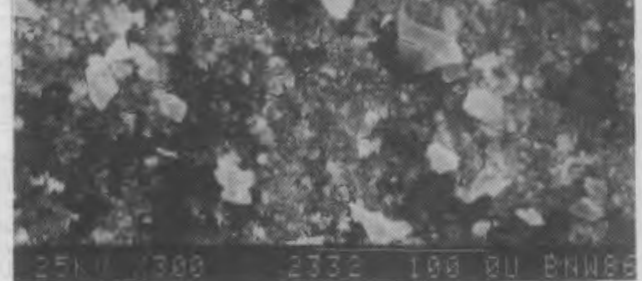

FIGURE 4.29. SEM of Solids Present After Decladding and After Metathesizing 
large agglomerate would, of course, be much easier to remove from solution than the small individual particles.

Results obtained with the metathesized solids are shown in Figure $4.29 \mathrm{~b}$. These solids appear to be approximately the same size as the declad solids, or perhaps somewhat smaller. Agglomeration of small particles also occurs here, as in the declad solids case. Also, as in the declad solids case, most locations show high uranium relative to zirconium but straw-like particles show high zirconium.

The solids resulting from adding rare earth nitrate to a portion of the declad slurry are shown in SEM pictures in Figure 4.29c. The bright appearing agglomerates were high in uranium and low in both zirconium and rare earths. No high zirconium particles were found in this mount. Comparison with the results obtained in the absence of rare earth shows an abundance of small "particles" in the rare earth case; these are presumably rare earth fluoride particles, but microprobe analysis showed approximately equal amounts of uranium and zirconium as well. Sorption/carrying of plutonium onto these particles, which is the reason for adding the rare earth, would not be effective in removing plutonium from the discharged waste unless these small particles are efficiently removed from the solution.

\subsubsection{Particle Size Measurements}

Several efforts were made to determine the sizes of the particles present in the declad and metathesis solution slurries. These efforts met with only 7 imited success, for reasons that are not completely understood.

\section{Declad Solids Sizes}

Visual observations disclosed the presence of at least two types of solids in the declad solution slurry; a heavy material that settled fairly rapidly and a light material that settled only slowly. The smallest particles of the heavy material settled at a rate of $1.0 \mathrm{~cm} / \mathrm{min}$, as indicated by the "trailing edge" settling rate. The ( $8-\mathrm{cm}$-deep) liquid above this settled material was still noticeably murky after $2 \mathrm{~h}$, but appeared to be clear after $20 \mathrm{~h}$. 
A portion of the solids was then analyzed on a sedimentation rate instrument, which deduces the particle size distribution from the change in $x$-ray sorption with time as the settling sample is moved past an $x$-ray beam at a programmed rate that is based on input parameters (solution density and viscosity and particle density). The particle density value used here was $4.0 \mathrm{~g} / \mathrm{cm}^{3}$, which is the approximate particle density measured by solution displacement (Table 4.17).

The sedimentation rate instrument is first zeroed with only solution in the beam and the beam intensity after passing through the stirred slurry is then adjusted to 100 mass percent. After stirring is stopped, the sample cell is moved down through the beam so that the effective settling depth is decreased over time, thus minimizing analysis time. The data output is a plot of cumulative mass percent that is smaller than different equivalent spherical diameters (the diameter of a sphere of the same material that falls under gravity with the same velocity as the particle).

The results obtained with the solids in the diluted declad solution are shown in Figure 4.30a. The apparent mass percent increase to $>100 \%$ demonstrates that something was amiss in this test. The factor thought to be most likely to have caused this problem is use of a particle density input value that was not correct (or not representative of all of the particles); large particles having a somewhat higher density than the input value would settle more rapidly than expected and accumulate in the region being scanned, thus giving a higher solids concentration than in the initial suspension. However, this hypothesis was not tested.

Based on the above hypothesis, the sharp drop in the curve (Figure 4.30a) at $\sim 9 \mu \mathrm{m}$ diameter can be explained as occurring when the dense, settled region dropped below the beam. Whether or not this hypothesis is correct, the data at smaller diameters should be meaningful. These data indicate that particles smaller than $5 \mu \mathrm{m}$ account for $-10 \%$ of the particulate weight.

These same particles were then suspended in a 50:50 glycerine-water mixture (a solvent commonly used with this instrument) and re-run using the appropriate solution density and viscosity input factors. The results of 
a) Sedimentation in diluted declad solution

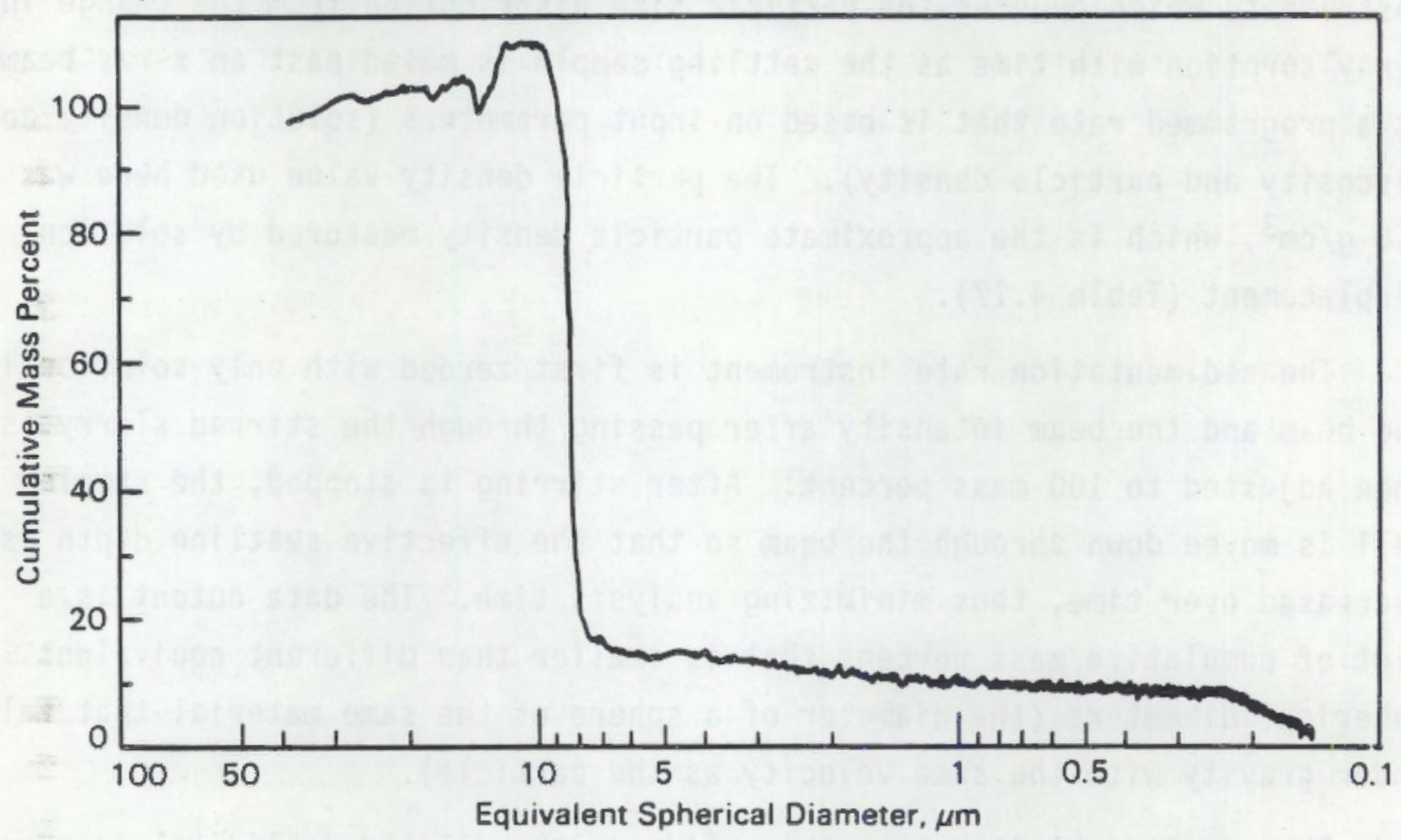

b) Sedimentation in glycerin/water mixture

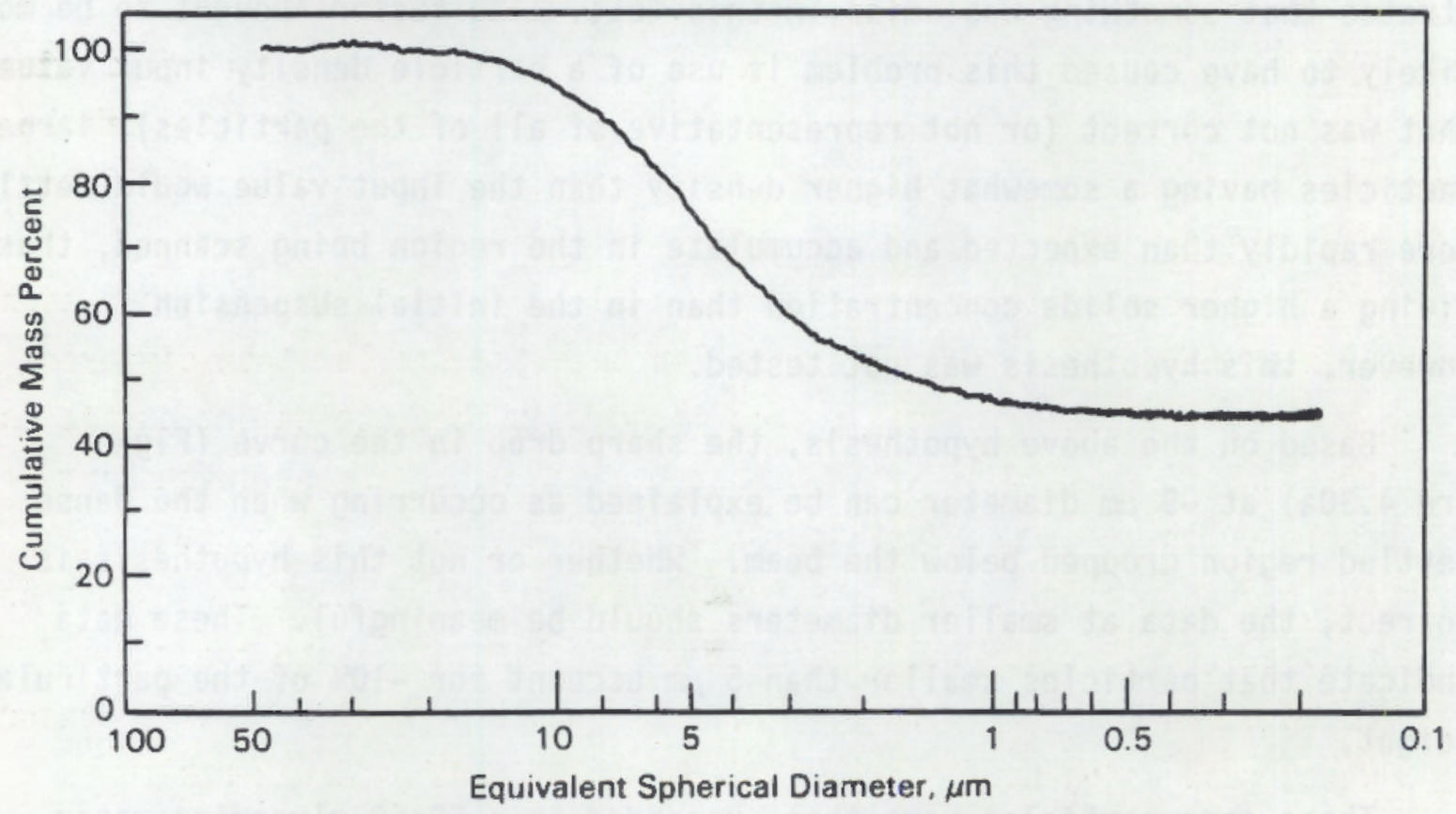

FIGURE 4.30. Declad Solids Particle Sizing by Sedimentation Rate 
this run (Figure 4.30b) were markedly different than those obtained in declad solution (Figure 4.30a). There was no increased concentration of particles in the initial stages of settling, and a much greater proportion of small particles was indicated. (Particles smaller than $5 \mu \mathrm{m}$ accounted for $-75 \%$ of the particulate weight and those smaller than $0.5 \mu \mathrm{m}$ accounted for $-45 \%$ of the weight.)

The difference between the particle size data obtained with particles suspended in declad solution and in 50:50 glycerine-water may be caused by the "de-agglomeration" of particles in the glycerine-water mixture.

Figure 4.29 showed a SEM micrograph of a (water-rinsed) particle obtained from another portion of the same CRW slurry. This micrograph shows a particle of $-20 \mu \mathrm{m}$ diameter that was an agglomeration of submicron-sized $(-0.3-\mu \mathrm{m})$ particles. If such particles "de-agglomerated" in glycerine-water, it would explain the differences in the data of Figures $4.30 \mathrm{a}$ and $4.30 \mathrm{~b}$. Evaluation of the sizes of the particles shown in the SEM pictures (Figure 4.29) also tends to verify the sedimentation result in the declad solution; that is, only a small fraction of the material was present in solids smaller than $5 \mu \mathrm{m}$.

The declad solids were also "sized" using a particle counter instrument that gives distribution data showing both the cumulative percentage of the number of particles that are larger than different sizes and the cumulative volume of the particles that are larger than different sizes (note that this method of representation is the reverse of that used with the sedimentation instrument, where percentages of particles that are smaller than different sizes are shown). Unfortunately, this instrument does not detect particles smaller than $1.5 \mu \mathrm{m}$, and it was necessary to use water as the suspending medium rather than the declad solution itself. Water could change the apparent size distribution by dissolving some zirconium salts that might have precipitated (see Section 4.1.8) as well as by leading to the break up of agglomerates; in either case, the particle size distribution that is measured in a water suspension may be different than that in the actual declad solution. 
The results of this test are shown in Figure 4.31 ; they show that $21 \%$ of the particles in this suspension (that were larger than $1.5 \mu \mathrm{m}$ ) were larger than $5 \mu \mathrm{m}$. On a volume basis, which is the same as a weight basis if the density is constant, the results indicate that $~ 90 \%$ of the solid material was in particles 1 arger than $5 \mu \mathrm{m}$, leaving $10 \%$ of the solids volume (weight) in particles smaller than $5 \mu \mathrm{m}$. These percentages refer to the solids that are

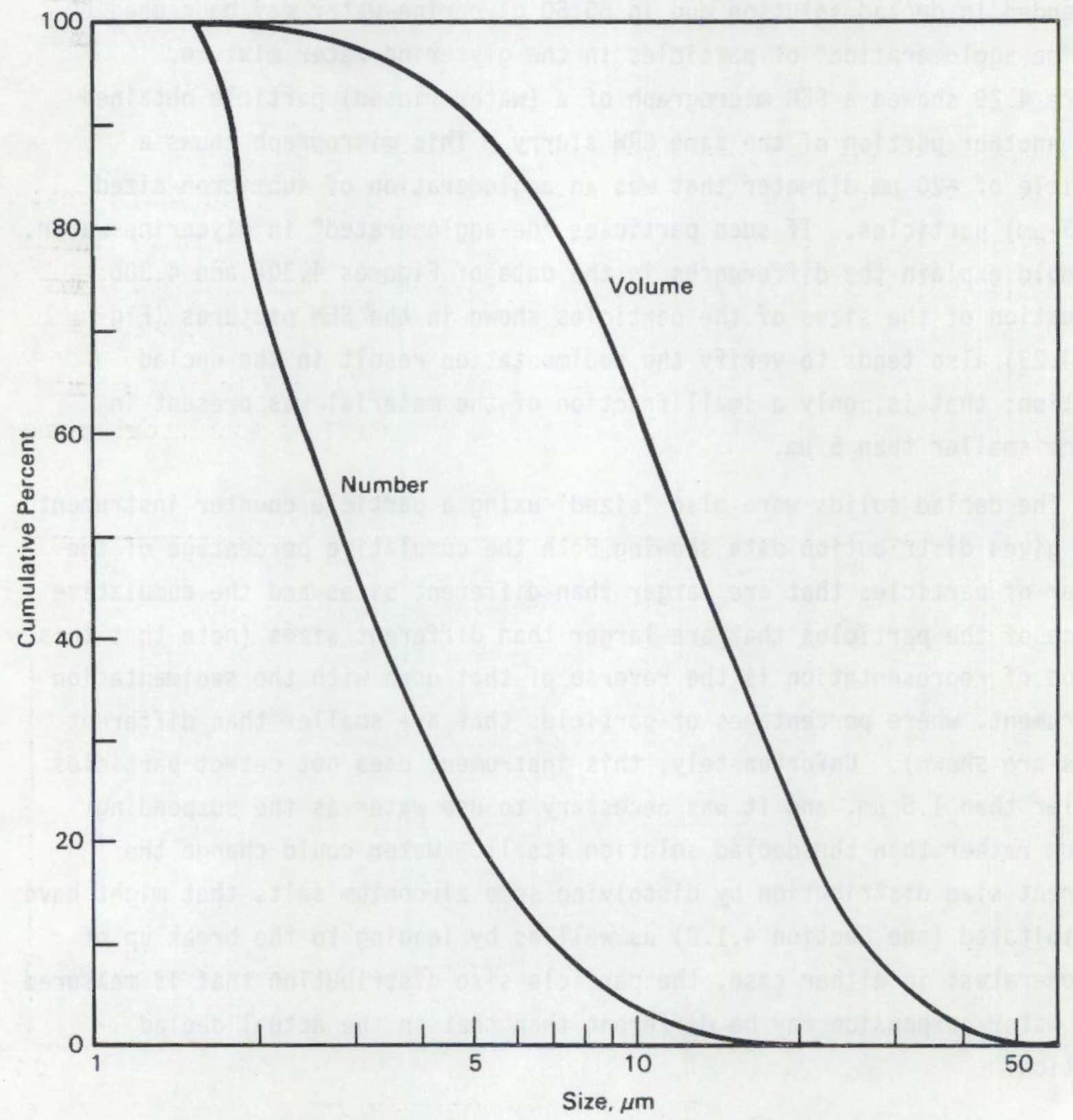

FIGURE 4.31. Declad Solids Particle Sizing by Particle Counting 
larger than $1.5 \mu \mathrm{m}$, which is the lower limit of the particle counter, and are thus not directly comparable to the percentages found with the sedimentation rate instrument, which goes to much lower particle sizes. The sedimentation run in the declad solution itself (Figure 4.30a) indicated that $-11 \%$ of the declad solids were in particles smaller than $1.5 \mu$ m. Using this $11 \%$ value in conjunction with the particle counter data (Figure 4.31 ) gives $34 \%$ of the material in particles smaller than $8 \mu \mathrm{m}$ and $20 \%$ in particles smaller than $5 \mu \mathrm{m}$. These values compare only moderately well with those of $22 \%$ and $15 \%$, respectively, obtained by sedimentation in the declad solution (Figure $4.30 \mathrm{a})$.

\section{Particle Sizes in Rare Earth-Treated Declad Solution}

Visual comparison of the settling characteristics of the solids present in untreated and rare earth-treated declad slurries showed them to be roughly comparable, but with some differences. The rare earth-treated solids were less well settled after 10 minutes, but more settled after 30 minutes.

Results of a sedimentation rate run with the rare earth-treated suspension are shown in Figure 4.32. Although there was no increase to above

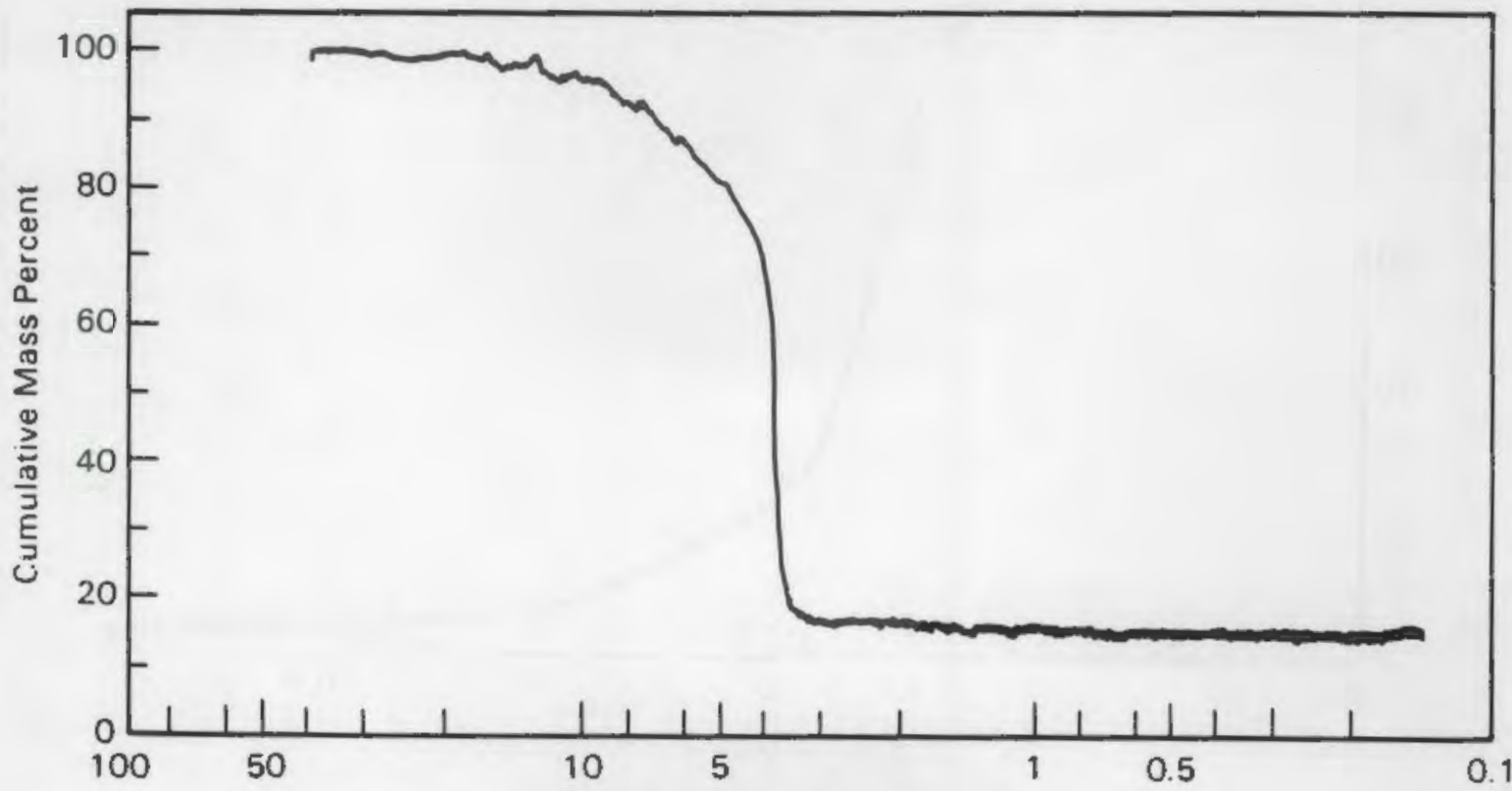

Equivalent Spherical Diameter, $\mu \mathrm{m}$

FIGURE 4.32. Rare Earth-Treated Declad Solids Particle Sizing 
$100 \%$ in this run, like there was in the run with untreated declad solids (Figure 4.30a), the same uncertainties do pertain here. These data indicate that $-14 \%$ of the rare earth-treated material is in particles smaller than $0.15 \mu \mathrm{m}$, compared to $-7 \%$ in the untreated declad solids case (Figure .4.30a). An increase in the quantity of small particles in the rare earth-treated material was also noted by SEM examination (Figure 4.29c); however, the difference there appeared to be much greater than the factor of two indicated by the sedimentation rate data.

\section{Metathesis Solids Sizes}

Results of a sedimentation rate method particle size run on metathesis solids in $2.5 \mathrm{M} \mathrm{KOH}$ are shown in Figure 4.33 (a particle density value of $5.0 \mathrm{~g} / \mathrm{cm}^{3}$, which is within the range of values measured by solution displacement, was used here). This curve does not exhibit a sharp drop like those observed with the declad slurries (Figures 4.30a and 4.32), which leads one to believe that these size distribution data may be more meaningful. The fraction of metathesis solids that was present as submicron particles was

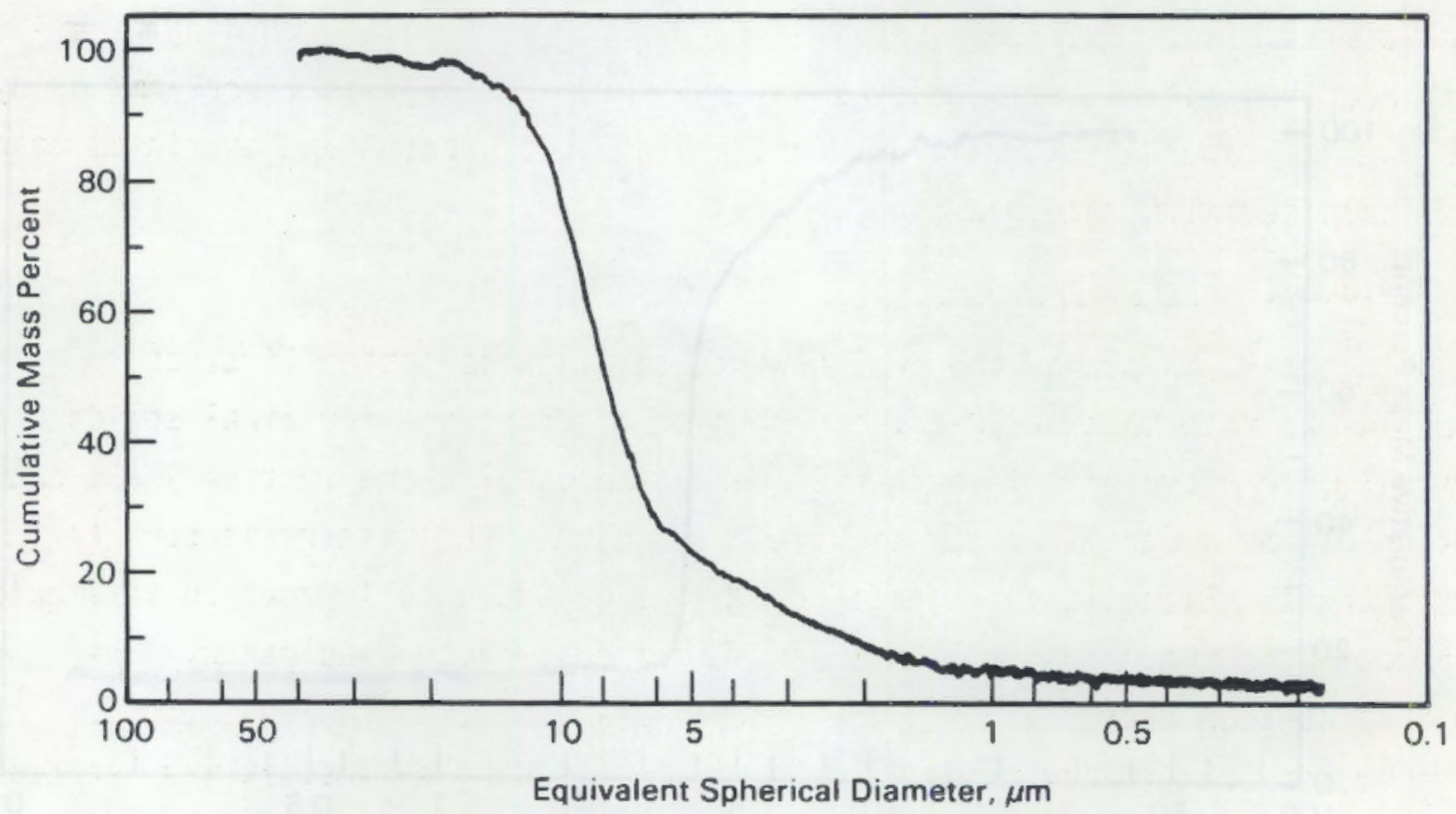

FIGURE 4.33. Metathes is Solids Particle Sizing 
approximately half that observed with untreated declad solids and one-third that observed with rare earth-treated declad solids.

Visual comparison of the solids settling characteristics of metathesis slurries and declad slurries showed them to be roughly comparable, but with some differences. The metathesis solids were less well settled through $\geq 0.5 \mathrm{~h}$, but were better settled after $2 \mathrm{~h}$. However, the metathesis solids settled much more poorly in the metathesis rinse solution than in the metathesis solution itself.

\subsubsection{Flocculating Agents to Improve Settling of Solids}

The use of flocculating agents to improve solids removal in existing plant equipment was also examined. This effort addressed metathesis solids as well as declad solids and examined an inorganic flocculant for use in metathesis rinse solutions, in addition to the polymeric organic flocculants that were of primary interest.

These results showed that little if any improvement in the settling of plutonium- and americium-containing declad solids came from using a polymeric organic flocculant, even though improved settling of uranium-containing declad solids was observed. Improved settling of uranium-containing metathesis solids was also obtained with a polymeric organic flocculant or by adding the proper amount of aluminum nitrate; no plutonium and americium data were obtained with metathesis solids.

\subsubsection{Flocculation of Declad Solids}

In the PUREX plant, the declad waste solution is jetted first to tank TK-D2, then to tank TK-E3, and then to a centrifuge for final solids removal (for recycle) before the solution is made alkaline in tank TK-E5 and the resultant neutralized cladding removal waste (NCRW) slurry is sent to waste tanks. Flocculating agents could thus be added to improve solid/liquid separation in the dissolver itself or in the centrifuge feed tanks. The initial considerations assumed addition of flocculant to the feed tanks. However, in preliminary tests with typical decladding solids, it was learned (by us as well as by others) that the effectiveness of polymeric flocculating agents deteriorated markedly on holding for several hours at $-50^{\circ} \mathrm{C}$ or with 
vigorous agitation, both of which occur in the centrifuge feed tanks. Our study then centered on addition of flocculating agents to the dissolver, where agitation is not severe and the solution can be removed a short time after the agent is added.

Our principal involvement in the study of flocculating agents for decladding waste was to measure the results with one such agent (chosen based on the results of others) in a flowsheet simulation run with irradiated fuel. The test approximated, as best we could, the conditions (e.g., radiation field, nature of solids) encountered in the plant dissolver. Uranium, plutonium, and americium concentrations were measured in the declad slurry after different settling times without flocculant and at two different flocculant concentrations. A similar scouting run with unirradiated fuel also gave some additional results for uranium.

Data bearing on the effect of the flocculating agent on the settling rates of uranium-, plutonium-, and americium-containing solids are summarized in Table 4.18. These data were obtained with the declad solution from Run $7 B$, which involved a $6-\mathrm{h}$ exposure of an already partially declad WG outer element. The solution was diluted and cooled to $\sim 60^{\circ} \mathrm{C}$ as usual and was sampled (near the top) during the air sparge and at several times after the sparge was stopped. After $-0.5 \mathrm{~h}$ of settling, the air sparge was resumed, flocculant was added to $10 \mathrm{ppm}$, and the sampling procedure was repeated. The procedure was then repeated again with an additional $30 \mathrm{ppm}$ of flocculant.

Table 4.18 also contains uranium data obtained under similar conditions in Runs 12 and $12 B$ (with unirradiated fuel); these data provide an illustration of the variability in the data, for uranium at least. In nearly every case, the uranium concentration found in the settled sample was lower in the presence of flocculant than in the corresponding sample without flocculant. This indicates that the flocculant was indeed effective in enhancing the settling rate of the uranium-containing solids. However, the plutonium and americium concentrations did not follow the same trend; the concentrations of these elements found in settled samples containing flocculant scattered both above and below the values in the corresponding samples without flocculant. The fact that the flocculant appeared to be effective for uranium-containing 
TABLE 4.18. Effect of a Polymeric Flocculant on Settling Rates of Declad Solids

Found in Dip Sample from Top of Solution

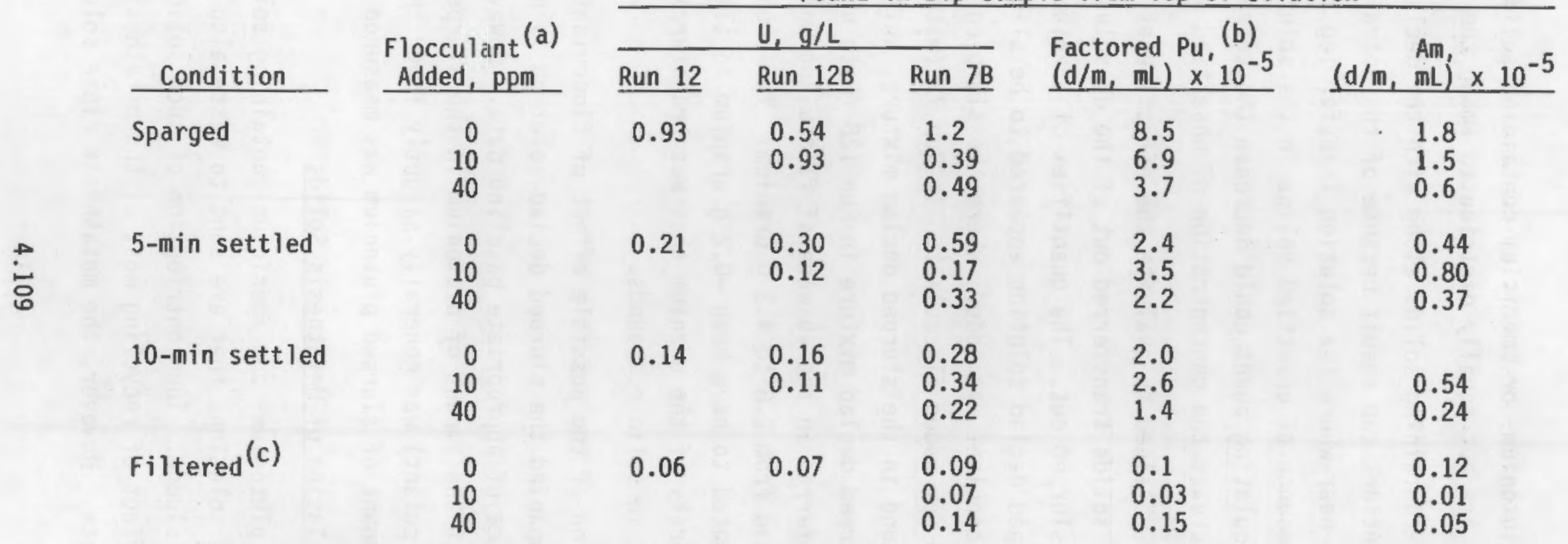

(a) Betz-1131, which was the one favored by operating contractor personnel at the time of these tests.

(b) Actual plutonium analysis multiplied by a constant factor.

(c) $0.2-\mu \mathrm{m}$ pore size. 
solids but not for plutonium- or americium-containing solids indicates that these three elements are not equally distributed among the solids.

Transfer of TRU-containing solids along with the decladding waste and metathesis waste solutions can result because of the entrainment of solids that had settled out near where the solution transfer leg is located as well as because of the presence of unsettled solids in the solution. It is possible that a flocculating agent could decrease the entrainment of settled solids as well as decrease the concentration of unsettled solids.

A few data were obtained to evaluate the effectiveness of the flocculant on the quantities of solids transferred out of the dissolver vessel when the declad solution was slurped out. The quantities of uranium compounds that accompanied the slurped declad solution appeared to be slightly lower in the two runs in which flocculant was added, where the slurping was done following the settling with $40 \mathrm{ppm}$ added flocculant. In Run 7B (with irradiated fuel), $1.1 \mathrm{~g}$ uranium was found in the slurped declad mixture, while $2.2 \mathrm{~g}$ uranium was found in the slurped declad mixture in Run 12B (with unirradiated fue1). The quantities transferred in the absence of flocculant were given in Table 4.5; they ranged from 2.8 to $4.3 \mathrm{~g}$ uranium. The amount of uranium that was soluble is estimated to have been $\sim 0.2 \mathrm{~g}$ uranium in all of these runs; thus, the large majority of the uranium that was transferred with the solution was present in solid compounds.

Proper evaluation of the possible effect of flocculants on the amount of plutonium that accompanied the slurped declad solution is not possible because of the absence of appropriate baseline data. However, the existing data do indicate that the amount of plutonium in the slurped declad mixture in Run 7B (with flocculant) was generally slightly lower than in the other runs in which the amount of slurped plutonium was measured.

\subsubsection{Flocculation of Metathesis Solids}

Entrainment of plutonium- and americium-containing solids in metathesis and metathesis rinse solutions that are sent to waste also contributes to the TRU content of NCRW sludge. The contribution of such solids in the past was reduced as a side effect of recycling most of the metathesis solution instead of sending it to waste. However, the metathesis rinse solution was sent to 
waste so solids entrained there did contribute to the TRU content of the waste. Also, in some $F G$ fuel campaigns, the metathesis solution was used on a once-through-to-waste basis. Thus, some tests were run to test the effectiveness of flocculating agents with metathesis solids.

\section{Tests with Polymeric Flocculant}

The polymeric flocculant used in these tests was Superfloc-1226, (a) which, by the time these tests were run, had supplanted Betz-1131 (b) as the flocculant preferred by operating contractor personnel. The solids tested were metathesis solids that had aged for several months in dilute potassium hydroxide solution. Conclusions in these tests were based on visual observations of solution clarity, supported by photographs.

The addition of $10 \mathrm{ppm}$ Superfloc-1226 to stirred suspensions of metathesis solids at $-60^{\circ} \mathrm{C}$ resulted in greatly increased clarity of the settled solutions with the following metathesis solution compositions:

- $2.2 \underline{\mathrm{M} \mathrm{KOH}}, 1.6 \mathrm{M} \mathrm{KOH}+0.6 \mathrm{M} \mathrm{KF}, 1.0 \mathrm{M} \mathrm{KOH}+1.2 \mathrm{M} \mathrm{KF}$

- $5.0 \underline{\mathrm{M} \mathrm{KOH}}, 3.5 \underline{\mathrm{M} \mathrm{KOH}}+1.5 \underline{\mathrm{M} \mathrm{KF}}$.

Comparable results were obtained with $3 \mathrm{ppm}$ flocculant, but increasing the concentration to $30 \mathrm{ppm}$ had a deleterious effect.

Solids that were flocced at the higher potassium hydroxide concentrations remained that way initially on exposure to dilute potassium hydroxide (such as results from using water to rinse the fluoride away from the metathesized solids), but not after heating at $100^{\circ} \mathrm{C}$ for $\sim 0.5 \mathrm{~h}$. Since the metathesis rinse solution is normally boiled in the plant to reduce its volume, the effectiveness of the flocculant would not be expected to persist through the rinse step. Addition of fresh Superfloc-1226 was effective at potassium hydroxide concentrations down to $\sim 0.3 \underline{M}$. This suggests the use of $\sim 0.3 \mathrm{M} \mathrm{KOH}$ instead of water to rinse away the fluoride, so that a flocculant could be used to aid solid settling in the rinse step as well.

(a) Superfloc is a trademark of American Cyanamid, Wayne, New Jersey.

(b) Betz is a trademark of Betz Laboratories, Inc., Langhorne, Pennsylvania. 


\section{Tests with Aluminum Nitrate Flocculant}

Flocculation of metathesized solids in metathesis rinse solution was a] so observed when aluminum nitrate was added to the solution in the proper amount. The proper amount of aluminum to add varies with the potassium hydroxide concentrations, as shown in Figure 4.34. This figure shows

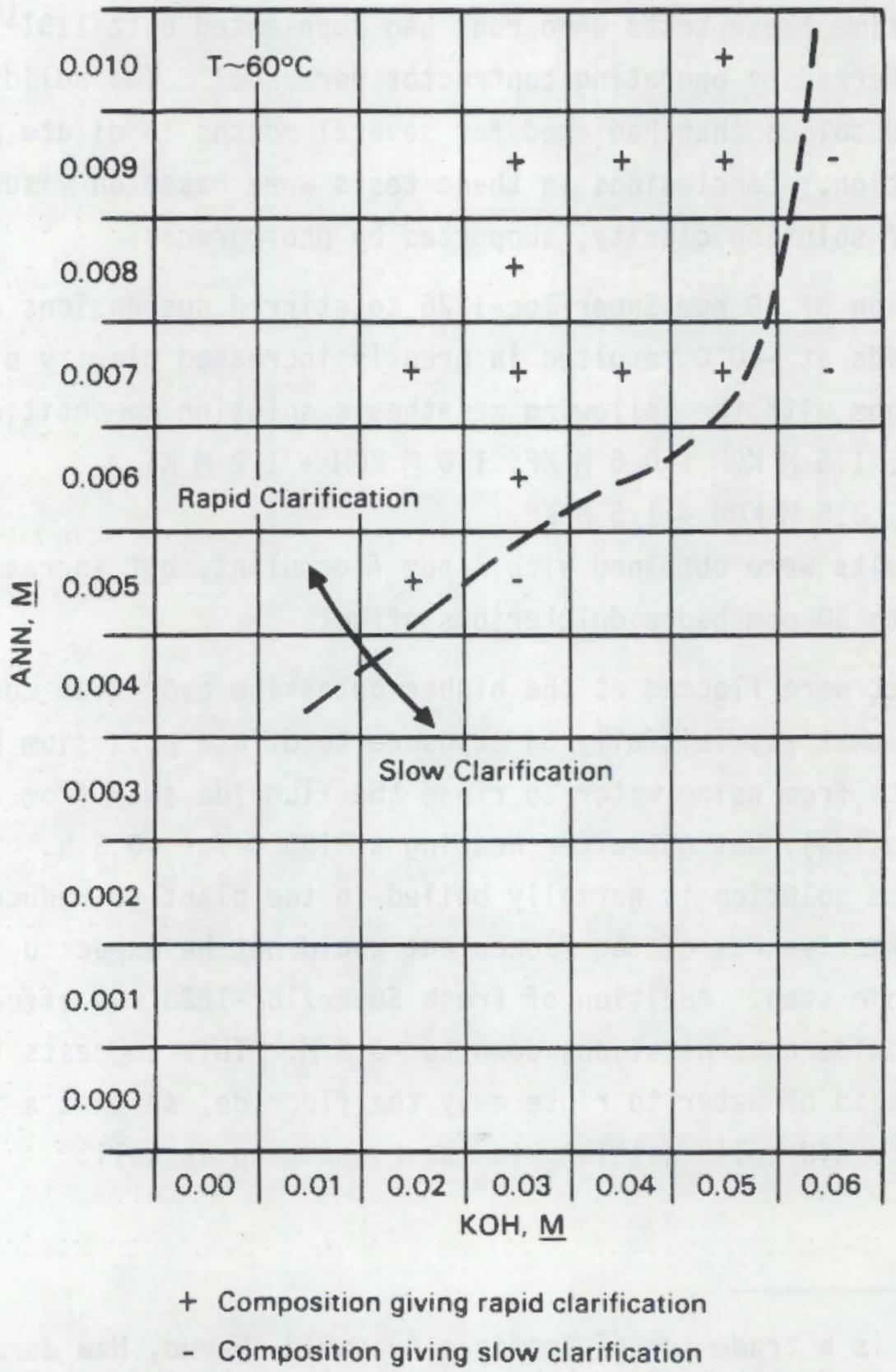

FIGURE 4.34. Solids Flocculation by Adding ANN to Metathesis Rinse Solution 
compositions that gave rapidly settling solids, denoted by plus signs, and compositions that did not give rapidly settling solids, denoted by minus signs. The clarities of the settled solutions achieved here were better than the clarities in the best conditions achieved by adding polymeric flocculants.

The compositions that give good solids settling appear to be those that also give precipitation of aluminum hydroxide. In some preliminary tests at room temperature in $0.6 \mathrm{M} \mathrm{KOH}$, little if any aluminum precipitation occurred at $0.012 M$ added ANN and the metathesized solids settled poorly, while $-40 \%$ of the aluminum precipitated at $0.014 \mathrm{M}$ added ANN and the metathesized solids settled rapidly. The presence of aluminum in the settled solids is not bad per se because large quantities of aluminum are routinely added to minimize corrosion during the acid cut. However, the volume of settled solids increases as the amount of precipitated aluminum increases; this increased solids volume could result in transfer of settled solids along with the solution, which could greatly decrease the benefit achieved by faster solids settling. Thus, the optimum conditions for efficient separation of solution from the solids would lie just slightly above the line drawn in Figure 4.34.

One test (at $0.05 \underline{M} \mathrm{KOH}+0.01 \underline{M}$ ANN) was made of the effect of temperature; after boiling for $10 \mathrm{~min}$, the clarity of this solution was worse than it had been at $60^{\circ} \mathrm{C}$. Thus, for maximum efficiency, the aluminum should not be added until after the metathesis rinse boiling step. To assure the presence of a proper set of concentrations, it might be desirable to add a premixed, concentrated potassium hydroxide/ANN mixture to the cooled rinse solution.

The addition of aluminum to metathesis solution (as opposed to metathesis rinse solution) is not likely to be a feasible approach. In the few tests that were done, it was found that no aluminum solids were formed in $1.4 \mathrm{M} \mathrm{KOH}+1.0 \mathrm{M} \mathrm{KF}$ until the aluminum concentration had been increased to nearly $0.35 \underline{M}$, and that a slight increase in aluminum concentration then gave 
a large increase in solids volume. The solids volume also increased with decreasing fluoride concentration; because of the variable fluoride content of metathesis solutions, it would be difficult to know in advance how much aluminum should be added to give the right amount of aluminum precipitation. 


\subsection{FUTURE WORK}

Additional work related to ruthenium volatilization from ammonia scrubber solution (Section 4.5.1) is in progress. However, this work is emphasizing ruthenium volatilization during ammonia destruction processes such as might have to be implemented to maintain compliance with the recently imposed ammonia discharge limits. Ammonia destruction by reaction of ammonium nitrate solution with sodium nitrite solution is the candidate process being examined first. Other ammonia abatement processes are also being examined.

Additional work aimed at minimizing problems associated with, and in improving the rate of, processing FG fuel could also be beneficial. Such work should be aimed at minimizing the extent of uranium reaction during decladding. One possible approach to be evaluated is to perform the first acid cut before the declad step instead of after it. This approach would reduce the extent of uranium reaction during decladding by dissolving much or all of three different reactive uranium sources in nitric acid before they can react with the decladding solution:

1) the hydrous uranium dioxide formed by reaction with water during storage (and which is still present in/on the fuel)

2) small pieces of uranium metal exposed by break-up of waterreacted fuel when it is charged to the dissolver

3) the uranium heel left from the preceding cycle.

Minimization of the uranium heel could also result from additional study of dissolution procedures to assure that uranium dissolution is indeed (essentially) complete before the next charge is added to the dissolver. 



\subsection{REFERENCES}

Delegard, C. H. 1987. Solubility of $\mathrm{PuO}_{2} \cdot \mathrm{XH}_{2} \mathrm{O}$ in PUREX Plant Metathesis Solutions. RHO-RE-ST-53 P, Rockwe11 Hanford Operations, Richland, Washington.

Hodgson, K. M., D. L. Herting, W. W. Schulz, L. A. Bray, and J. L. Swanson. 1984. "Content and Removal of TRU Elements from Aqueous Zirconium Cladding Waste." In Actinide/Lanthanide Separations, eds. G. R. Choppin, J. D. Navrital, and W. W. Schulz, pp. 326-347, World Scientific Publishing Co., Singapore.

Mueller, W. M., J. P. Blackledge, and G. G. Libowitz. 1968. "Metal Hydrides." Academic Press, New York, pp. 521-27.

Swanson, J. L. 1958. "The Selective Dissolution of Zirconium or Zircaloy Cladding by the Zirflex Process." In Proceedings of the Second United Nations Conference on the Peaceful Uses of Atomic Energy, Vol. 17, pp. 154-161, United Nations.

Swanson, J. L. 1961. "The Zirflex Process." In Process Chemistry, eds. F. R. Bruce, J. M. Fletcher, and H. H. Hyman, pp. 289-303, Pergamon Press, New York.

Swanson, J. L., L. A. Bray, H. E. Kjarmo, J. L. Ryan, C. L. Matsuzaki, S. G. Pitman, and J. H. Haberman. 1985. Laboratory Studies of Shear/Leach Processing of Zircaloy Clad Metallic Uranium Reactor Fuel. PNL-5708, Pacific Northwest Laboratory, Richland, Washington, p. 7.13. 



\section{DISTRIBUTION}

No. of

Copies

OFFSITE

76 DOE/Office of Scientific \& Technical Information

\section{ONSITE}

3 DOE Richland Operations Office

J. K. Erickson

L. S. Semmens

M. J. Zamorski

36 Westinghouse Hanford Company

J. N. Appel

D. W. Bergmann

M. W. Bowman

D. R. Bratzel

B. R. Dickey

J. H. Ellis

S. D. Godfrey

J. G. Granger

W. M. Harty

D. L. Herting

E. G. Hess

L. L. Jacobs

P. F. Kison

E. J. Kosiancic

J. K. McClusky

R. L. McCormack

D. E. McKenney

J. D. Moore

J. P. Murphy

A. L. Pajunen

K. E. Plummer

A. L. Prignano

D. W. Reberger
No. of

Copies

Westinghouse Hanford Company (contd)

R. C. Roal

W. W. Shulz

J. P. Slaughter

R. J. Staudacher

N. N. Takata

R. E. Van Der Cook

R. L. Walser

E. D. Waters

A. G. Westra

G. R. Wilson

G. A. Wolf

J. C. Womack

J. J. Zimmer

39 Pacific Northwest Laboratory

L. A. Bray

T. L. Gilbride

R. S. Kemper

L. T. Pedersen

A. D. Peoples

G. M. Richardson

J. L. Ryan

R. D. Scheele

J. L. Straalsund

J. L. Swanson (20)

R. L. Treat

P. C. Walkup

E. J. Wheelwright

Technical Report Files (5)

Publishing Coordination 
